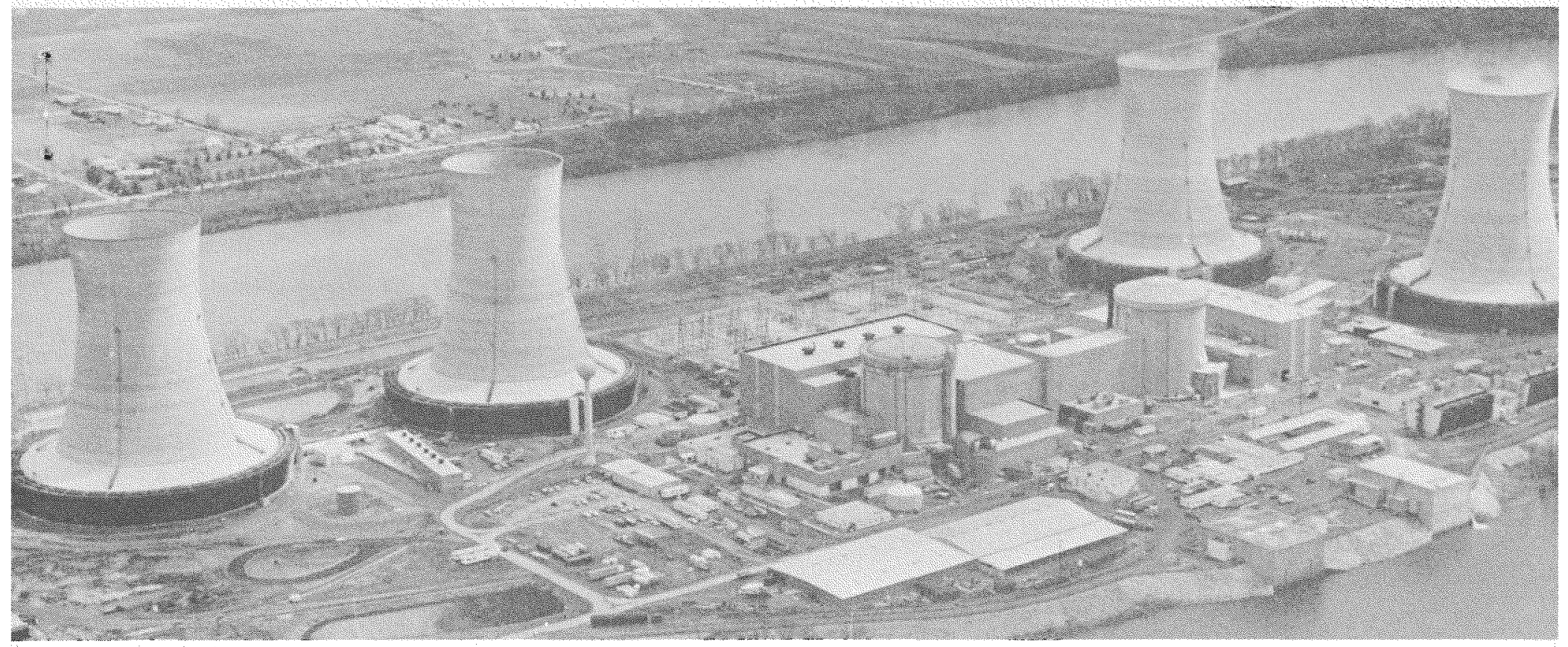

\section{GEND}

General Publit Utitities - Eletric Pouser Pesenech lnstitute U.S. Nudear Regulatory Commission - U.S. Deparment of Eneroy

\section{TMI-2 Technical Information and Examination Program 1984 Annual Report}

Edited by Cynthia J. Hess

April 1985

Prepared for the

U.S. Department of Energy

Three Mile Island Operations Office

Under DOE Contract No. DE-AC07-76ID01570 
Prnted in the United States of Amenca

Avalable from

Natonal Techncal information Sernce

U S Deparment of commerce

5285 Port Royal Road

Sprngfield. VA 22161

NTIS Price Codes Printed Copy A04

Mucrofiche A01

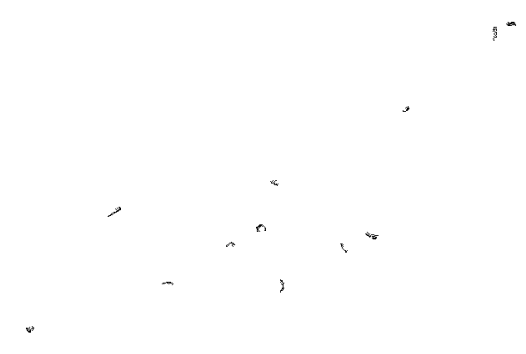

\section{DISCLAIMER}

This book was prepared as an account of work sponsored by an agency of the Unted States Government Nether the Unted States Government nor any agency thereof nor any of ther employees, makes any warranty, express or mpled, or assumes any legal labity or responsibilly for the accuracy completeness. or usefulness of any information, apparatus product or process disclosed, or represents that is use would not infrnge prwately owned rights References heren to any spectic commercal product, process, of servce by trade name trademark manufaciurer or othemise. does not necessarly constutute or mply its endorsement fecommendation, or favorng by the Unted States Govermment or any agency thereof The vews and opinons of authors expressed herem do not necessarly state or reflect those of the Unted States Government or any agency thereof 


\section{DISCLAIMER}

This report was prepared as an account of work sponsored by an agency of the United States Government. Neither the United States Government nor any agency Thereof, nor any of their employees, makes any warranty, express or implied, or assumes any legal liability or responsibility for the accuracy, completeness, or usefulness of any information, apparatus, product, or process disclosed, or represents that its use would not infringe privately owned rights. Reference herein to any specific commercial product, process, or service by trade name, trademark, manufacturer, or otherwise does not necessarily constitute or imply its endorsement, recommendation, or favoring by the United States Government or any agency thereof. The views and opinions of authors expressed herein do not necessarily state or reflect those of the United States Government or any agency thereof. 


\section{DISCLAIMER}

Portions of this document may be illegible in electronic image products. Images are produced from the best available original document. 
This report was prepared as an account of work sponsored by an agency of the United States Government. Neither the United States Government nor any agency thereof, nor any of their employees, makes any warranty, express or implied, or assumes any legal liability or responsibility for the accuracy, completeness, or usefulness of any information, apparatus, product, or process disclosed, or represents that its use would not infringe privately owned rights. Reference herein to any specific cormmercial product, process, or service by trade name, trademark, manufacturer, or otherwise does not necessarily constitute or imply its endorsement, recom. mendation, or favoring by the United States Government or any agency thercof. The views and opinions of authors expressed herein do not necessarily state or reflect those of the United States Government or any agency thereof.

\title{
TMI-2 TECHNICAL INFORMATION AND EXAMINATION PROGRAM 1984 ANNUAL REPORT
}

\author{
Edited by Cynthia J. Hess
}

Published Aprill 1985

EG8G Idaho, Inc. 9501781
Idaho Falls, Idaho 83415

Prepared for the

U.S. Department of Energy

Three Mile Island Operations Office

Under DOE Contract No. DE-AC07-761D01570 


\begin{abstract}
In 1984, the U.S. Department of Energy's Technical Information and Examination Program entered its fifth year of research and development work at Three Mile Island Unit 2 (TMI-2) and at the Idaho National Engineering Laboratory and other supporting laboratories. The work concentrated on six major areas: waste immobilization, reactor evaluation, data acquisition, information and industry coordination, core activities, and EPICOR II and waste research and disposition.

While the general technology being developed is of direct benefit to the recovery operations at TMI-2, this technology will serve to benefit the entire nuclear power industry. Others engaged in research and development, design, construction, operation, maintenance, and regulation of nuclear plants will have access to this technology to enhance plant safety and reliability.
\end{abstract}




\section{ACKNOWLEDGMENTS}

The editor thanks Judy A. Ramsthaler, EG\&G Idaho, Inc., for coordinating program input from the Idaho National Engineering Laboratory and the staff of the EG\&G Idaho, Inc., Technical Integration Office for contributing the information on activities at Three Mile Island. 


\section{CONTENTS}

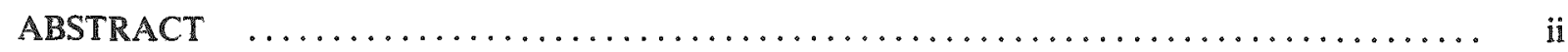

ACKNOWLEDGMENTS $\ldots \ldots \ldots \ldots \ldots \ldots \ldots \ldots \ldots \ldots \ldots \ldots \ldots \ldots \ldots \ldots \ldots \ldots$

PROGRAM PURPOSE AND HISTORY $\ldots \ldots \ldots \ldots \ldots \ldots \ldots \ldots \ldots \ldots \ldots \ldots \ldots \ldots \ldots \ldots$

SUMMARY OF SIGNIFICANT ACCOMPLISHMENTS OF $1984 \ldots \ldots \ldots \ldots \ldots \ldots \ldots$

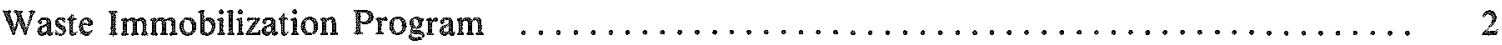

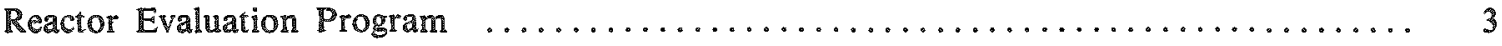

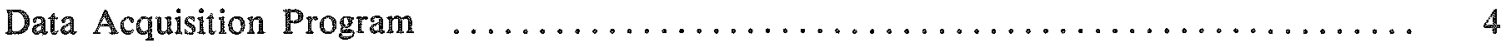

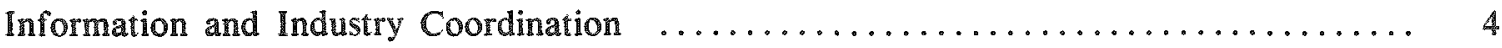

EPICOR and Waste Research and Disposition Program $\ldots \ldots \ldots \ldots \ldots \ldots \ldots \ldots$

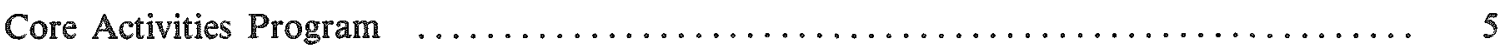

WASTE IMMOBILIZATION PROGRAM $\ldots \ldots \ldots \ldots \ldots \ldots \ldots \ldots \ldots \ldots \ldots \ldots \ldots$

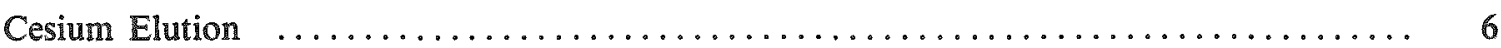

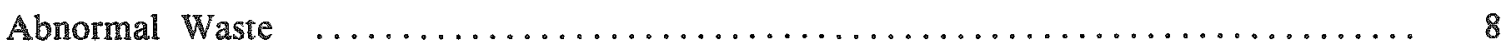

REACTOR EVALUATION PROGRAM $\ldots \ldots \ldots \ldots \ldots \ldots \ldots \ldots \ldots \ldots \ldots \ldots \ldots \ldots \ldots \ldots \ldots$

Reactor Vessel Head Removal $\ldots \ldots \ldots \ldots \ldots \ldots \ldots \ldots \ldots \ldots \ldots \ldots \ldots \ldots \ldots \ldots \ldots \ldots \ldots$

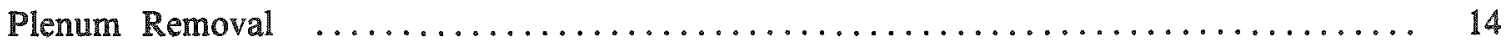

Preparations for Plenum Removal $\ldots \ldots \ldots \ldots \ldots \ldots \ldots \ldots \ldots \ldots \ldots \ldots \ldots \ldots \ldots \ldots$

Fuel and Core Debris Removal $\ldots \ldots \ldots \ldots \ldots \ldots \ldots \ldots \ldots \ldots \ldots \ldots \ldots \ldots \ldots \ldots \ldots \ldots \ldots \ldots \ldots$

Defueling Debris Canisters $\ldots \ldots \ldots \ldots \ldots \ldots \ldots \ldots \ldots \ldots \ldots \ldots \ldots \ldots$

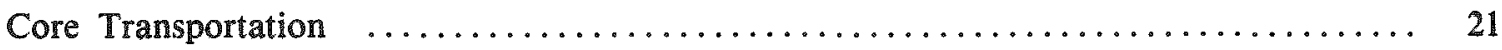

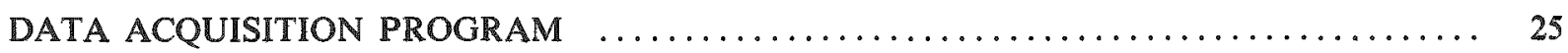

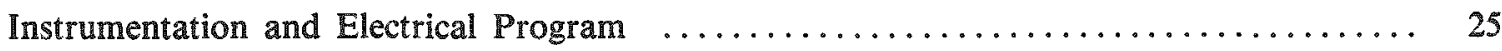

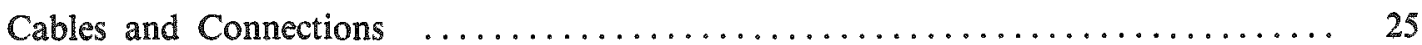

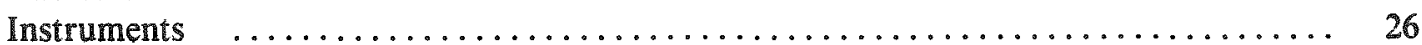

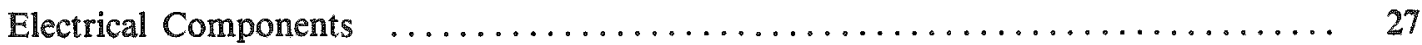

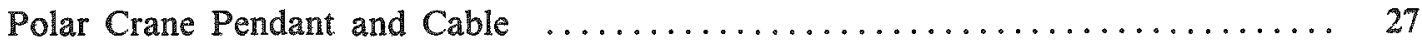

Core Sample Acquisition and Examination Project $\ldots \ldots \ldots \ldots \ldots \ldots \ldots \ldots \ldots \ldots$ 
Core Stratification Sample Acquisition and Lower Head Inspection $\ldots \ldots \ldots \ldots \ldots .28$

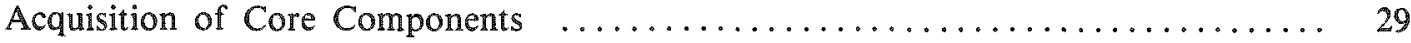

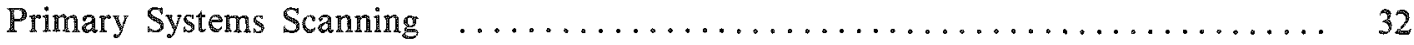

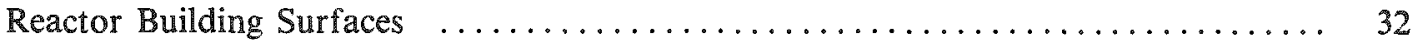

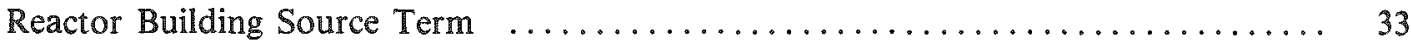

Resistance Temperature Detector Acquisition $\ldots \ldots \ldots \ldots \ldots \ldots \ldots \ldots \ldots \ldots, 33$

Reactor Vessel Internals Documentation $\ldots \ldots \ldots \ldots \ldots \ldots \ldots \ldots \ldots \ldots \ldots . \ldots . \ldots . \ldots$

INFORMATION AND INDUSTRY COORDINATION $\ldots \ldots \ldots \ldots \ldots \ldots \ldots \ldots \ldots \ldots$

Calculation for Determining Safe Storage Time for Waste $\ldots \ldots \ldots \ldots \ldots \ldots \ldots \ldots . . \ldots$

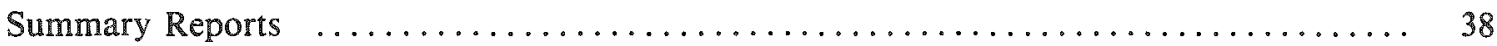

EPICOR AND WASTE RESEARCH AND DISPOSITION PROGRAM $\ldots \ldots \ldots \ldots \ldots \ldots .40$

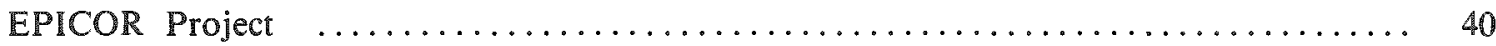

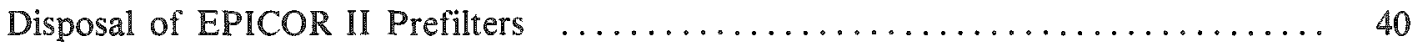

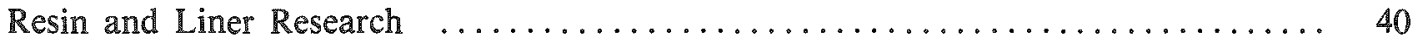

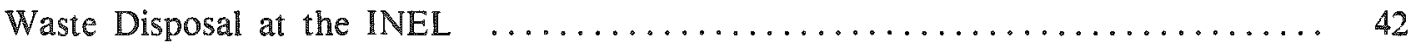

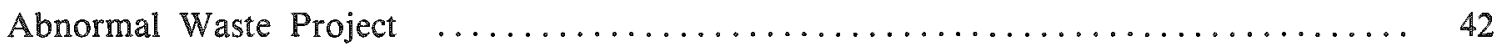

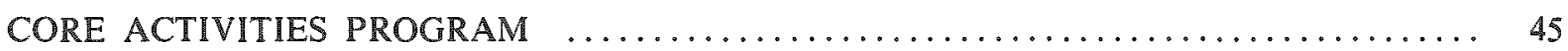

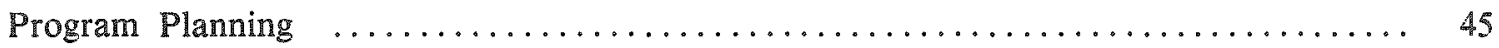

TMI-2 Core Receipt and Storage Project $\ldots \ldots \ldots \ldots \ldots \ldots \ldots \ldots \ldots \ldots \ldots \ldots$

Core Sample Acquisition and Examination Project $\ldots \ldots \ldots \ldots \ldots \ldots \ldots \ldots \ldots . \ldots . \ldots . \ldots . \ldots$

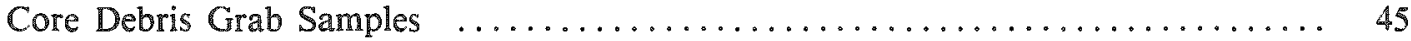

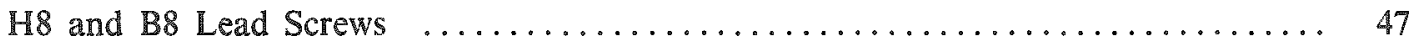

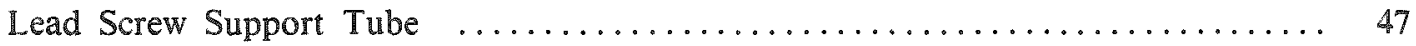

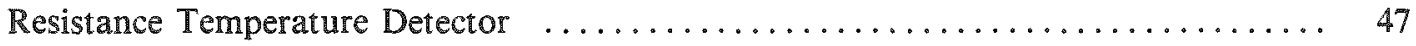

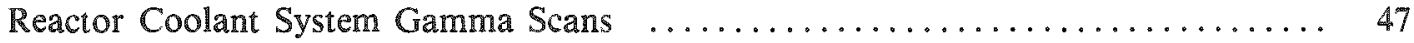

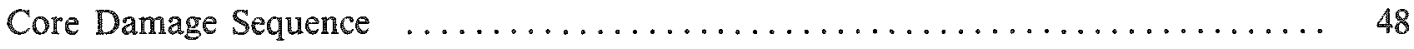

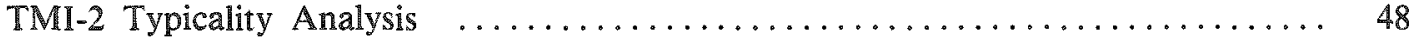

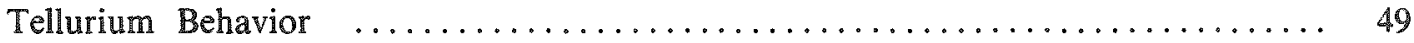

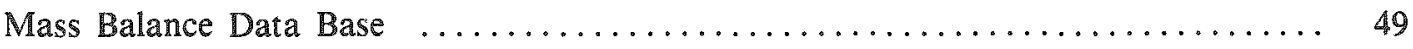


, 


\section{TMI-2 TECHNICAL INFORMATION AND EXAMINATION PROGRAM 1984 ANNUAL REPORT}

\section{PROGRAM PURPOSE AND HISTORY}

The Technical Information and Examination Program (TI\&EP) in 1984 marked its fifth year of recovery assistance and research and development work at Three Mile Island Unit 2(TMI-2). In 1980, plant owner GPU Nuclear, the Electric Power Research Institute (EPRI), the U.S. Nuclear Regulatory Commission (NRC), and the U.S. Department of Energy (DOE) established the TI\&EP at TMI with a number of objectives in mind: to obtain and analyze data on the March 1979 accident and its aftermath, develop new techniques for responding to the unique challenges at TMI, and share these findings and technologies with the commercial nuclear power industry.

The Data Acquisition Program (DAP) became the TI\&EP's primary data gathering and distribution arm, its targets of evaluation being accident and postaccident performance of instrumentation and electrical equipment; physical, chemical, and metallurgical behavior of fuel cladding and core components; fission product behavior, transport, and deposition; general physical damage to surfaces, structural components, and equipment in the building; and techniques for decontaminating the surfaces and equipment. Through its evaluations, DAP expects to (a) identify possible design changes in equipment standards and regulations, (b) improve the understanding of fission product release pathways and retention mechanisms; (c) provide the industry with new techniques for decontamination and recovery; and (d) have an understanding of the accident scenario and sequence. In conjunction with DAP, an Information and Industry Coordination staff was established to communicate program findings directly to the industry through various information networks.

The TI\&EP in October 1981 responded to new challenges for research and development by establishing two more programs: the Waste Immobilization Program to adapt and develop advanced waste processing technologies in answer to the special wastes generated as a result of the accident, and the Reactor Evaluation Program to acquire data and determine the appropriate methods for disassembling and defueling the damaged reactor.
Since the accident, GPU Nuclear, DOE, and their contractors have reached a number of milestones in the recovery operation. In 1979, the EPICOR II system began cleaning the contaminated water in the basement of the Auxiliary Building. Television cameras and radiation instruments were used in the first inspection of the Reactor Building. In 1980 , $43,000 \mathrm{Ci}$ of radioactive krypton gas were safely vented from the Reactor Building, allowing workers to begin entries on a routine basis. In 1981, the Submerged Demineralizer System (SDS) began to decontaminate the radioactive water from the basement of the Reactor Building. Shipments of the SDS liners containing the waste were initiated in May 1982. Also in 1982, workers lowered cameras into the damaged reactor and conducted the first inspection of the core.

In the summer of 1983 , the last solid waste from the processing of original accident-related water was shipped from the Island. Later that year, further explorations inside the reactor vessel produced the first samples of the damaged core, as well as a topographical map of the core void and the clearest videotapes of the damaged core to that date.

A number of major steps toward reactor disassembly dominated activities during the 1984 calendar year, beginning in February with the load test of the TMI-2 polar crane, qualifying it to lift the reactor vessel head. Five months later, the head of the reactor was successfully moved to its storage stand in the Reactor Building, and shielding was installed over the vessel, giving workers safe access to the reactor's internal components to prepare for defueling. Finally, in December, the plenum assembly was inspected, cleaned of hanging debris, and jacked $18.4 \mathrm{~cm}$ from its seated position.

The accomplishments to this point have been significant not only in moving the entire recovery effort closer to completion, but in demonstrating that every new challenge this unique situation presents can be met; and the DOE program has been instrumental in keeping the industry well informed of the progress at TMI. 


\section{SUMMARY OF SIGNIFICANT ACCOMPLISHMENTS OF 1984}

Progress continues at Three Mile Island, where disassembly of the damaged Unit 2 reactor is well under way and defueling nears. GPU Nuclear and DOE together achieved a number of accomplishments in 1984 through their respective recovery and research and development efforts (see Figure 1). During each step of disassembly, important questions about the nature and impact of the accident have been answered.

\section{Waste Immobilization Program}

The Waste Immobilization Program demonstrated significant progress in removing cesium from the resins of the two makeup and purification demineralizer vessels. At year's end, the decontamination work was estimated to be $40 \%$ complete. After the accident, the demineralizer vessels contained the greatest concentration of radioactivity remaining in the plant, apart from the reactor vessel itself. During normal plant operation, the resins in the demineralizer tanks remove impurities from the reactor coolant system water. But during the 1979 accident, highly contaminated coolant water passed through the tanks, whose resins may have captured as much as 3.5 million $\mathrm{Ci}$ of radioactive iodine and $36,950 \mathrm{Ci}$ of radioactive cesium. (After being trapped by the resins, the iodine decayed away in a matter of days.) The tanks also contained as much as $4.1 \mathrm{~kg}$ of reactor fuel particles.

The method by which the resins are being decontaminated is called cesium elution. A mixture of water and sodium hydroxide is pumped into each vessel, and the ions of radioactive cesium are exchanged for sodium ions from the sodium hydroxide. After a "soaking period" of at least $24 \mathrm{~h}$, the chemical solution, now containing ${ }^{137} \mathrm{Cs}$,

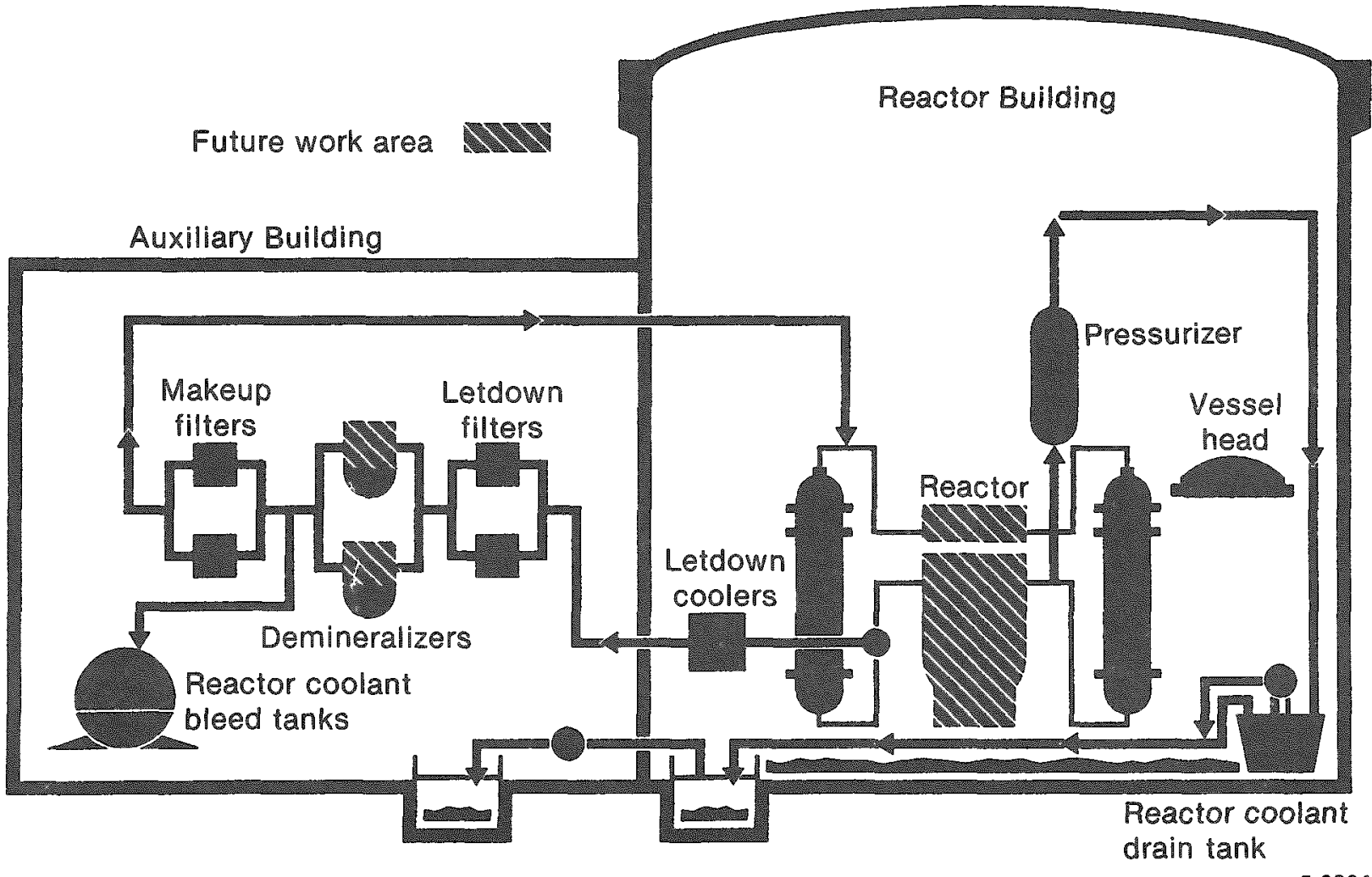

Figure 1. The TMI recovery and research and development work in 1984 reached a number of milestones, including reactor vessel head removal, plenum lift, and the partial elution of cesium in the two makeup and purification demineralizer tanks. 
is withdrawn, mixed with processed water, and pumped through filters. Based on simulations of the process performed on resin samples from the two demineralizer vessels, researchers expect to elute $90 \%$ of the cesium from the highly loaded B demineralizer and about $70 \%$ from the less highly loaded A demineralizer. In addition, the Submerged Demineralizer System (SDS) is processing the filtered eluant and is expected to capture $99.99 \%$ of the cesium freed from the demineralizer resins. The loaded SDS liner will be shipped to Hanford, WA, for burial. It will be the last SDS liner to be buried as part of the Monitored Retrievable Burial Demonstration Program.

In this program, SDS liners containing radioactive waste with contamination levels exceeding commercial disposal limits were placed in instrumented concrete overpacks and buried in shallow trenches at the Hanford site. The instruments on the burial containers afford scientists the opportunity to regularly monitor the contents and obtain valuable data on the safe and economic disposal of high specific activity waste.

Other high specific activity materials from TMI-2 have been part of DOE-funded laboratory research toward understanding the 1979 accident. EPICOR II organic ion-exchange material from water-cleaning operations in the TMI-2 Auxiliary Building were disposed of commercially in highintegrity containers ( $\mathrm{HICs}$ ). DOE and the NRC performed significant research on the materials, and DOE provided waste preparation assistance to GPU Nuclear on a cost-reimbursable basis.

During the year, DOE and GPU Nuclear initiated negotiations toward an understanding that $\mathrm{DOE}$ provide, on a full cost-recovery basis, disposal for abnormal waste generated from the cleanup work. The intent of this agreement is to prevent TMI from becoming a long-term storage site for abnormal waste. Until final disposal sites and methods are selected, the Idaho National Engineering Laboratory (INEL) will store this waste in heavywalled temporary storage containers that will sit on a paved storage pad.

\section{Reactor Evaluation Program}

The Reactor Evaluation Program in 1984 met two highly visible milestones toward reactor defueling: reactor vessel head removal and plenum jacking.
In July 1984, GPU Nuclear successfully lifted the TMI-2 reactor vessel head and placed it on its storage stand in the Reactor Building. Preparations in the months preceding this event included the polar crane lift test, removal of the 60 studs that fastened the head to the reactor vessel, installation of a seal plate that closed the gap between the flange of the reactor vessel and the floor of the refueling canal, processing of the reactor coolant system water to reduce radioactivity levels, installation of sand-filled tanks for shielding at the storage stand periphery, and worker training on mockups of the reactor head and other components and apparatus.

Once the head was on its stand, preparations began for plenum jacking. Using specially designed underwater cameras and lights, workers inspected the plenum to check clearances in certain normally tight areas. The inspectors found some debris and slight distortion to the lower portion of the plenum, neither of which were considered preclusions to plenum jacking. Initiating the first intentional movement of substantial amounts of fuel in the damaged reactor, workers knocked stubs of fuel assemblies from the bottom of the plenum.

Four hydraulic jacks were tested on a mockup of the plenum assembly and then installed in the Reactor Building; and in December the plenum was jacked $18.4 \mathrm{~cm}$ from its seated position. Workers knocked more debris and end fittings from the bottom of the plenum after each of two lifting stages until no more fuel material was attached.

In May 1985, the plenum will be removed from the reactor vessel and placed in the flooded deep end of the refueling canal. The core region will then be accessible for defueling.

During 1984, planners closely reviewed the designs for the system by which the core will be defueled, and manufacture of the defueling tools began. Much of the work will be carried out manually with long-handled tools. Debris will be loaded into canisters either by vacuuming or "pickand-place" work, and the loaded canisters will be temporarily stored in the spent fuel pool until their shipment.

Two rail casks, the design for which was selected in 1984, will be used to transport all of the loaded canisters to the INEL. The casks, each designed to hold seven loaded canisters at a time, will meet federal regulations for double containment of 
plutonium-bearing materials. Each cask will be loaded upright in the TMI-2 truck bay, placed on its side on a rail car, and transported to the INEL, where the cask will be unloaded and returned empty to TMI for the next shipment.

\section{Data Acquisition Program}

The Dara Acquisition Program (DAP) in 1984 made considerable progress in two principal areas: the Instrumentation and Electrical (I\&E) Program and the Cors Sample Acquisition and Examination Project.

Consequences of the loss-of-coolant accident (LOCA) on the cables and connections in the Reactor Building have been the focus of a major investigation by $1 \& \mathbb{E}$ engineers. Completing Phase I of the investigation, operations personnel testedwithout removing-about one-third of the Reactor Building's circuits, finding about one-third of those tested exhibiting anomalies and classifying about one-fourth as inoperable. Laboratory personnel used the resultant data to determine which anomalous cables should be removed for further analysis-Phase III of the project.

Meanwhile, a task was formulated to acquire samples of the core's postaccident stratification. These samples will serve as a permanent record of the undisturbed, damaged reactor core beneath the rubble bed. During the year, INEL engineers tested various drill bits on a simulated TMII-2 fuel stub assembly and finalized the operational sequence by which the core samples will be obtained.

Visual documentation of the core's condition plays a vital role in DAP activities. In 1984 a new video enhancement system was successfully tried out when GPU Nuclear inspected and jacked the plenum and subsequently probed the core. With this system, several frames of high-resolution, broadcast-quality videotape are compiled into one image, giving a more distinct view than can be seen in any one frame. This visual information will help to define samples to be taken during the defueling operation.

\section{Information and Industry Coordination}

The Information and Industry Coordination (I\&IC) staff prepared a number of summary reports that present the results of various TMI projects and address issues of general interest to the commercial nuclear power industry.

During the last quarter of 1984, I\&IC developed a formula that utilities could use to meet NRC requirements for hydrogen gas generation in radioactive waste containers sealed for shipment. Using known parameters for the waste and container type, plant operators would be able to calculate the safe storage time before the hydrogen gas concentration reaches a combustible mixture. The calculation would be a cost-effective alternative to venting radioactive waste containers.

\section{EPICOR and Waste Research and Dispositition Program}

Recovery work in the EPICOR and Waste Research and Disposition Program continued in 1984 as personnel at the INEL began disposing of 46 of the 50 EPICOR II prefilters that were used in the TMI-2 cleanup. The prefilters are being buried at a commercial disposal facility in Washingt on State loaded in HICs that have been approved by the NRC and certified by the state. So far, 37 prefilters in HICs have been processed and buried at the site.

The four remaining EPICOR II liners are part of a research project to examine the resins from the prefilters to develop a data base for low-level waste. Information obtained in this work will be used to determine survivability of waste forms composed of radioactive ion-exchange media solidified in cement and Dow polymer. The tests on the prefilters specifically address liner integrity and resin degradation and solidification. In lysimeter field tests, researchers are studying radionuclide leaching from solidified waste buried in a natural environment.

Preparations began in 1984 for the receipt of abnormal waste from TMI. A special storage pad 
is being designed for temporary INEL storage of radioactive materials, mostly transuranic contaminated wastes, such as plant cartridge filters, organic ion-exchange resins, sludges from various tanks and building sumps, cartridge and sand-filter assemblies from the SDS, and miscellaneous contaminated pieces of hardware.

\section{Core Activities Program}

Receipt, storage, and examination of core debris, components, and samples are the focus of the INEL's Core Activities Program. In 1984, preparations continued for receiving the canister-loaded shipping casks, transporting the casks to the Test Area North hot shops, unloading the casks, and placing the canisters in the water pit. Workers started modifying some of the equipment in the hot shop for proper handling of the debris-loaded canisters.

In the INEL's Core Sample Acquisition and Examination Project, personnel analyzed 11 core debris grab samples, two lead screws from the damaged reactor, a lead screw support tube, and a resistance temperature detector. Especially revealing were the results of the grab sample analyses; scientists found distinct evidence that the core reached at least $2922 \mathrm{~K}$, which is $156 \mathrm{~K}$ below the melting point of uranium dioxide fuel. Other studies on these samples are providing analysts with valuable information regarding the behavior of radionuclides under conditions like those at TMI; the data will aid in the design of equipment and tools for defueling the damaged reactor. 


\section{WASTE IMMOBILIZATION PROGRAM}

The Waste Immobilization Program (WIP) carried out two major efforts in 1984. These were cesium removal from the makeup and purification demineralizers and preliminary work toward the disposal of radioactive waste not acceptable for commercial disposal. Also in 1984, WIP continued its zeolite disposition program.

\section{Cesium Elution}

Resin removal in commercial nuclear power plants normally is accomplished by sluicing, or washing the resin from the demineralizer vessel to a spent resin storage tank. The resin at TMI- 2 could not be directly removed, however, because its dose rates exceeded the values used in designing the spent resin transfer system. Therefore, elution of cesium was required to lower the dose rates for transfer.

Removal of ${ }^{137} \mathrm{Cs}$ from the resins of the $\mathrm{A}$ and $B$ makeup and purification demineralizer vessels (Figure 2) was estimated to be $40 \%$ complete by the close of 1984. Preparations for this processing began in 1982 with the characterization of the demineralizers using remotely positioned and operated instruments. This work was followed by a chemical analysis of resin samples taken in 1983 . Personnel in 1984 took a second sample from demineralizer $\mathrm{A}$ after adding water and loosening the resin; previously, the resin was too dry to take an adequate sample.

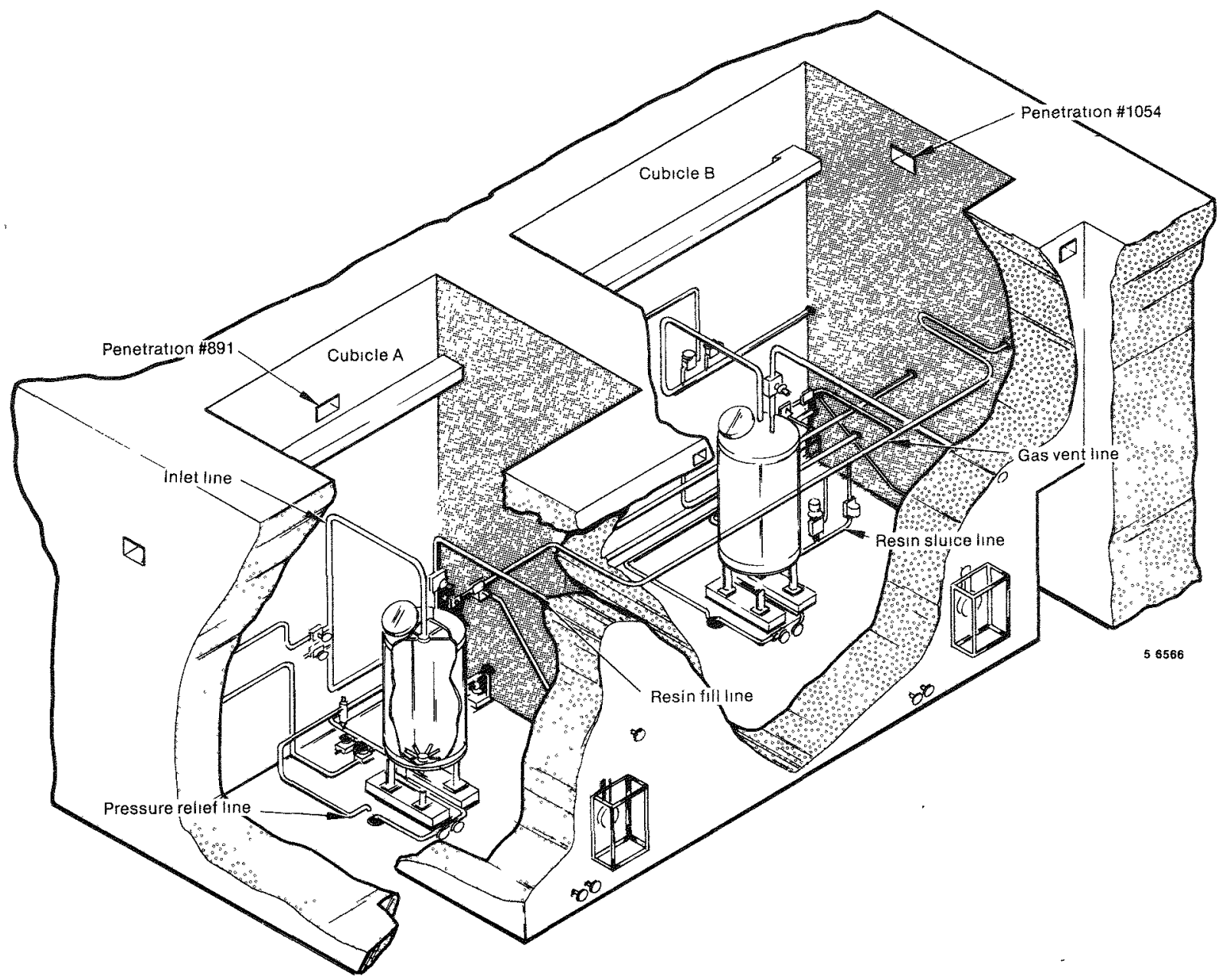

Figure 2. The two makeup and purification demineralizer tanks, located in adjacent cubicles, may have captured as much as $36,950 \mathrm{Ci}$ of radioactive cesium. 
Oak Ridge National Laboratory (ORNL) analyzed the samples to validate the chemical process by which GPU Nuclear planned to remove cesium from the demineralizer resins. Performing a laboratory simulation of the process flowsheet, ORNL subjected sample materials from the demineralizer vessels to a 17-stage rinse and elution test. In the initial stage of the process, sample material was rinsed with $0.18 \mathrm{M}$ boric acid. Subsequent stages subjected the ion-exchange resin samples to increasing concentrations of sodium borate and, in the final stages, to sodium hydroxide. Figures 3 and 4 are the results of the cesium elution simulation for the resin samples from the $A$ and $B$ demineralizer vessels, respectively. These results indicated that approximately $70 \%$ of the cesium could be eluted from the A demineralizer resin, and $90 \%$ of the cesium could be eluted from the more highly loaded $B$ demineralizer resin. After ORNL's tests, the specific activity of the $A$ and $B$ samples was similar. Process flowsheet simulation also involved testing to determine the effectiveness of the TMI-2 Submerged Demineralizer System (SDS) zeolite ionexchange material in removing cesium from the eluant. The zeolites removed $99.99 \%$ of the cesium in this test.

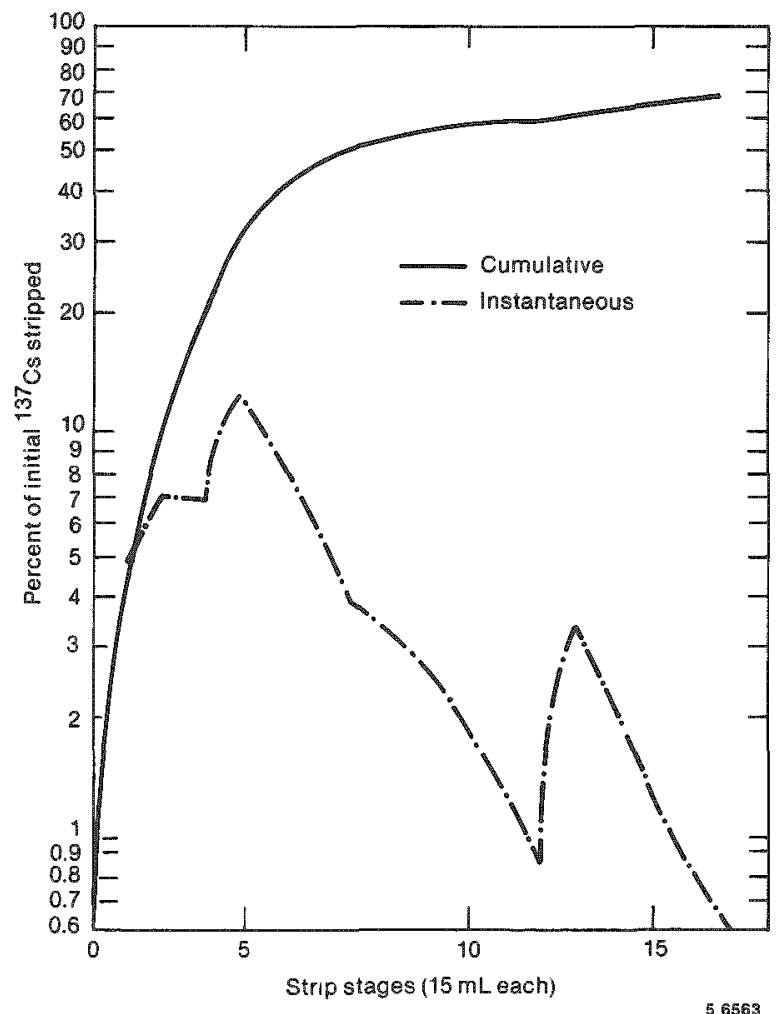

Figure 3. About $70 \%$ of the ${ }^{137} \mathrm{Cs}$ was stripped from a sample of demineralizer $\mathrm{A}$ resin.

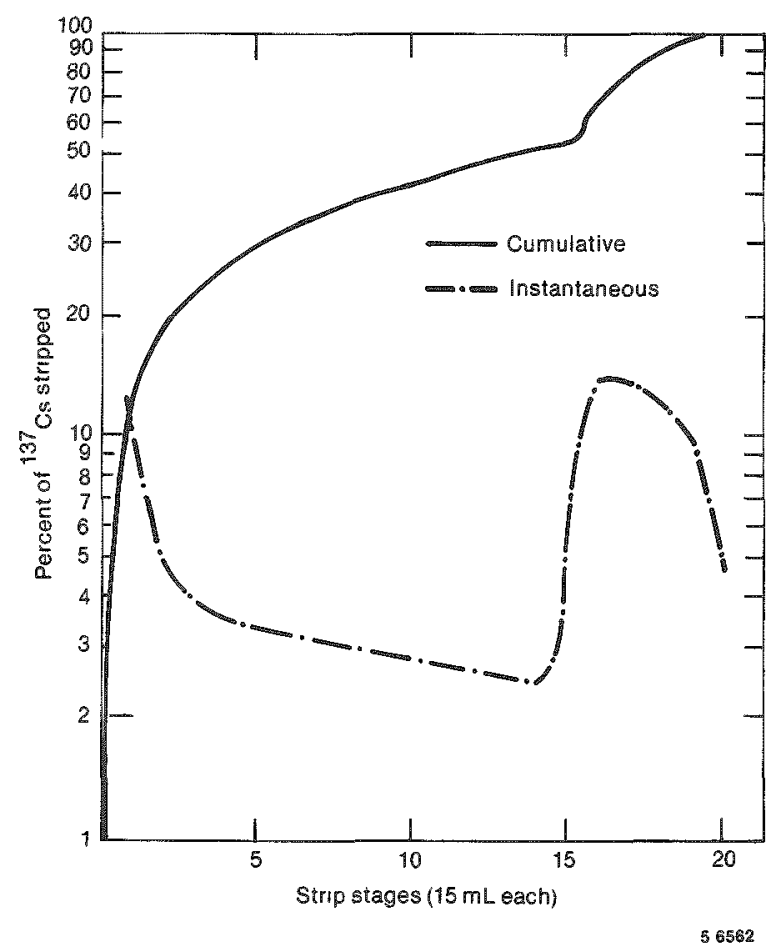

Figure 4. Ninety percent of the ${ }^{137} \mathrm{Cs}$ was stripped from a sample of demineralizer $B$ resin.

ORNL also investigated effluent filtration that was to precede SDS treatment. Filtering is intended to prevent the unnecessary introduction of particulate matter to the SDS ion-exchange material. ORNL's filtering tests showed that a $0.5-\mu \mathrm{m}$, sintered, stainless steel filter was quickly and irreversibly clogged by the process effluent. Similar filters $10 \mu \mathrm{m}$ and greater also were tested and found to remove the particulate without the rapid plugging experienced using a filter with smaller pores. The 10- $\mu \mathrm{m}$ fillter, however, did get plugged but not as quickly as the $0.5-\mu \mathrm{m}$ filter. A $20-\mu \mathrm{m}$ filter, meanwhile, effectively prevented unacceptably large particles from passing through, yet without the undesirable plugging.

In addition to the laboratory simulation described above, ORNL performed microscopic and macrophotographic examinations of the A and B demineralizer samples. These examinations indicated that even though the $B$ sample was more highly loaded with fission products, the resin in the A sample sustained more extensive physical damage. While the B sample appeared to be somewhat discolored, the resin beads were mostly intact, and they experienced no apparent charring or agglomeration. Significant charring and bead agglomeration were visible in the A sample, however. Temperatures on the order of $810 \mathrm{~K}$ are required for this resin to char, as Battelle 
Pacific Northwest Laboratory demonstrated in previous resin degradation experimental work.

Figure 5 illustrates the equipment being used for cesium elution. Westinghouse Hanford Company designed and fabricated this equipment under DOE funding. The chemicals discussed above are mixed in the chemical addition skid batch feed tank and pumped into the demineralizer tanks. After a 24-h "soaking period," the chemical solution now containing $137 \mathrm{Cs}$ from the contaminated resins is withdrawn from the demineralizers by either the corresponding transfer pump or eductor, mixed with processed water to reduce the downstream dose rate, and pumped through the sintered, stainless steel filters.

In preparing to process the demineralizer resins, engineers faced the problem of how to gain access to the tank to withdraw the decontaminating solution, or eluant. Chemicals were added using the chemical addition skid and fill pump and entered the demineralizer vessels through existing piping. GPU Nuclear created a new pathway for removing the elution water. A resin fill line was introduced into the gas analysis room just outside the demineralizer cubicle. Workers threaded a polyethylene tube into the resin fill line, through the air-operated weir valve on the fill line, and into the void above the resin bed. The system was closed then by welding a slip flange on the newly cut resin fill line and mating the suction hose to a pipe leading to the pump eductor skid. Provisions allowed the water from filter backflushing and rinsing to be routed to the demineralizers through the resin fill line.

While testing the elution and filter equipment, Westinghouse personnel noted a greater-thanexpected filter pressure drop and found that filter backflushing was necessary more often than expected. The $0.5-\mu \mathrm{m}$ filter, originally considered for the system, was plugged with particles that were in the test water. Analysts attributed this condition to particle sizes being close to the nominal pore size of the filter and, like the ORNL scientists, questioned whether these filters would disrupt successful processing of the resin. Because rinse water is added to the system after backflushing, frequent backflushing could increase system water volume to a point where the tanks would be too full to permit further system operation.

To finally determine an acceptable pore size for the filters, GPU Nuclear conducted its own benchscale tests using filters of various pore sizes. Because the predominant constituent filtered by the system would be the rinse and elution water, tests were performed to either establish the compatibility of the previously selected $0.5-\mu \mathrm{m}$ filter with the water or otherwise determine the filter pore size that should be used. Figure 6 is a schematic of the filter test system used. The filter test system simulated cesium elution filter equipment for both filtering and backflushing. The testing established that TMI-2 process water is compatible with all pore sizes of sintered metal filter media tested, including $0.5-\mu \mathrm{m}$ media. GPU Nuclear's final selection of $20-\mu \mathrm{m}$ elements was based on the earlier described parallel testing that ORNL performed on demineralizer material samples. The larger pore size consequently was designed into the system in combination with a weak anionic ion-exchange resin for adsorption of organics in the demineralizer liquid.

From the filters, the solution is routed to the neutralizer tanks and then fed in batches to the SDS. The filters are backflushed using pressurized $\mathrm{N}_{2}$ from bottles whenever the filter pressure drop increases beyond the operational limit of $103 \mathrm{kPa}$. Water in the filters and piping at the time of backflush is routed to the demineralizer opposite the one being processed, allowing the particulate backflushed from the filters to settle for two or more days. After backwash, the piping is flushed with $76 \mathrm{~L}$ of processed water before elution continues.

The amount of dilution water added to the elution flowstream during processing is based on the dose rate measured in downstream piping, specifically downstream of the backflushable rilters. The dose rate in this piping is kept at a maximum of $200 \mathrm{mR} / \mathrm{h}$. The dilution water is injected into the elution flowstream at the pump eductor skid. This requires the entire diluted stream to be filtered, but it allows the dose rates in the area of the filters and water meter skid to be kept much lower than would be the case if undiluted eluant were present.

Cesium elution of the two demineralizer vessels will be completed in early 1985 . The loaded SDS liner will then be packaged for safe shipment to Hanford, WA, where it will be properly buriedthe last SDS liner in the Monitored Retrievable Burial Demonstration Program.

\section{Abnormal Waste}

To date, waste generated during the TMI-2 cleanup has either been disposed of at commercial 


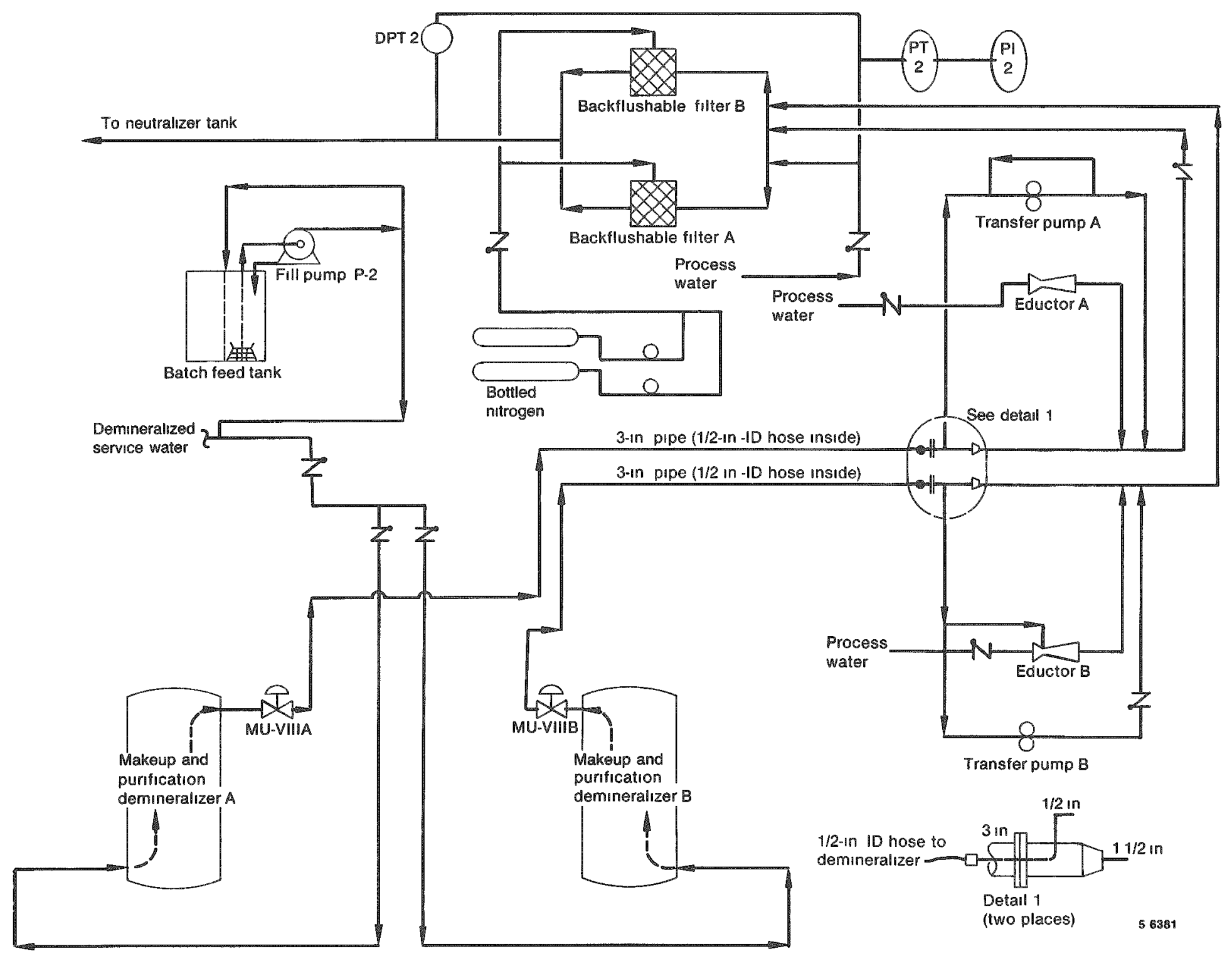

Figure 5. Westinghouse Hanford Company designed this cesium elution equipment. 


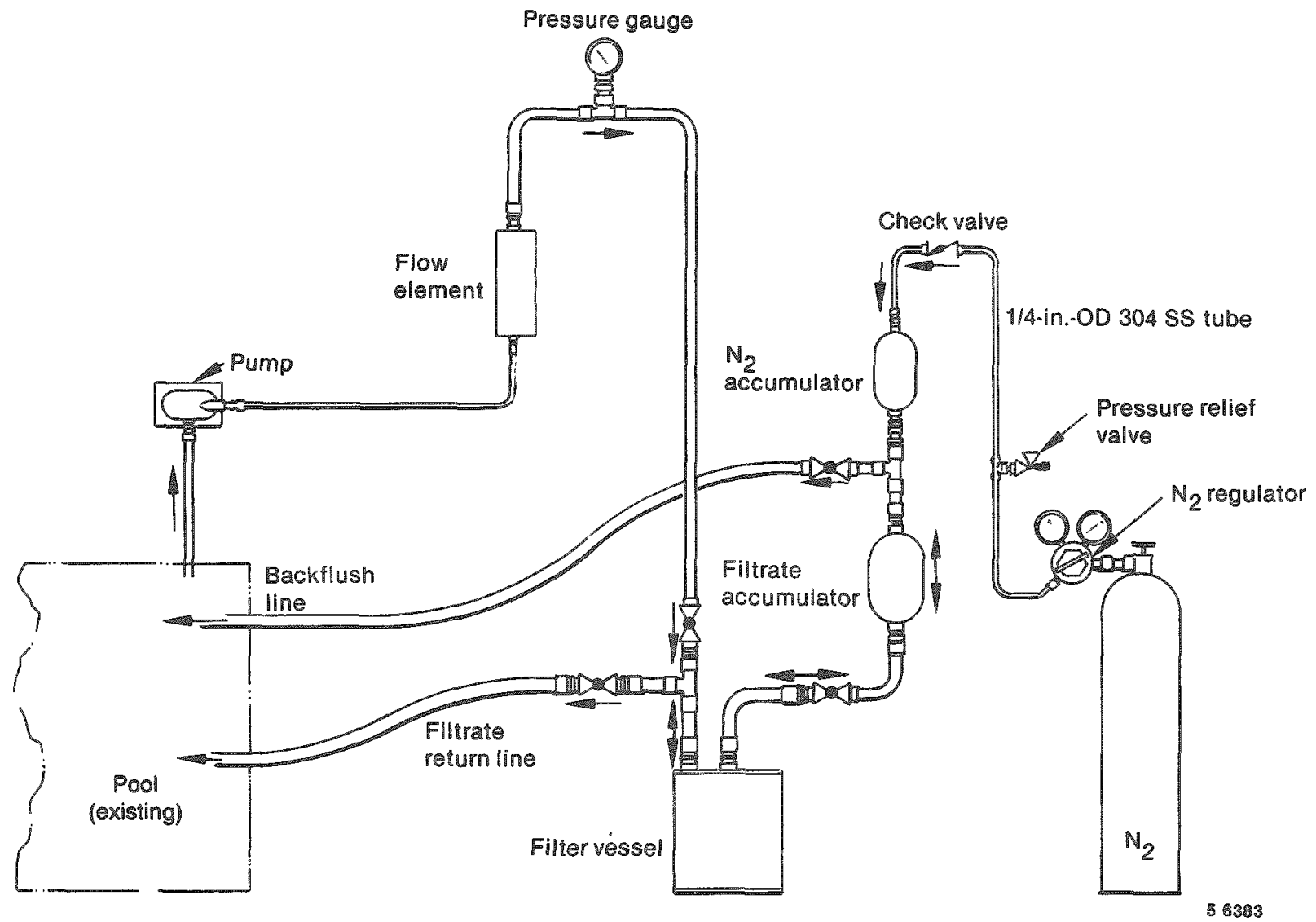

Figure 6. This filter test system was used to determine the appropriate pore size for filters in the cesium elution system.

burial grounds or included in DOE-sponsored research and development programs for waste disposal or treatment. The waste that DOE used for research has provided valuable data on the disposal of high-specific-activity waste. Waste materials with high curie contents have been instrumented, overpacked, and buried in shallow trenches at the DOE Hanford site in Washington state. Other high specific activity materials from TMI-2 have been part of DOE-funded laboratory research toward understanding the 1979 accident. Organic ionexchange material expended in early water-cleaning operations in the TMI-2 Auxiliary Building have been disposed of commercially, with waste preparation assistance from DOE facilities, in high-integrity containers that were developed in a DOE research program.

As the cleanup progresses and the damaged fuel is removed from the reactor, GPU Nuclear expects to generate more high specific activity nonfuel wastes. Commercial disposal sites in Barnwell, SC, Hanford, WA, and Beatty, NV, operate within NRC limits on specific activity of waste received. Up to now, wastes exceeding the NRC limitsstipulated in 10 CFR 61-have been handled through research projects. Future waste has no identified research and development value and is not acceptable at a commercial disposal site. This waste is referred to as "abnormal waste."

Recognizing the desire to prevent TMI-2 from becoming a long-term storage site for abnormal waste, the NRC and DOE agreed in a 1982 Memorandum of Understanding that DOE will accept abnormal waste on a full cost-recovery basis from GPU Nuclear. Toward this end, DOE and GPU Nuclear are negotiating a disposal agreement. Acceptance of waste would be governed by the INEL TMI Abnormal Waste Acceptance Criteria. DOE would accept title to all waste classified for abnormal waste disposal. However, GPU Nuclear would retain the liability for the cost of disposal. In the agreement being negotiated, GPU Nuclear would pay for handling costs as incurred and create a trust fund for eventual waste disposal. Because a final disposal method and site have not been selected for such abnormal waste, the waste will be transported to the INEL, placed in heavy-walled temporary storage containers, and placed on a paved pad at the Test Area North facility. Disposition will be the subject of investigations until a highlevel waste repository is available. 


\section{REACTOR EVALUATION PROGRAM}

Among the highly visible accomplishments of the Reactor Evaluation Program, the head of the damaged reactor vessel was removed and the plenum was jacked. Both efforts were preceded by months of preparations and inspections. Tool and equipment design and fabrication also were well under way, as GPU Nuclear continued toward plenum removal and reactor defueling. Also during the year, a contractor was selected to design and fabricate the rail cask that will be used to ship debris-loaded canisters from TMI to the INEL.

\section{Reactor Vessel Head Removal}

In July 1984, GPU Nuclear successfully lifted the TMI-2 reactor vessel head and placed it on its storage stand in the Reactor Building in one of a series of actions making the damaged vessel accessible for defueling (see Figure 7). During the months preceding head lift, GPU Nuclear developed techniques for applying a sealing compound at the joints of the canal seal plate (see Figure 8). Serving as an additional seal, this compound ensured that water would nor leak into the space between the reactor vessel and the canal, had it been necessary to flood the canal during head removal as a radiation control measure. Although the canal was not flooded for this operation, the sealed installation remains in place in case flooding is required for subsequent ativities.

In late Fobruary 1984, the polar crane was successfully tested and found qualified to lift the reactor vessel head and service structure. The crane lifted and maneuvered a $194 \mathrm{-Mg}$ load of missile shields (concrete blocks), the specially constructed lifting frame, and assorted rigging assemblies.

The 60 studis that fastened the head to the reactor vessel were partially detensioned to identify the studs that might have been stuck as a result of corrosion. The studs were detensioned by first stretching them and then loosening the nuts on them. Two of the studs were removed at that time, leaving holes in the head flange that later were lined up with the two guide pins on the storage stand on which the head was seated. In later entries, workers fully detensioned and removed the other 58 stud and nut assemblies, each weighing $304 \mathrm{~kg}$, and placed them in storage racks. Finally, the stud holes were filled with a preservative and sealed, preventing them from corroding.
After completing this work, GPC Nuclear in April 1984 installed the canal seal plate, closed of the reactor coolant system, and refilled the reactor vessel with borated water. Processing of the reacfor coolant system could then resume to reduce the water's radionuclide activity level. Clearing a path for the head to be transported through the south end of the refueling canal, the auxiliary fuel handling bridge was dismantled and moved to the north end of the canal. (This bridge holds the crane for normal defueling and straddles the refueling canal.) The guide bushings in the internals indexing fixture (IIF) were modified so the IIF could sit on the reactor vessel flange without interference.

Meanwhile, in the Unit 2 Turbine Building, GPU Nuclear assembled a mockup of the IIF. This mockup was used to test various components, equipment, and systems before their actual use in the Reactor Building. Among the items tested were the gasket seal, the IIF processing system, and the IIF work platform. After its fit was confirmed, the platform was disassembled and staged in the Reactor Building in June 1984. Processing of the reactor coolant system was completed, and the system was drained to the 321 -ft, 6-in. elevation in preparation for head removal.

Temporary lead shielding was installed on the reactor vessel head's service structure in anticipation of high radiation levels that resulted as the lead screws were raised from inside the vessel and placed in their "parked" positions in the reactor vessel head.

Also to shield radiation fields, portable Fiberglas tanks filled with sand were placed at the periphery of the head's storage stand. In the days prior to head lift, closed-circuit television systems, height gauges, and radiation monitoring equipment were installed to monitor the head lift operations. Also, personnel completed training, a critical part of the head removal effort. By rehearsing in the Unit 2 Turbine Building on mockups of the reactor head, IIF, temporary work platform, and other components and apparatus, workers were prepared to enter the Reactor Building and carry out their functions safely and efficiently. Consequently, they were able to reduce their time in the building and minimize their exposure.

Actual head lift operations began on July 24, 1984. The head was placed on the storage stand the 


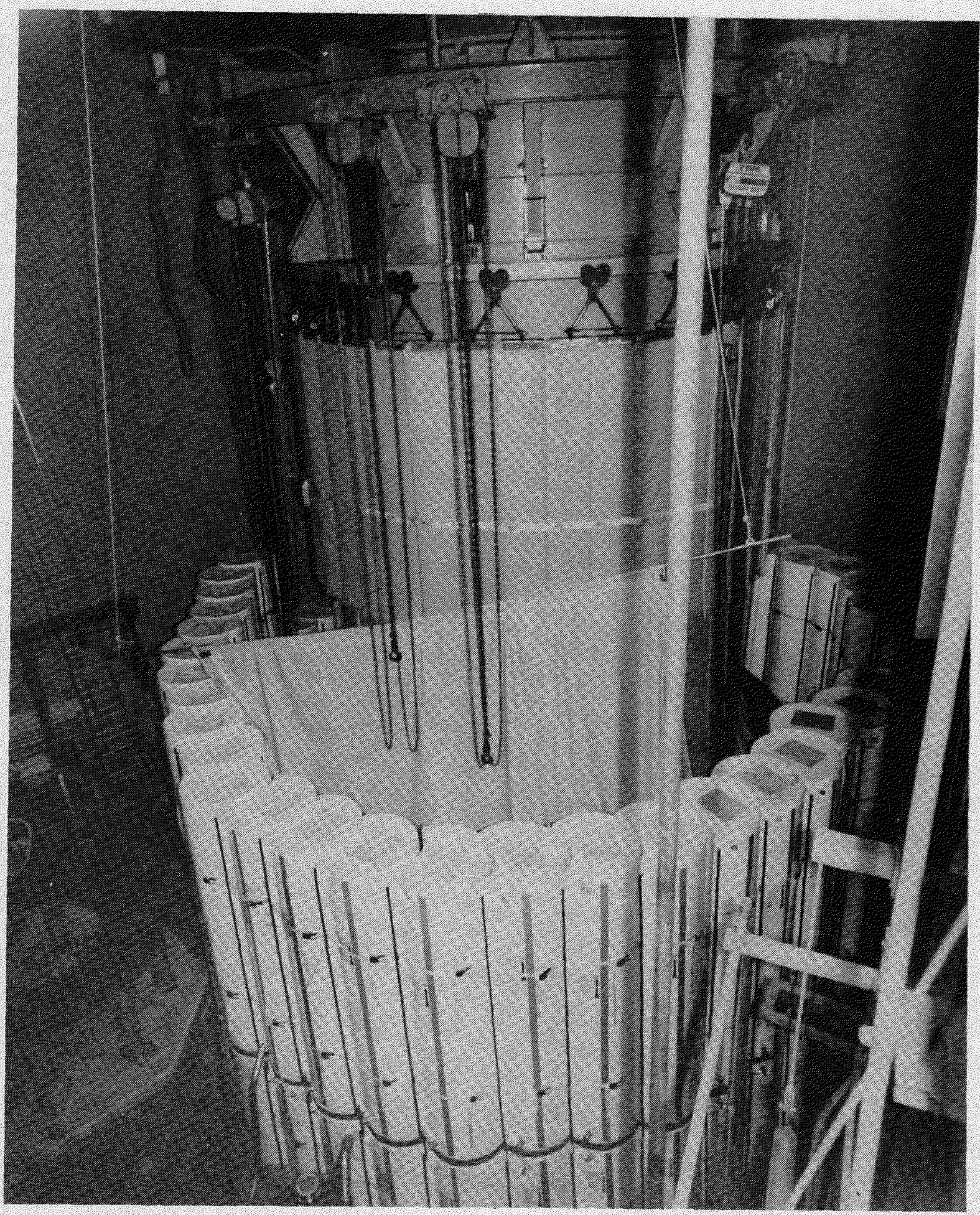

Figure 7. The reactor vessel head sits on its storage stand, surrounded by sand-filled Fiberglas tanks for radiation shielding. 


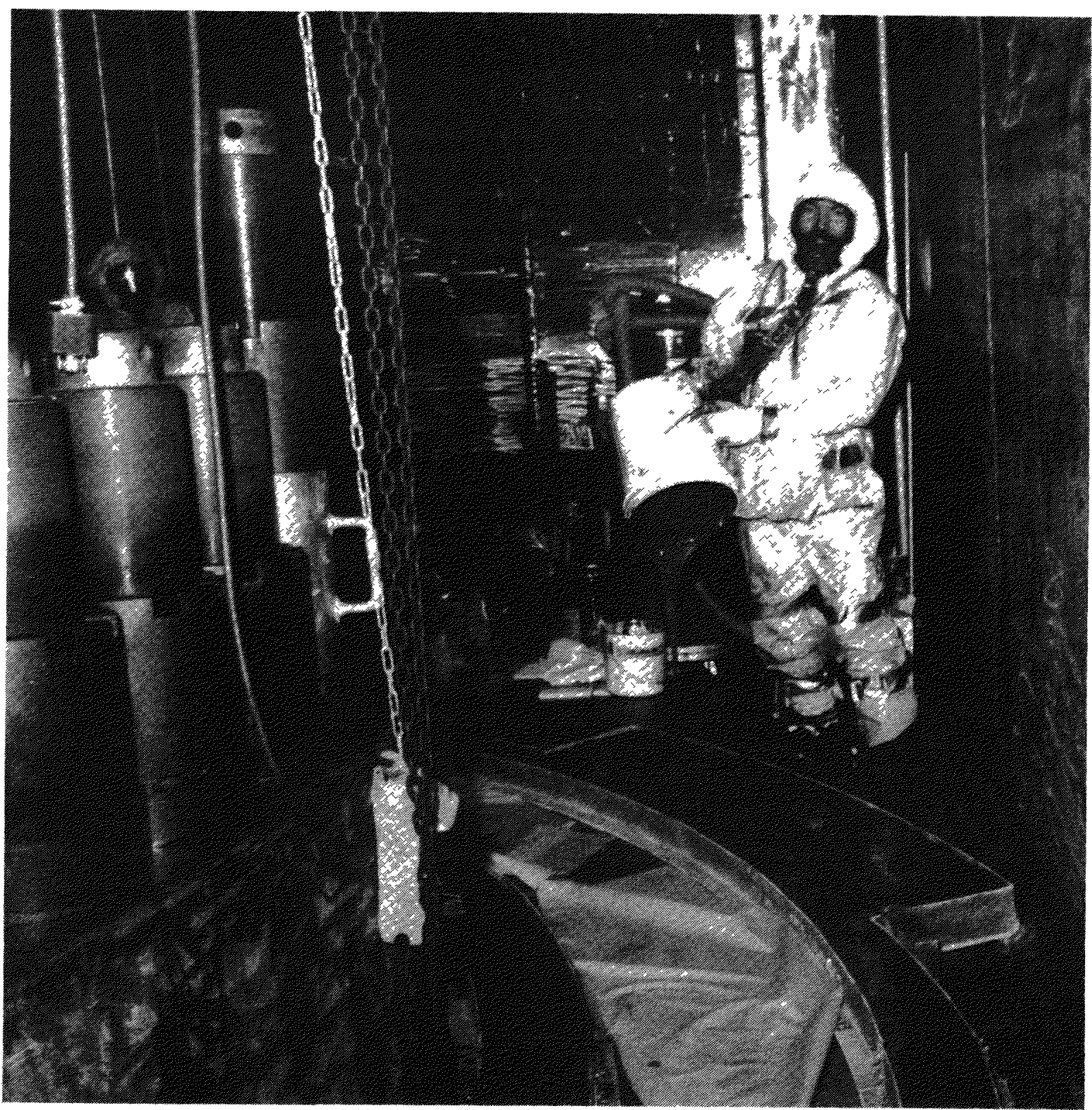

Figure 8. Sealant and a metal seal plate were placed between the refueling canal and the reactor vessel so the canal could have been flooded, if necessary, for shielding. 
following day. Then, the IIF was placed in position over the open reactor vessel, the reactor coolant system water level was raised into the IIF to sheld the open vessel, and the temporary work platform was seated over the IIF (see Figure 9). All head removal operations were completed on July 27 , 1984, 10 days ahead of schedule.

\section{Plenum Removal}

With the reactor vessel head removed, attention turned to the plenum assembly, which also has to be removed to gain access to the core for defueling. The plenum assembly is scheduled to be removed and placed on a stand in the deep end of the refueling canal in May 1985. In preparation for this next milestone, GPU Nuclear in December 1984 jacked the plenum $18.4 \mathrm{~cm}$ from its seated position (see Figure 10). This work ensured that the plenum assembly could be hifted out of the vessel without obstruction. It also gave workers the opportunity to knock debris and broken end fittings from the plenum's underside, thereby reducing the amount of fuel and debris that could drop from the plenum when it is transported from the vessel to its storage stand. This work will also permit the plenum to sit evenly on its storage stand.

Preparations for Plenum Removal. The plenum assembly's removal from the reactor vessel requires unique equipment and methods due to the abnormal condition of the TMI-2 reactor. The plenum assembly was subjected to severe overheating during the 1979 accident. Some parts of the $49.9-\mathrm{Mg}$ assembly became hot enough to experience localized melting. In other parts of this stainless steel structure, whose diameter is $4.24 \mathrm{~m}$ and height is $3.81 \mathrm{~m}$, the thermal expansion exceeded the design clearances, causing distortion. Such conditions could have resulted in binding because the plenum and core support shield assemblies were machined to close tolerances to be sure the fuel and control rod assemblies would be properly aligned. Because of this potential for binding, special equipment had to be designed to free the plenum assembly from the core support shield.

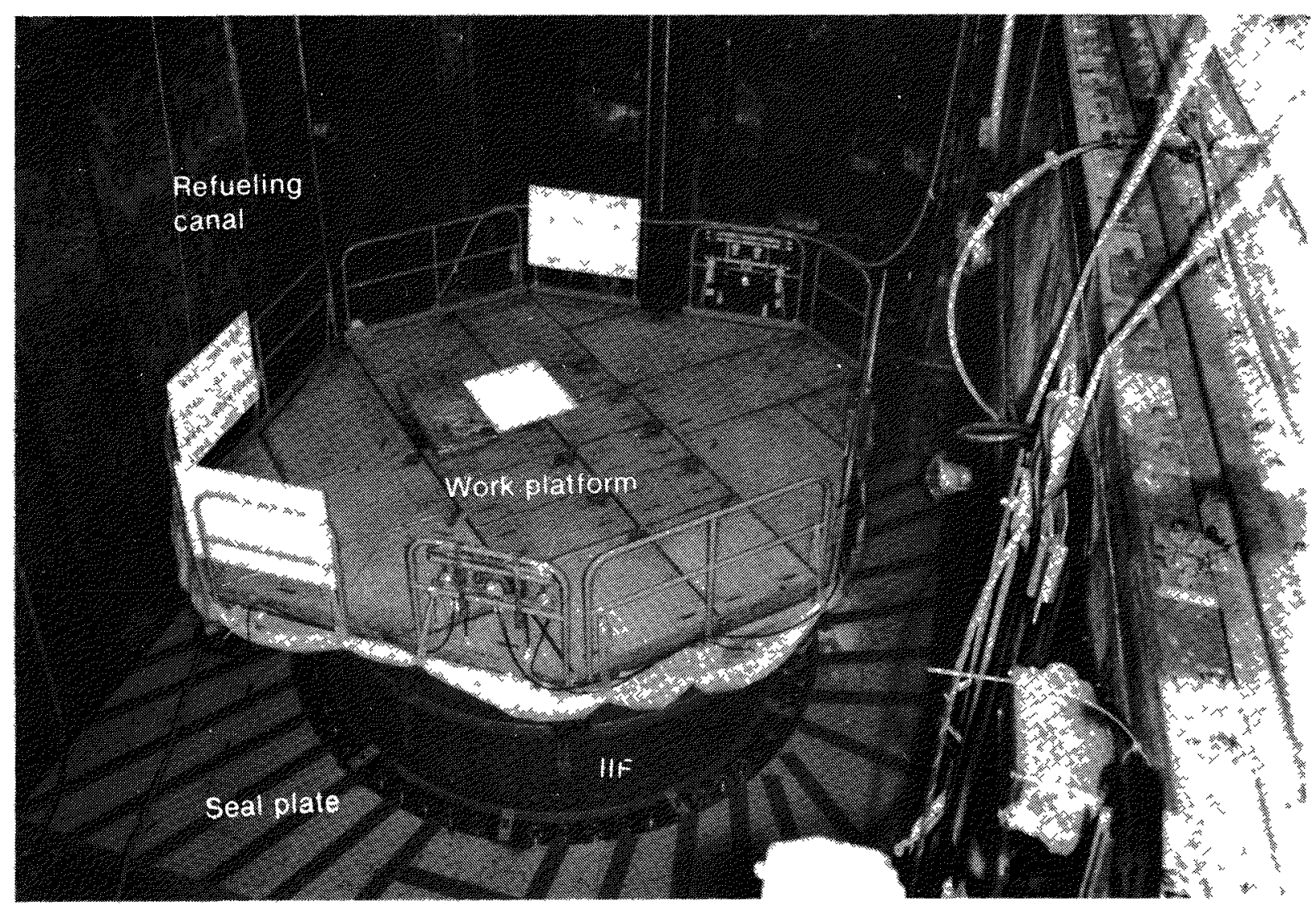

Figure 9. The IIF, filled with water, and the temporary work platform over the open vessel provide sufficient shielding for workers preparing for defueling. 


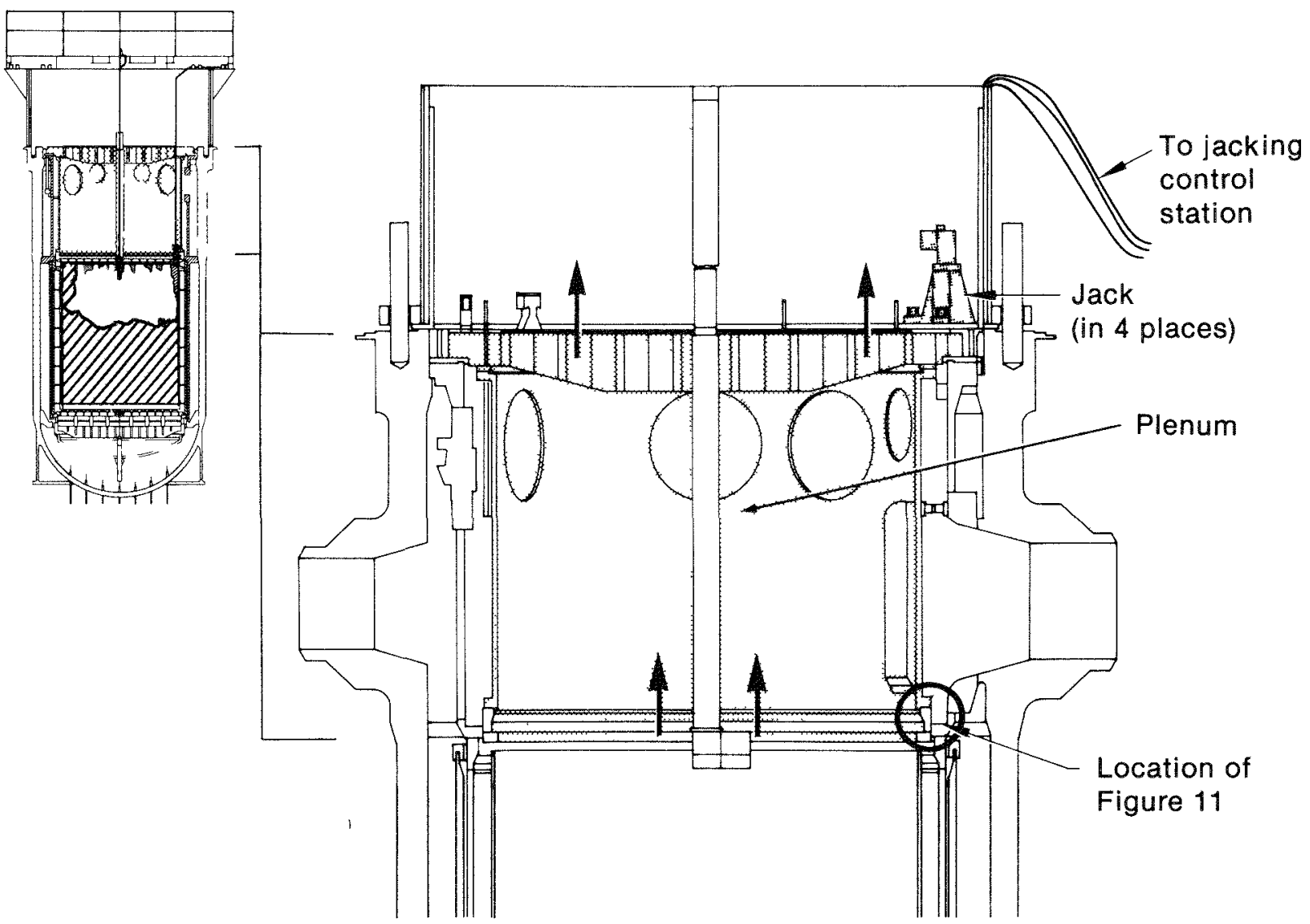

Figure 10. In December 1984, the plenum assembly was jacked to $18.4 \mathrm{~cm}$. The highlighted area indicates the location of the photographs in Figure 11.

The accident conditions also caused severe damage to the fuel assemblies in the reactor core, which in turn, caused large quantities of highly radioactive fuel debris to circulate throughout the reactor coolant system. As a result, the plenum assembly is coated with a thin, highly radioactive adherent coating in addition to light deposits of fine core debris. The transient also caused the upper portions of many broken fuel assemblies to become stuck to the bottom of the plenum assembly. Another possible consequence factored into the removal tooling system was the potential degradation of certain plenum structural components.

Because of these unique conditions, inspections preceded plenum lift to check for clearances, distortion, and damage. The conditions called for special apparatus capable of high-capacity vertical lifting to overcome potential binding between the plenum assembly and the core support shield. Water and lead shielding would be necessary to avoid excessive radiation exposure to personnel. And contamina- tion control barriers would prevent the uncontrolled spread of radioactive debris. Also seen as necessary were longer lifting pendants capable of reaching a structurally sound portion of the plenum assembly.

In determining the tools necessary for plenum removal, planners had to consider the step-by-step operations toward removal: inspection and initial separation of debris, initial lift of the plenum, additional separation of debris from the plenum's underside, removal of the temporary work platform sitting atop the IIF, final lift and subsequent removal of the plenum assembly, installation of a temporary cover on the IIF, and placement of a contamination control cover around the plenum. Another factor taken into account in tool planning included the intent to remove the plenum assembly intact.

Detailed inspections of the reactor internals were conducted to further assess conditions that could affect plenum assembly removal. These inspections 
documented the need for special rools to free the plenum assembly from the reactor internals, dislodge suspended fuel assembly remnants, and lift, transfer, and store the plenum assembly in the deep end of the refueling canal. Storage in the canal's deep end represents a departure from the original plan to flood the entire refueling canal. So that defueling operations personnel can work on the platform directly over the reactor (they would have to conduct their work from the $347-\mathrm{ft}$ elevation if the entire canal were flooded), GPU Nuclear decided to confine the water to the deep end of the canal by installing a dam, whose fabrication began in 1984. Substantially less water will have to be processed during the TMI-2 recovery operations using this technique. The water in the deep end and a specially designed contamination control cover in which the plenum will be wrapped will provide suf ficient shielding and minimize the spread of contamination. For shielding over the reactor vessel, the IIF remains fastened to the reactor vessel flange and filled about $1.5 \mathrm{~m}$ deep with water.

Preceding plenum lift, workers used an integrated video and communication system to examine areas of the plenum assembly and reactor vessel components that would interface with plenum tooling, points of potential binding that would make plenum lift difficult, sections that could unexpectedly separate during lifting, and areas that required cleaning. This was the first detailed examination of thermally induced structural deformation. The state-of-the-art video system comprised special radiation-hardened underwater cameras and lighting. Inspectors saw localized damage and core debris larger than previously detected in the plenum's lower regions. Also, the inspection confirmed GPU Nuclear's plans to remove the plenum in one piece; technicians determined that no physical conditions would preclude successful plenum jacking. The major inspection check points included the plenum keyways, jack contact surfaces, vent valves, LOCA bosses, and the core support assembly and grid annulus clearance. A measurable bow in the plenum's north-south axis with a corresponding bow in the east-west axis region was evaluated. But this degree of thermal deformation was predicted by TMI-2 recovery engineers, and any resultant binding forces were evaluated to be well within the plenum jacks' lifting capacity.

As an integral part of this prelift inspection, workers dislodged and removed upper fuel assembly end fittings and debris suspended from the bottom of the plenum using specially designed, manually actuated, slide-hammer tools. All eight of the axial power shaping rod assemblies were removed at this time, as well. GPU Nuclear chose to remove these materials to minimize transfer of radioactive material as the plenum is transported from the reactor to the refueling canal. The work also eliminated the concern about protruding material interfering with placement of the plenum on its stand or puncturing the soft cover in which it will be wrapped. The video system, located on the temporary work platform over the reactor vessel, allowed the operators to monitor their work and control the equipment. A supplementary video system was located in the Command Center inside the Turbine Building.

During all of this prelift work, GPU Nuclear verified the performance of tools and equipment associated with plenum jacking and removal, and personnel received training in equipment use on four test assemblies set up in the adjoining Fuel Handling Building. An interface test assembly simulared a section of the TMI-2 plenum, core support assembly, and IIF. A tesi stand was used for end fitting separation training. A jack qualification fixture was used to load-test each of the four jack assemblies. And a jacking system test assembly was used to evaluate the performance of the entire jacking system. A test assembly also will be used to verify the operability of equipment for the plenum's final lift, transfer, and storage.

GPU Nuclear also conducted a load-drop analysis, in which the plenum was assumed to be jacked over the reactor vessel. Technicians evaluated the boron concentration in the reactor coolant system water to ensure the concentration is great enough that the reactor will remain shut down during the removal operation. And a chilled air system was installed in the Reactor Building to reduce heat stress the workers experienced during their recovery operations.

Finally, personnel installed the hydraulic jack system, with which the plenum was lifted. Fabricated and delivered to the site during the year, the four hydraulic jacks were specially designed to provide a controlled lifting stroke of $25.7 \mathrm{~cm}$. Each jack was originally designed to lift $54.4 \mathrm{Mg}$, for a total lifting capacity of $217.7 \mathrm{Mg}$, to provide enough force in case the plenum was stuck. However, one of the four jacking frames had to be modified for proper seating (drawings of TMI-2 as 
built are nonexistent and thus were unavailable for jack design). As a result of the modification, each of the four jacks was rated at a lower lifting capacity of $45.4 \mathrm{Mg}$, still sufficient capacity to lift the plenum if it were stuck. The jacks were also equipped with mechanical followers to support the plenum assembly between lifts.

The jacks were seated in triangular openings at each of the plenum quadrants situated near the reactor vessel flange (see Figure 10). The jack's hydraulic cylinder, attached to a custom main frame, pushed down on the core support shield flange and lifted under the upper plenum ribs. To engage the plenum, a lifting lug support leg extended into the annulus between the plenum cylinder and the core support shield.

In the first phase of jacking, December 6, 1984, the upper plenum was raised $6.35 \mathrm{~cm}$. Much of the debris that was still attached to the plenum before jacking fell to the rubble bed upon this initial lift, and workers removed some of the debris that did not fall. GPU Nuclear determined at that time that the plenum could be lifted to the full $18.4 \mathrm{~cm}$, rather than to another interim level between, as originally planned, because the first jacking phase was executed smoothly.

Therefore, the lift continued on December 11 , and the plenum was jacked to $18.4 \mathrm{~cm}$, as four workers operated the hand pumps from a central pumping station in the Reactor Building (see Figure 11). The plenum will remain at this level until its removal in May 1985. Most of the debris that was not removed from the plenum at its $6.35-\mathrm{cm}$ jacked level separated under its own weight during the second lifting operation. Any debris still clinging to the plenum's underside was easily separated using a long-handled tool.

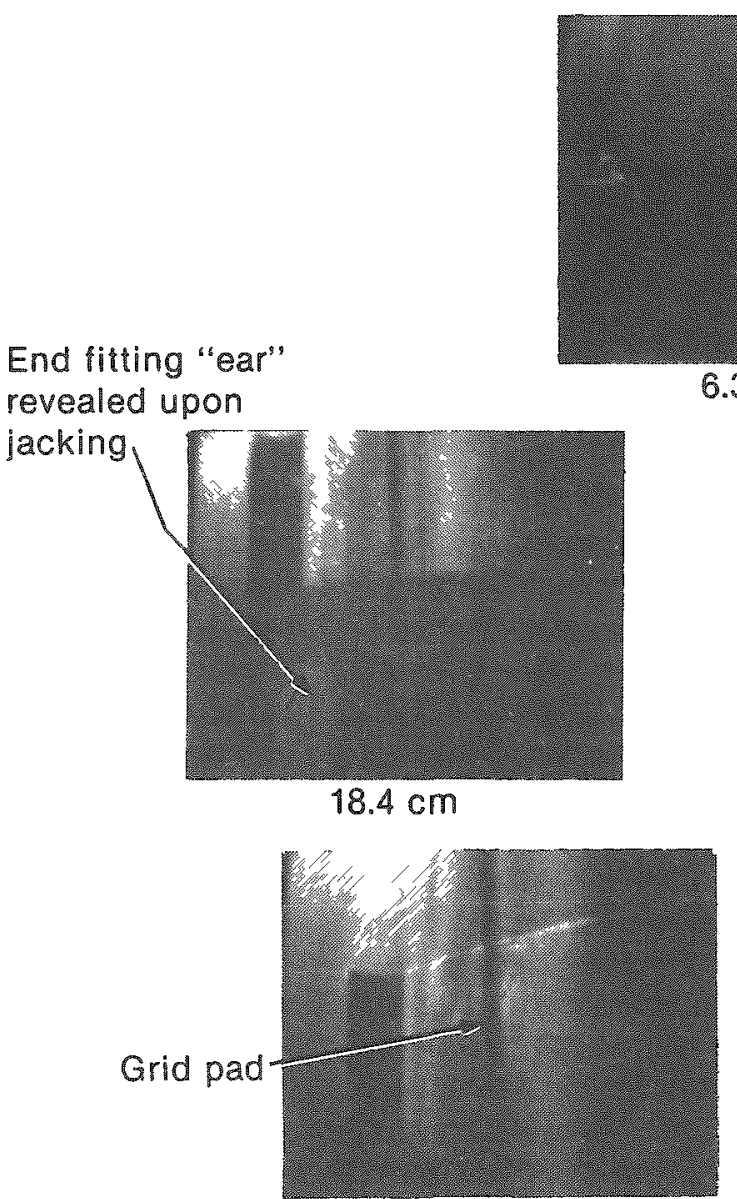

$15.25 \mathrm{~cm}$
$6.35 \mathrm{~cm}$

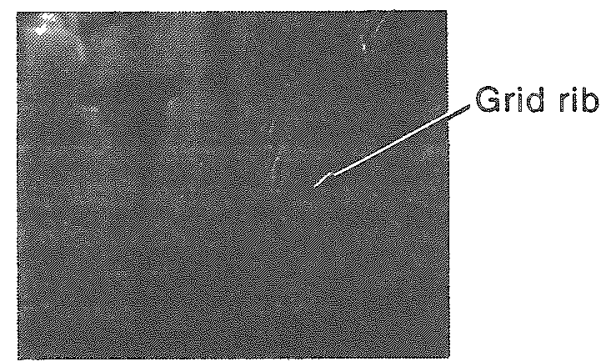

$10.16 \mathrm{~cm}$

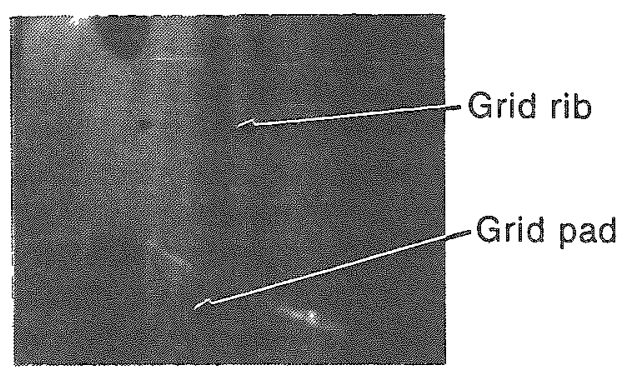

$12.7 \mathrm{~cm}$

Figure 11. Clockwise from top center, these enhanced photographs show the plenum at five jacking stages. The photographs, magnified two to three times the actual size, were taken from a small area inside the plenum using an $11-\mathrm{mm}$ lens. (See Figure 10 for the location of the photographs.) 
The plenum inspection, debris separation, and jacking did not significantly increase radiation levels in the Reactor Building. And based on the minimal vertical lifting forces experienced during plenum jacking and final inspection results, there appears to be no notable impediment to plenum assembly removal in May 1985 using the polar crane.

According to present plans, the polar crane, a handling tripod, and three new lifting pendants, whose fabrication began in 1984 , will be used to lift the plenum assembly from the reactor vessel and transport it to a storage stand in the flooded deep end of the refueling canal. Two of the lifting pendants will be equipped with load positioner controls to keep the plenum aligned and level. After the plenum is placed on its stand, it will be wrapped in a specially designed soft container that will already have been spread on the storage stand. This container and the water in the canal will serve as contamination barriers and shielding against radiation emitting from the plenum assembly. A soft cover will also be placed over the IIF after plenum removal to temporarily cover the open reactor vessel until a rotating work platform, being fabricated specially for defueling operations, can be installed.

\section{Fuel and Core Debris Removal}

During the year, the reference design for Westinghouse Electric Corporation's fuel and core debris removal system underwent significant scrutiny by GPU Nuclear; the EG\&G Idaho, Inc., Technical Integration Office (TIO); and GPU Nuclear advisory groups. Westinghouse Electric Corporation is GPU Nuclear's subcontractor for the development of tools to defuel the damaged Unit 2 reactor. As a result of these conceptual reviews, the defueling scheme was reshaped to conform to GPU Nuclear's desire to rely as little as possible on untried tools and techniques. The emphasis of the system shifted from Westinghouse Electric Corporation's originally proposed highly automated, remotely controlled fuel removal system to one that relies primarily on manually operated, long-handled tools. The automated approach called for the use of a clamshell-like tool that would excavate the core and place debris into a shredder located in the reactor vessel. The tool was to have been supported by an in-vessel robotic arm. But when the plan was revised to stress manual removal, the "clamshell" and shredder concepts were discontinued, although certain automated features were preserved. In all, the technical approach to defueling the reactor is being designed such that failure of automated equipment will not seriously disrupt fuel removal operations.

Worker and public safety and the importance of maintaining radiation exposure rates that are as low as reasonably achievable (ALARA) were never subordinated in GPU Nuclear's evaluations of alternate fuel removal methods. Instrumental in selecting the present defueling system were the specially formed Fuel Removal Working Team and the Fuel Removal Feasibility Review Group. The Working Team evaluated system and operational costs and worker exposure. The Feasibility Review Group, whose members are representatives of the various organizations involved in the recovery program, reviewed the Working Team's assumptions, evaluated the candidate defueling systems, and addressed technical issues that influenced the final selection of a defueling system concept. The findings and recommendations of this group underwent rigorous reviews that finally led GPU Nuclear to a defueling concept called the Expedited Fuel Removal Program.

Fuel and core debris removal operations will be carried out in three phases: initial early fuel removal, early fuel vacuuming, and bulk fuel removal.

Phase I, initial early fuel removal, is scheduled to begin in July 1985. During this phase, workers standing on a specially designed, rotating, shielded work platform will lower long-handled tools through a 46-cm-wide slot to pick out and place in a canister debris small enough to be loaded without being cut (see Figure 12). The canister will be suspended in the reactor vessel in a single canister bracket. Debris and end fittings too large to be loaded into the canister will be placed in baskets and moved out of the way of removal operations. Later, these larger pieces will be cut and loaded into other canisters. Also during this phase, large debris fragments, such as fuel assemblies, will be placed in another area of the debris bed to make way for vacuuming. Once loaded, the fuel canisters will be transferred to storage racks in the dammed and flooded deep end of the refueling canal.

In Phase II, early fuel vacuuming, workers will vacuum and pick out as much of the smaller loose core debris as practical. The canisters to receive this debris will be positioned in a carousel that can hold 


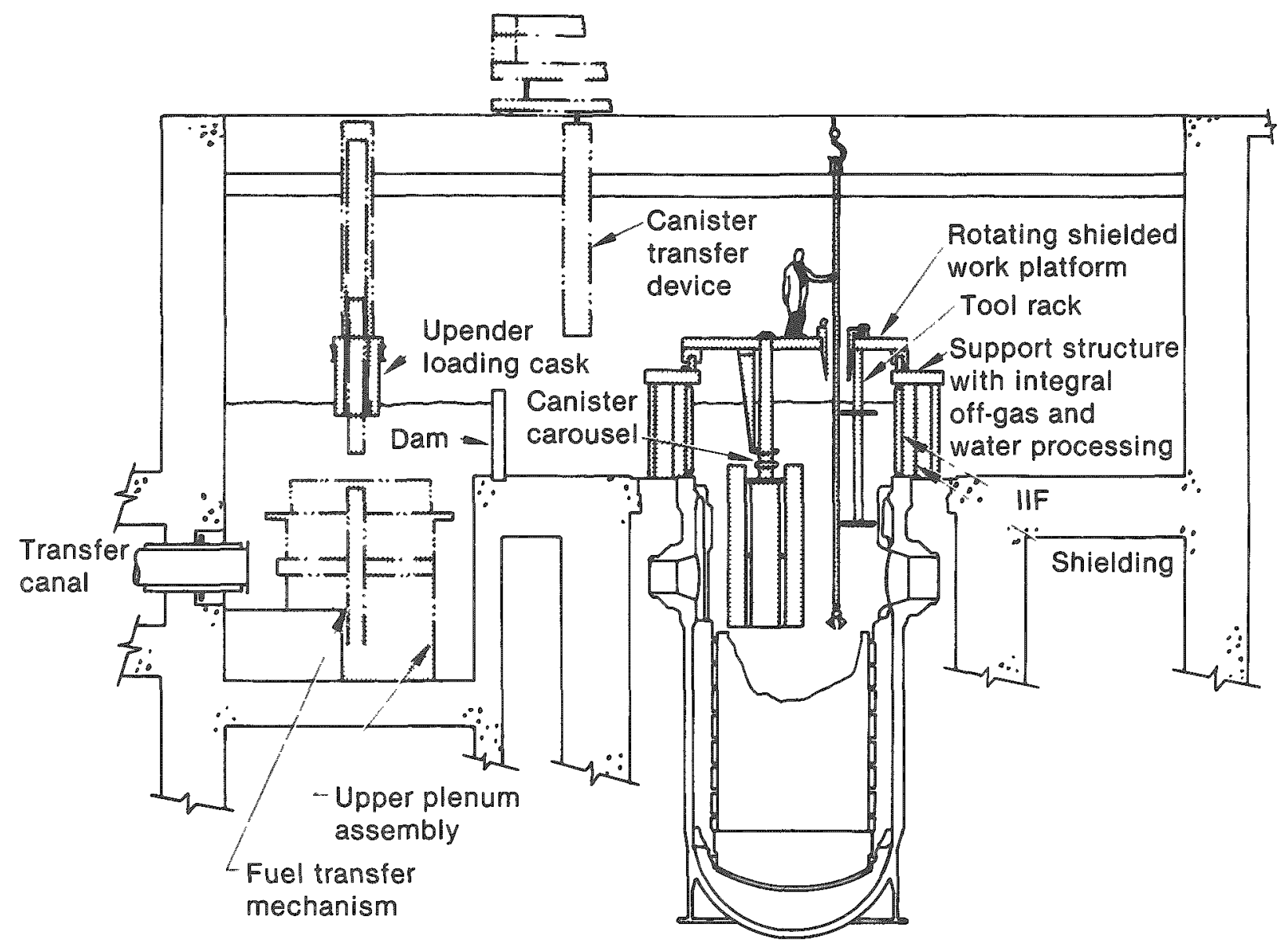

rigure 12. This shematic illustrates the early defueling system. Early defueling is scheduled to begin in July 1985.

as many as five loaded canisters in-vessel. The carousel permits one canister at a time to rotate into the loading position. (If the single canister bracket can still be of use, it will not be removed.) In the vacuuming operation, the debris and fine particles, all in the reactor coolant system water, will be drawn through a nozzle that will be manually operated with a long-handled tool supported from the handrail of the work plat form. The debris will flow into the knockour canisters that will retain particles ranging in size from about $130 \mu \mathrm{m}$ to the size of whole fuel pellets. The knockout canister will remove the medium-sized debris from the water by reducing the flow velocities, thereby allowing the particles to settle. The fine debris that is not retained in the knockout canisters will be drawn through a pump and discharged through filter canisters that will retain particles as small as $0.5 \mu \mathrm{m}$. The processed reactor coolant water will then be channeled back into the reactor vessel. In other Phase II work, personnel will load fuel canisters with debris that does not need cutting and continue to move large debris fragments around the debris bed, load the debris basket with oversized debris and end fittings, and scoop into fuel canisters the small loose debris that cannot be vacuumed. As in Phase I, the loaded defueling canisters will be placed in the deep end of the refueling canal for transfer to the pool in the Fuel Handling Building.

In Phase III, bulh fuel removal, workers will cut up and section the debris that is larger than the canister opening. Equipment used in the earlier phases will be augmented by Westinghouse Electric Corporation's Remotely Operated Service Arm (ROSA)-a robotic device-and several heavyduty, long-handled tools. A manual tool positioning system will employ many of the bulk defueling end effectors (power tools) to section debris that is $21.61038 .1 \mathrm{~cm}$ in diameter, while other tools will be capable of sectioning large debris (greater than $38.1 \mathrm{~cm}$ in diameter). Also during this phase. workers will section the debris that is fused to the rubble bed, remove partial length fuel assemblies 
from the lower core, vacuum the lower reactor vessel through the core support assembly grid plates, and install plugs into the lower grid plate.

All of this work will be carried out with much of the refueling canal dry. As mentioned before, the deep end of the refueling canal will be llooded to provide shielding for the plenum and the loaded canisters before the latter are sent through the fuel transfer canal to storage racks in spent fuel pool A. To the extent possible, defueling activities will be confined to the reactor vessel, shielded with reactor coolant system water that rises into the IIF that sits atop the vessel and under the shielded work platform. For additional shielding, the loaded canister will be lifted from the reactor vessel into a protective transfer bell, carried to the deep end of the refueling canal, and lowered into the water.

Among the major systems in design stages in 1984 was the defueling water cleanup system (DWCS), which will filter and process reactor coolant system water to control contamination and clarify the water for improved visibility. A dewatering system, also in the design stage, will dewater the loaded canisters before they are shipped. A modified fuel transfer system will be used to transfer the canisters from the refueling canal in the Reactor Building to the spent fuel pool in the Fuel Handling Building, where they will be placed in the storage racks or taken to the dewatering station.

Design work for the defueling tools was also well under way at the close of 1984 , and several of the tools and end effectors, including a hydrolaser, hydraulic saw, fuel rod shear, jack hammer, and hydraulic impact chisel, underwent proof-ofprinciple tests. Also, planners decided which tools would be part of training exercises on the test assembly mockup, and they completed the TMI-2 Fuel Removal ALARA Program Plan.

These tool designs are being developed such that they can be taken into the Reactor Building without removing the equipment hatch. However, GPU Nuclear investigated the possibility of removing the hatch long enough to transport complete assemblies into the Reactor Building. Special efforts are provided to ensure the lowest practicable ambient radiation fields at work stations, both by reducing streaming from the water in the vessel and by reducing direct or backscattered radiation from the canal and building walls.
Among the major equipment and structures for early defueling, the vacuum system, the work platform and its support structure, and the camera monitoring system were released for fabrication. Also by the close of the year, final designs neared completion for the single canister bracket, carousel, cable management system, long-handled tools, and tool racks. Meanwhile, preliminary designs were completed for the major bulk defueling components, including ROSA, and the tool positioner.

Of the major documents produced with this predefueling work, GPU Nuclear published the TMI-2 Defueling Design Document and the TMI-2 Reactor Defueling Interface Control Document. The Defueling Design Document describes the defueling scope and approach that are to be implemented and defines the functional and performance requirements for the tool designs and plant modifications required to remove the damaged core. The Reactor Defueling Interface Control Document defines the major design interfaces among the various participating engineering and vendor organizations.

Important to the defueling operation is the placement and clearance of defueling equipment inside the reactor vessel. GPU Nuclear is coordinating the designs for mounting the tools and equipment to the work platform to prevent obstruction and entanglement when the platform is rotated.

Defueling Debris Canisters. GPU Nuclear, canister subcontractor Babcock \& Wilcox (B\&W), the EG\&G Idaho TIO, and the INEL worked together to develop the canisters receiving the TMI-2 core debris. The INEL will be prepared to store the loaded canisters for up to 30 years.

Three types of defueling canisters-filter, knockout, and fuel-are being fabricated. The canisters will encapsulate core debris as small as fines and as large as partial fuel assemblies. In addition to serving as containers, the filter and knockout canisters will function as filtering devices-the former for both the DWCS and the fines and debris vacuum system. The fuel canister will serve as a receptacle for larger pieces of core debris that can be picked up and placed inside the container. Important to the application of these canisters is an acceptable design that is critically safe and ensures structural integrity, especially during shipment and long-term storage. A drop test was initiated to demonstrate the extent of structural deformation and its effects on criticality safety. 
After examining alternate debris canister design criteria based on the latest core examination data, GPU Nuclear decided on a 14-in. nominal outside diameter for the stainless steel pipe with a 0.25 -in.thick wall. The canister length was set at $150 \mathrm{in}$. Each fuel canister will be equipped with a square boral insert for criticality control, and the filter and knockout canisters will employ $\mathrm{B}_{4} \mathrm{C}$-filled tubes. GPU Nuclear selected these dimensions so it could have maximum flexibility in selecting a defueling system and shipping cask. The larger canister diameter will permit storage of the full cross-section of such core components as fuel assembly end fittings. Once the nominal outside dimensions were established, design and criticality analyses of the following components and systems proceeded: canister racks, the fuel transfer system, shipping casks, the defueling system, canister handling tools, the DWCS, and interfacing systems for canister receipt and storage at the INEL.

Designs and fabrication also began for tools to handle the canisters. These tools include canister grapples, inlet and outlet connection tools, dewatering hose connection tools, and a closure head bolt torque tool.

\section{Core Transportation}

In 1984, EG\&G Idaho selecied a rail cask design for transporting the debris-loaded canisters from TMI to the INEL (see Figure 13). Cask designer Nuclear Packaging, Inc. (NuPac), of Federal Way, WA, will provide two casks for the shipments.

The cask length is $21.25 \mathrm{ft}$, and its outside diameter is $5.5 \mathrm{ft}$. In accordance with federal regulation 10 CFR 71.63 , the cask has two levels of containment-the outer body and an inner vessel, both of which have "leak-tight" leak-rate seals and test ports in their lids. The cask can be used to transport the canisters without precise isotopic information that would be needed to calculate allowable release rates for higher-leak-rate seals.

The inner containment vessel has seven 14.5 -in.diameter cavities to hold seven debris-loaded canisters. The cask loading system at TMI will always shield operations personnel from the canisters and thus protect them from direct radiation exposure.

The method for loading the canisters into the cask is as follows: The canisters, loaded with core debris, will await shipment in spent fuel pool A. Preparing the cask to receive the canisters, workers operating a crane will remove the impact absorbers on the ends of the cask and stand the cask upright. (During the entire loading operation, the cask will remain on the rail car on which it was brought into the truck bay. Figure 14 is an illustration of the cask on the rail car.) A protective transfer bell carrying a canister from the spent fuel pool will come to rest on top of the cask. The trap door in the base of the transfer bell will meet a floor valve that sits over an opening in the cask. The transfer bell's trap door and the valve together will open, allowing the canister to be lowered into one of the cask's seven cavities. The transfer bell is then sent to bring the next canister for loading, while workers insert a shield plug in the space above the just-loaded canister.

So that the cask can be filled without exposing any of the already loaded canisters, NuPac designed a temporary loading head in the top of the cask that has an outer and center port, each of which can be plugged when not in use (see Figure 15). The loading head rotates so that the outer port can be positioned over the six outer cavities, one at a time. The center port is unplugged when workers are ready to lower a canister into the center cavity. Once fully loaded, the cask will be rotated from a standing to a horizontal position on the rail car.

Each NuPac cask will be loaded in four days, after which the two casks will be gone for 40 to 58 days. While the casks are away, the truck bay will be free for other operations. Shipping 238 canisters, seven canisters per cask, two casks per train, will take 23 to 33 months. The canisters will be taken to the INEL for research and for temporary storage in a water pit at the Test Area North facility.

The rail cask was not the only means considered for transporting the core debris. Early in the year, proposals for legal weight truck casks also were being reviewed. But a rail cask will provide greater flexibility and cost savings during fuel canister 


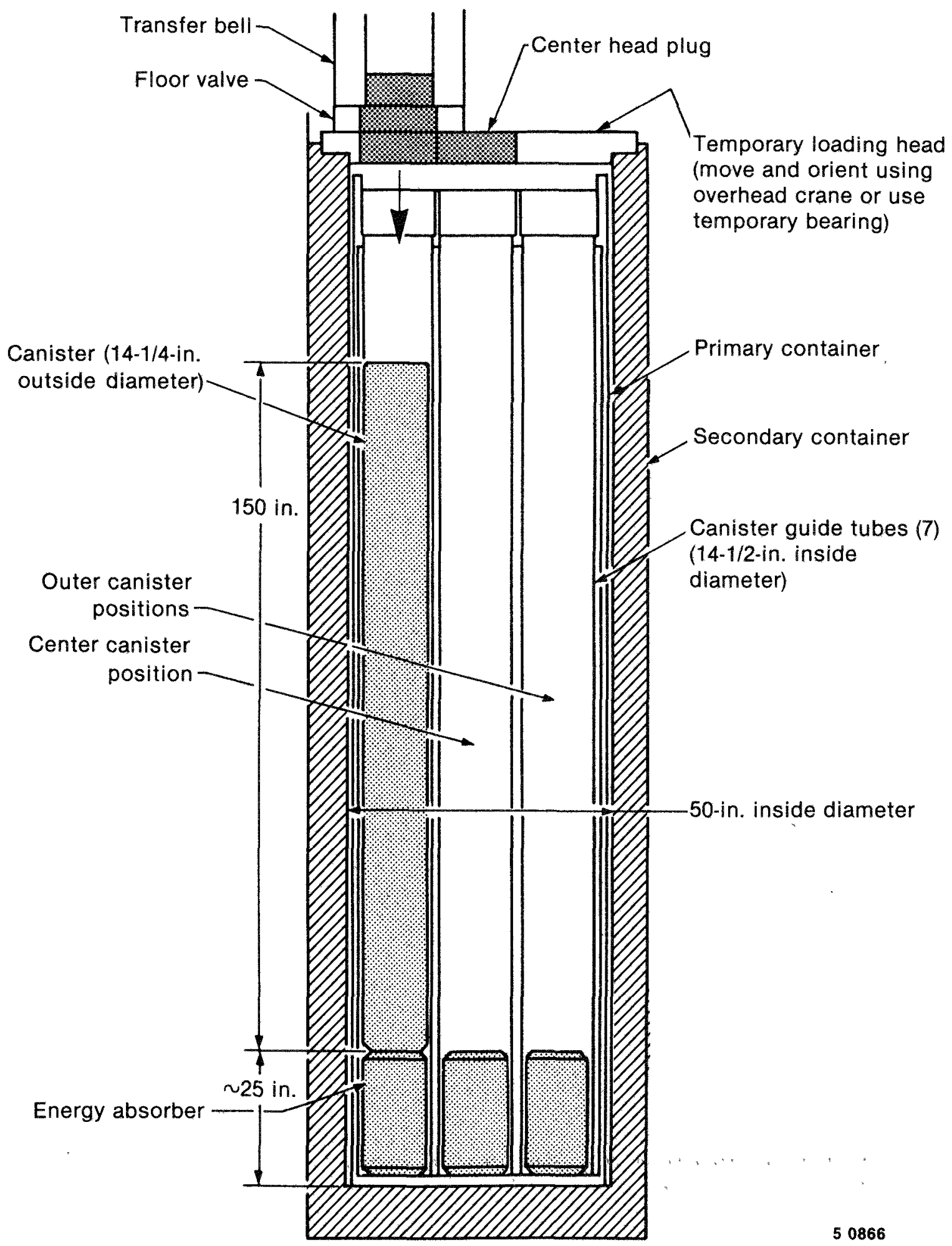

Figure 13. The selected shipping cask, designed to contain seven loaded canisters, will provide two levels of containment. 


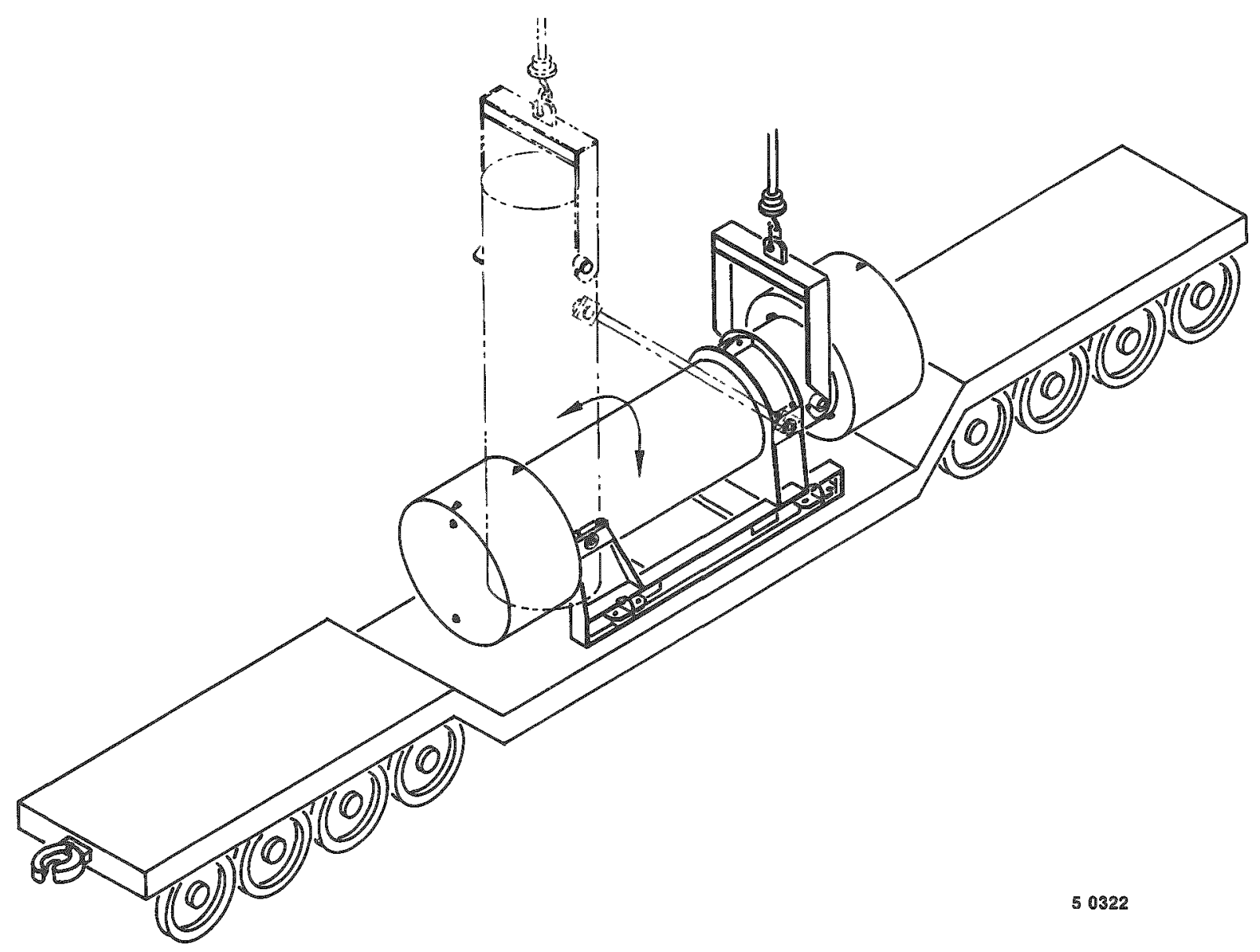

Figure 14. For loading, the NuPac shipping cask will remain on the rail car on which it will be brought into the truck bay.

handling and cask loading. Also, fewer crosscountry shipments are required by rail than by truck.

The study groups that evaluated the proposed cask designs took into account such factors as dry loading (the cask will not be submerged in water when loaded), the need for double containment of plutonium in accordance with federal regulations, facility modifications that may be necessary to accommodate the loading system, and criticality control.

Complementing the analytical approaches to demonstrating the safety of the NuPac cask, a onequarter-scale model of the cask will undergo a drop test in 1985 to verify the cask's structural performance during impact events. 


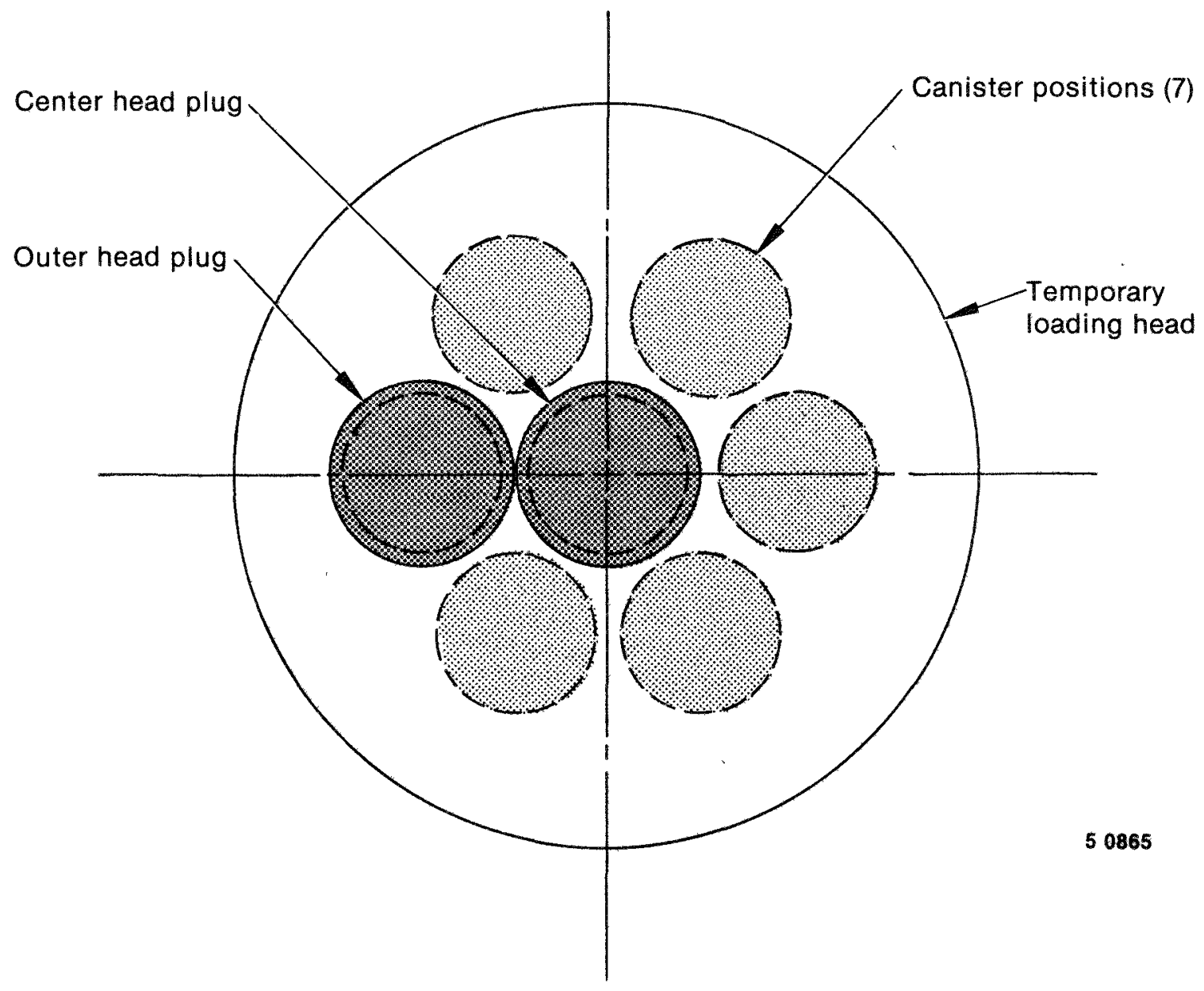

Figure 15. The temporary loading head has an outer head plug port for loading canisters into the cask's six outer cavities and a center head plug port to load the seventh canister into the center cavity. 


\section{DATA ACQUISITION PROGRAM}

The Data Acquisition Program (DAP) continued its efforts to characterize the condition of the Unit 2 Reactor Building, its systems and components, and its damaged core. The two major DAP programs through which this work is carried out are the Instrumentation and Electrical Program (I\&E) and the Core Sample Acquisition and Examination Project.

\section{Instrumentation and Electrical Program}

The I\&E staff completed a major phase of work, testing about one-third of the building's circuits to find which circuits are operable, which ones are not, and which ones exhibited anomalies. Also subject to analyses were a resistance temperature detector (RTD), in-core instruments, the power-operated relief valve (PORV) that malfunctioned and remained open during the accident, and the polar crane pendant.

Cables and Connections. The TMI-2 Cable and Connection Program was established to investigate the consequences of the IOCA on cable and connector components in the Reactor Building. The capability to receive readout signals from, and supply energizing voltages to, Class $1 \mathrm{E}$ instruments is essential to reactor control during periods of environmental stress. Therefore, it is important to characterize the functional properties of cable channels during accident and postaccident conditions.

The cable channels were characterized through a series of static in silu cable tests designed to determine the effects of the accident on the operation of all cable channels. Cables and connections are defined as all components in a given electrical channel or circuit from the Reactor Building electrical penetration assembly up to but excluding the end instrument. This definition encompasses penetration assemblies, terminal blocks, splices, bulk cable, and connections. The data gathered will help to formulate guidelines regarding the responses of cables and connections to a LOCA event. Such guidelines will help government regulators and the nuclear industry improve the reliability of these components, as well as reevaluate stringent qualification testing procedures and regulatory requirements in light of a LOCA event.
To accomplish the investigation, the program was divided into two distinct phases. Phase $\mathbf{I}$, in situ testing of the cables from the outer electrical penetration junction box, is complete. Based on the data obtained, cables and channels exhibiting anomalous behavior were identified. Phase II will be the removal of these selected cables from the Reactor Building for a thorough off-site examination.

Phase I in situ testing consisted of diagnostic measurements of the circuits' capacitance, inductance, insulation resistance, and loop resistance properties. Additionally, a time-domain reflectometry (TDR) technique was used to identify circuit anomalies and their locations. Of the 1800 total circuits in the Reactor Building, 567 were tested. And of the 567 tested, 232 or $41 \%$ exhibited anomalous behaviors and 153 or $27 \%$ were classified as inoperable.

Hanford Engineering Development Laboratory (HEDL) and the INEL compiled a list of cables exhibiting anomalies and sent it to the TIO at TMI for review. I\&E program personnel then made an entry into the Unit 2 Reactor Building to assess the feasibility of removing samples, taking into consideration safety, radiological factors, and cost. Eighteen cables were pinpointed in specific areas of the 305-and 347-ft elevations, where samples could easily be removed. Sample packages for each of these cables were written and submitted to GPU Nuclear for review.

At the end of the year, HEDL began preparing its laboratories for receiving and evaluating the samples. The test procedures are being reviewed by key personnel in the nuclear industry, including those employed by Anaconda, Kerite, Okanite, Combustion Engineering, and General Electric. This technical review will result in a complete spectrum of electrical and mechanical properties for a common cable testing method that satisfies both industrial and scientific requirements.

Also during Phase I, penetration R607 was retested as a representative to verify the quality of in situ electrical tests taken in 1983. The results of this work verified techniques for detecting cables located in a hostile environment. An overlay plot 
of the TDR measurements of the same circuit indicates the drying out of a previously wet cable. This can be seen by comparing the different impedances of the two traces taken only seven months apart (see Figure 16).

Through I\&E's Cable and Connection Program, techniques have been developed and proven effective for identifying cables, assuring the original integrity of a circuit, and providing methods for indepth troubleshooting. In an effort to share with the industry the unique measurement techniques used at TMI and information regarding the hardware and software of the portable data acquisition system, TIO personnel have been planning a workshop with representatives of EPRI and the Maintenance Equipment Acquisition Center, a research subdivision of EPRI. This workshop will allow the industry to make use of the new techniques for regular plant surveillance.
Instruments. A number of Reactor Building instruments underwent in situ or laboratory tests to determine their condition and the effects of the accident upon them.

Resistence Temperature Detectors. The data recorded by the Reactor Building RTDs during and after the accident provide temperature profiles that are key to understanding the accident and subsequent plant conditions. A dual-element RTD (RC-TE-3\&4) was removed for testing from the reactor coolant system inlet to steam generator $\mathrm{A}$. The INEL performed the basic examination, while ORNI. conducted a response time test.

An examination of the thermowell revealed hard deposits similar to those found on the lower portion of the lead screws. Various methods for removing the hardened deposits were subsequently tested. At the ORNL, the RTD was plunge tested at

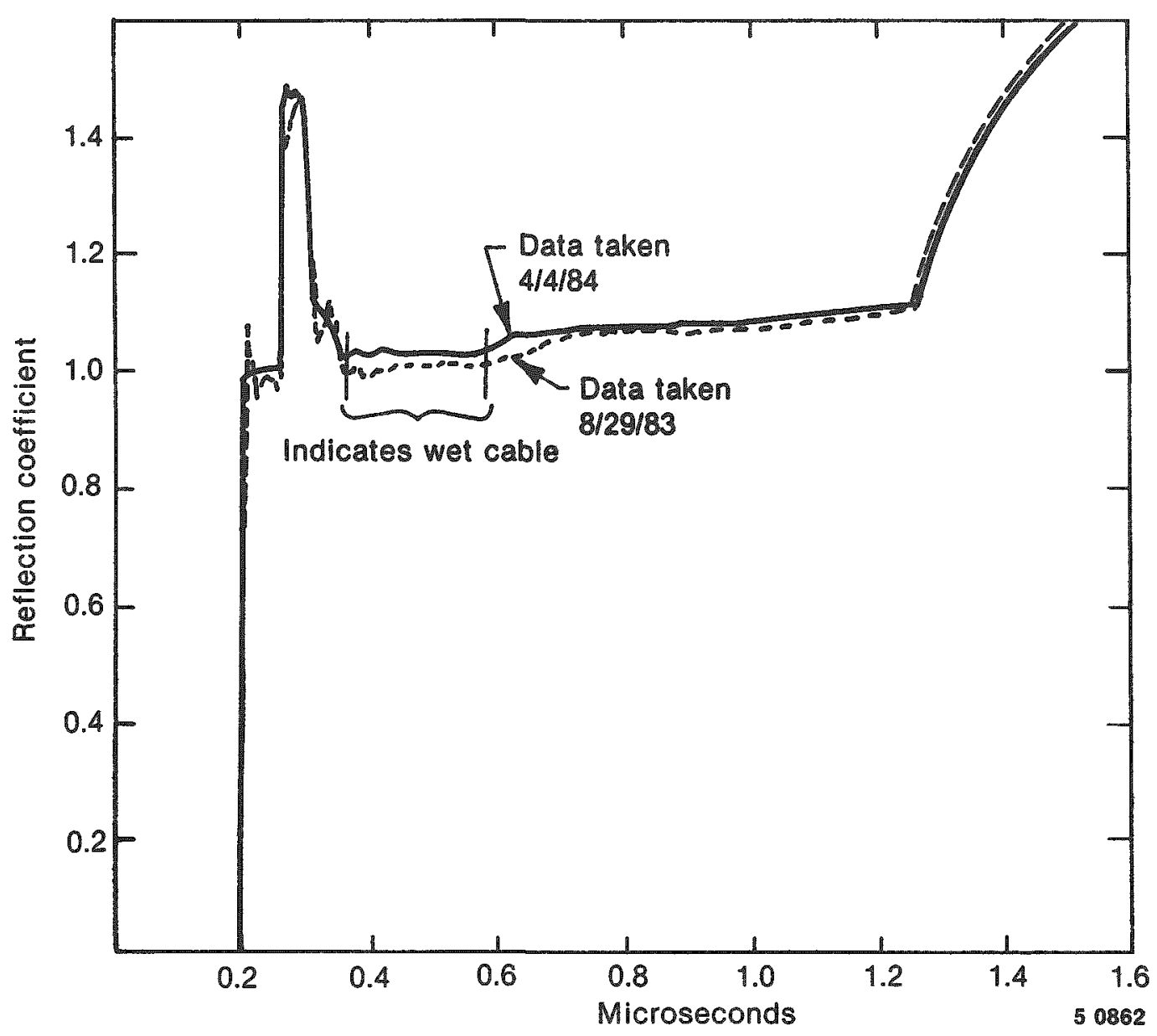

Figure 16. The different TDR measurements for the same circuit indicate the cable was wet and then dried. 
$0.9 \mathrm{~m} / \mathrm{s}$ and $322 \mathrm{~K}$. The response time was better than technical specification requirements. The RTD had low insulation resistance before its removal from TMI-2 but not after removal, indicating a bad cable. Inspection of removal pictures shows the conduit that goes into the RTD has a separation that could be the cause of cable damage.

In-Core Instrumentation. The in-core instruments are an integral part of the TMI- 2 core. The damage they sustained may strongly correlate with core damage. Consequently, tests of the in-core instruments were intensified to determine the extent of damage in the core. Preliminary results indicate extensive damage especially in the lower central regions of the core. In addition, the in-core instrumentation guide tubes are hypothesized to be pinched in the center region and free along the perimeter. The guide tubes enter the reactor vessel from the bottom region. To prove the hypothesis, workers will make an entry for the mechanical probing and gamma mapping of the in-core instrumentation guide tubes.

The I\&E staff continued its attempts to explain the unusually high readings recorded by the selfpowered neutron dosimeter (SPND) backup recorders. Approximately $3 \mathrm{~h}$ into the accident, very large positive signals were recorded, even though the control rods were fully inserted into the core. In an effort to understand this phenomenon, the backup recorder was removed from the control room and sent to the INEL for further evaluation. The circuit was also carefully examined, and accident conditions were simulated on a test SPND assembly in a controlled environment. Testing is continuing at the INEL. Similar assemblies have generated large positive signals when exposed to high-temperature steam.

Electrical Components. Personnel in 1984 continued to test Class $1 \mathrm{E}$ electrical components to determine the components' operational status and if they experienced any accident-related damages. One of the key items tested was the PORV, which during the accident, mechanically malfunctioned and remained open. In situ testing of the device revealed that both of the valve solenoid coils are functioning normally.

Examination of in situ test data for the pressurizer heaters has added possible new information confirming earlier theories that these heaters were uncovered during the accident. The heaters started tripping about $4 \mathrm{~h}, 39 \mathrm{~min}$. after the initial turbine trip. The test data collected before and after the accident indicate that the tripping problem was caused by a ground fault on the heater power circuit. Initial examinations of the in situ test data indicate that the most probable location of the ground fault is in the heater itself, inside the pressurizer. The ground fault may have been caused by overheating of the heater element when the water was removed and by subsequent mineral oxide insulation breakdown. This breakdown generally can be reversed if the temperature does not exceed structural failure. A plan is being developed to look further into this failure.

During a 1984 entry, workers removed a solenoid valve from the Reactor Building because it had an air leak. Overall, the solenoid valve assembly and the limit switches survived the accident without harm to their functions; they experienced only minimal degradation. The presence of rust flakes in the solenoid valve that was removed suggests that the instrument air piping is not sufficiently clean.

Polar Crane Pendant and Cable. In 1984, both the polar crane pendant and its cable were removed for laboratory evaluation. The pendant's cable was still intact after the accident. It was unwound near the center of the Reactor Building, from the bridge of the polar crane to the floor- $15.24 \mathrm{~m}$-with the excess coiled on the floor. Pieces of the cable were removed and cut into $76-\mathrm{cm}$ sections. The measured radiation levels that emitted from the cable are shown in Figure 17. The cable sections assigned low numbers commonly had relatively high radiation levels; these cable sections lay on the floor of the building, exposed to settling contamination. (The lower the section number, the closer the section was to the floor.)

By visually examining the cable sections, technicians were able to map the effect of the hydrogen burn on the cable sheath. The sections of higher elevation showed greater damage. Individual conductor insulation appeared unaffected.

Results of a tensile test of the conductor insulation (subjecting it to increasing longitudinal pulling stress until it fractures) are presented in Figure 18. Elongation results were essentially alike over the length of the cable. The trend of decreasing tensile strength with increasing section number does not follow the radiation pattern; the reduction in tensile strength is more likely due to heat from 


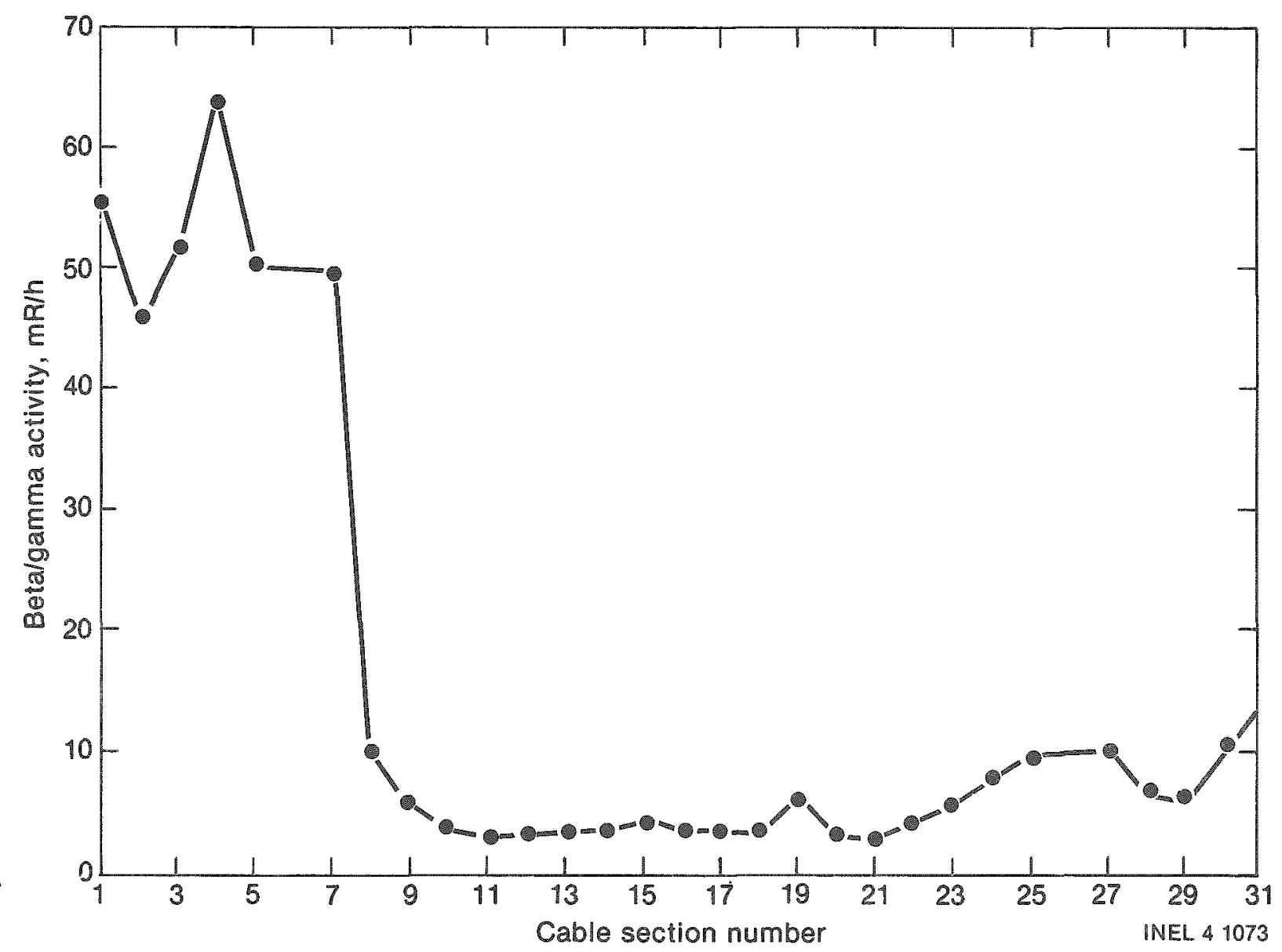

Figure 17. The polar crane pendant cable was cut into $76-\mathrm{cm}$ sections, whose radiation levels were then measured. The lower the cable section number, the closer the section was to the noor.

the hydrogen burn. The cable sections exhibited similar electrical properties, regardless of their vertical location in the building.

\section{Core Sample Acquisition and Examination Project}

The Core Sample Acquisition and Examination Project encompasses acquisition of samples and data at TMI and examination of these samples and data at the INEL. Acquisition is addressed in the following subsections, and examination is detailed under Core Activities Program, the last section of this report.

Core Stratification Sample Acquisition and Lower Head Inspection. In 1984, the scope of the core stratification sample acquisition task was sufficiently identified to proceed with preliminary documentation of project requirements. Also, ini- tial contacts with commercial vendors were made to determine the availability of appropriate core drilling hardware.

The primary purpose of this acquisition work is to obtain a preserved stratified sample of the solid core material beneath the rubble bed. The core sample would include standing fuel rod stubs, onceliquefied core material above and among the fuel stubs, and the lower stainless steel fuel end fiting. Four full-length, stratified samples of the core will be extracted from the core at predetermined locations, allowing personnel to establish the extent and distribution of core damage, maximum temperatures reached, material interactions, and fission product release and retention in core materials.

In conjunction with this project, personnel will visually examine the lower reactor vessel head area by inserting a remotely operated closed-circuit 


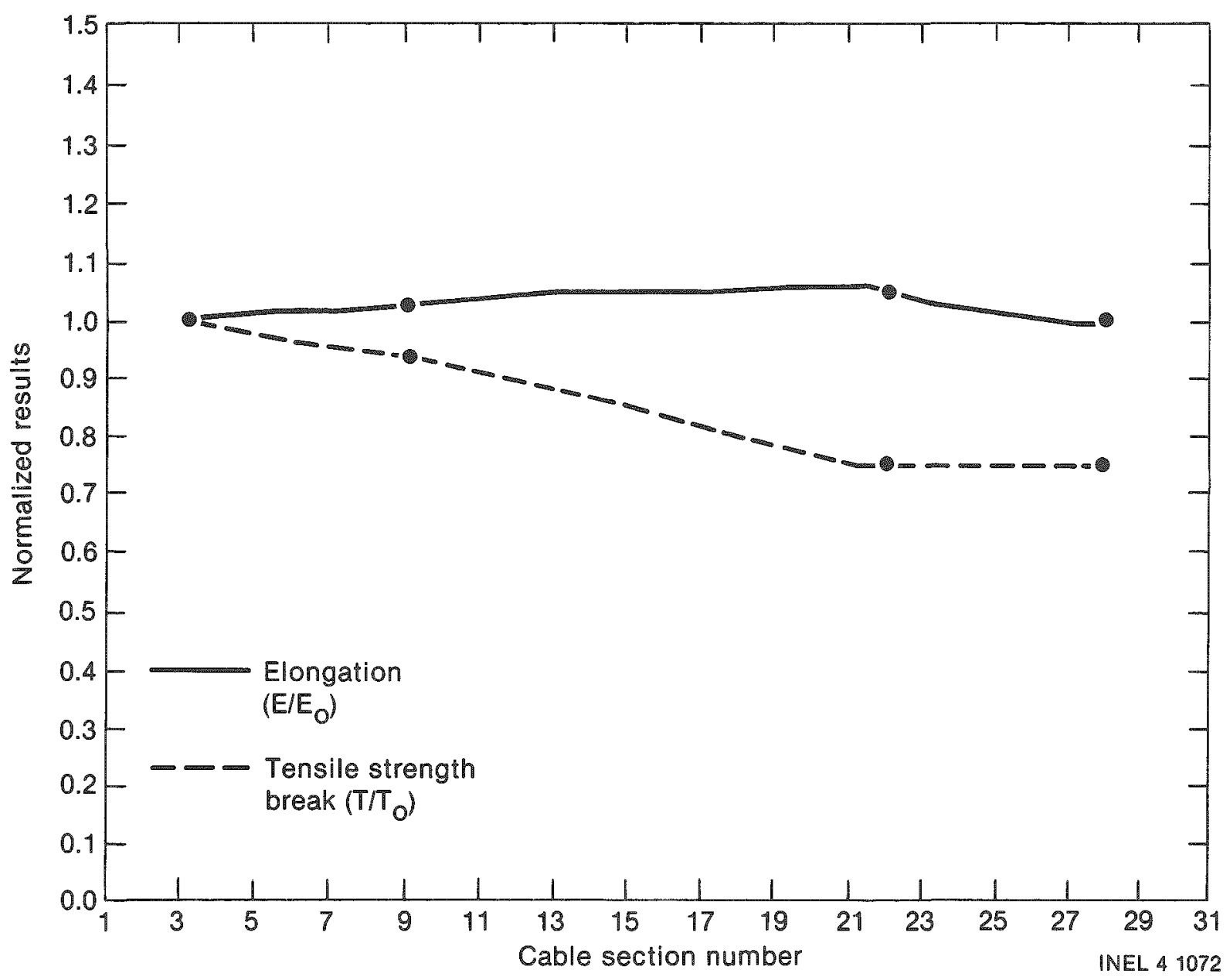

Figure 18. Tensile properties for the pendant cable are presented by cable section number.

television camera through two of the four core sample bore holes. The core samples will be placed in standard fuel canisters for shipment to the INEL for analysis.

Meanwhile, the INEL conducted proof-ofprinciple tests using commercially available core boring equipment to evaluate the ability of different drill bits to penetrate a simulated TMI-2 fuel stub assembly. The simulated assembly consisted of oxidized zircaloy, ductile zircaloy, stainless steel control rods, Inconel spacer grids, quartz rods for simulated fuel, and a stainless steel lower end fitting. One bit with tungsten carbide teeth faced with industrial diamonds was particularly successful, and thus was incorporated into the final design.

Figure 19 presents the proposed locations for core sample acquisition and lower vessel inspection. Eight candidate positions have been identified. Four of these positions allow alignment of the coolant flow holes in the lower vessel flow distributor grids, giving personnel a vertical passage through which a camera may be inserted to inspect the region under the core support flange. The other four positions are at noninspection locations.

Figure 20 is an illustration of the core boring mechanical equipment and support structures installed on the reactor vessel. The figure depicts drill piping completely inserted into the core before sample withdrawal.

Following careful coordination of technical input with GPU Nuclear and its subcontractors, INEL engineers designed the equipment and developed operational sequences for obtaining the core samples. Procurement will being in early 1985 as design drawings are released for fabrication.

Acquisition of Core Components. Planners in 1984 began formalizing tasks to retrieve fueled rod 


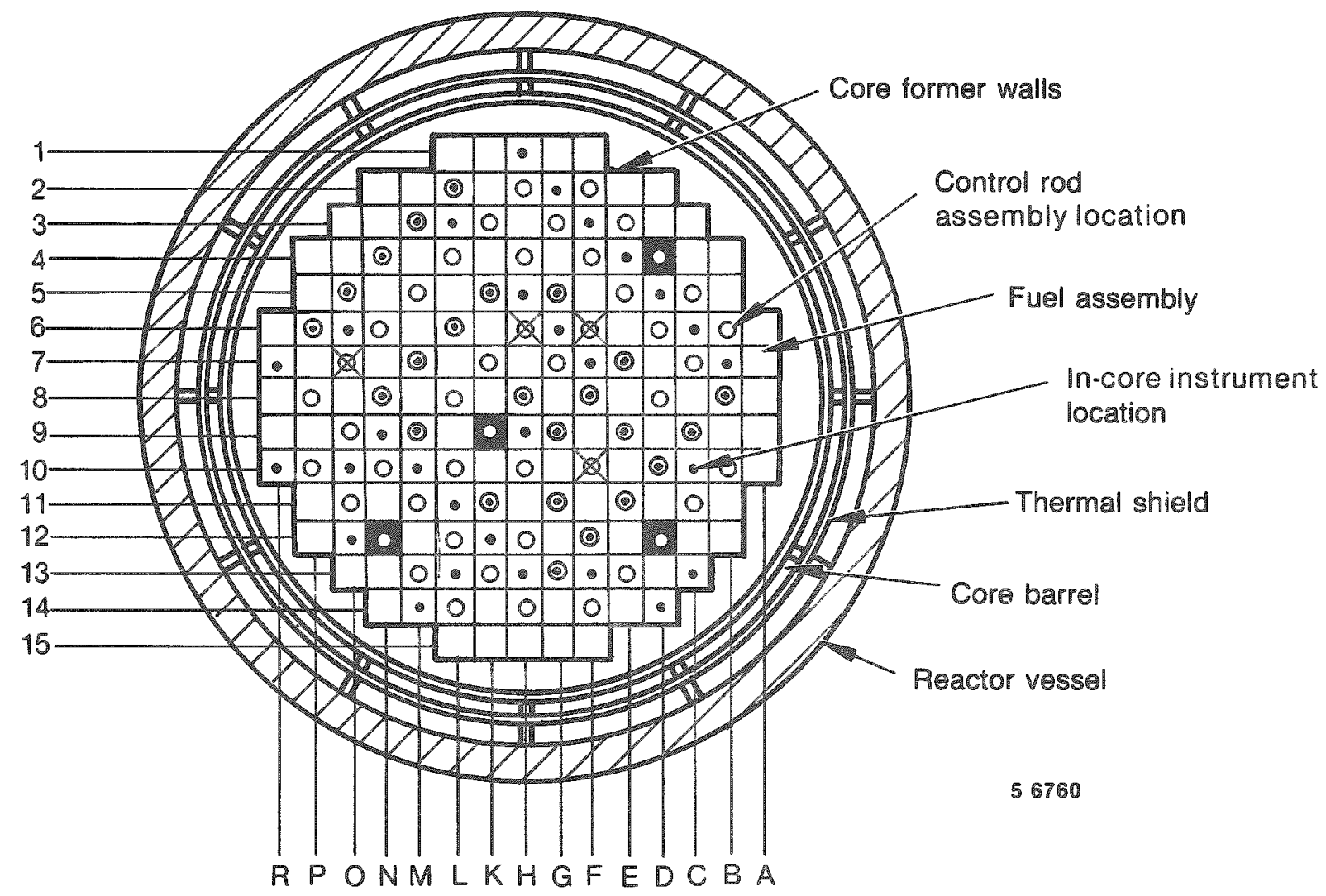

Figure 19. Samples will be acquired from four of these eight proposed core locations; two of the four positions to be selected will be subject to an inspection after samples are obtained.

segments, additional control rod lead screw segments, and selected specimens of in-core instruments and distinct fuel assembly components. As outlined in the sample packages for these tasks:

- Six short, intact, fteled rod segments will be acquired from the damaged reactor core. This acquisition, scheduled to accompany early defueling, will require the design and fabrication of a shielded holder in which the rod segments will be packaged and shipped to the INEL for analysis. A licensed shipping cask and compatible shipping canisters will be provided for transporting the rod segment samples off-site. At the INEL, analysts will characrerize the fueled rods that represent the boundary, or transition zone, between the melted and loose debris and the partially intact standing fuel assemblies at the core's periphery.

- Seven control rod drive lead screws will be acquired from the reactor vessel head. The task involves removing, cutting, packaging, and shipping short sections of each control rod. Off-site analysis of the control rods will aid in characterizing the role of the upper plenum region during the Unit 2 accident.

- Representarive components of fuel assemblies and in-core instruments will also be retrieved during defueling operations. Candidate specimens will be identified based on video surveys of the reactor before and during defueling operations. 


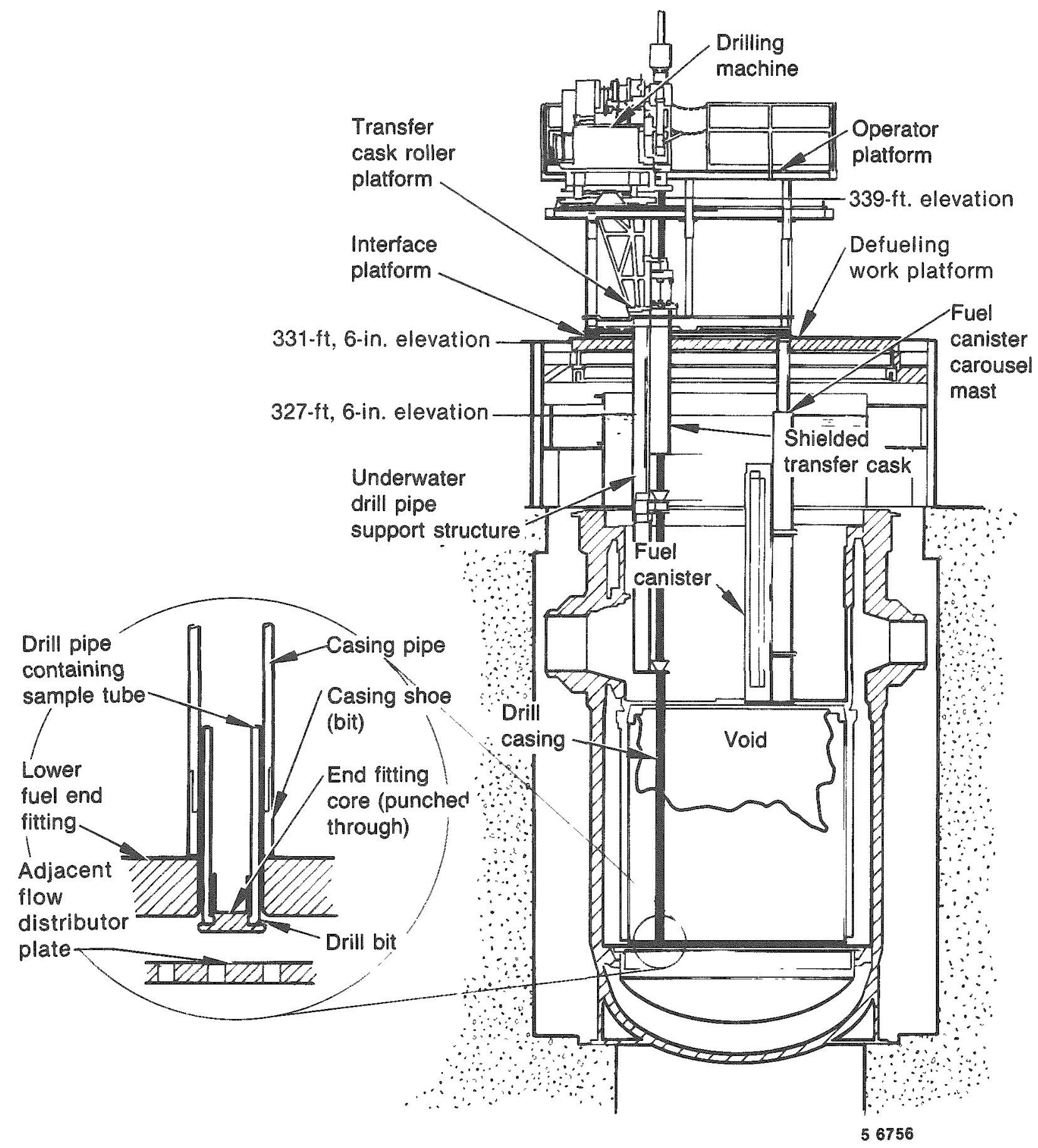

Figure 20. The core sample drill is illustrated here as completely inserted before sample withdrawal. 
The selected specimens will be placed in intermediate sample containers, identified, and subsequently placed in a fuel canister. The canisters will be stored and ultimately shipped to the INEL during a regular fuel shipment. The conceptual designs for the intermediate containers were initiated in 1984.

Primary Systems Scanning. Video and sonar analyses of the reactor core revealed a significant void. GPU Nuclear estimated that 8 to $16 \%$ of the core material may have left the reactor vessel and may be dispersed among the pressurizer, steam generators, connecting inlet and outlet pipes, decay heat system pipes, and core flood system pipes. GPU Nuclear implemented a radiological measurement project in an effort to locate and characterize the deposition sites for the ex-vessel fuel debris. This sampling project consisted of gross gamma directional surveys, thermoluminescent dosimeter mapping, and gamma spectroscopy measurements. Inaccessibility of certain components and general area radiation levels limited the types of measurement techniques technicians could use. The data they acquired will be useful to developers of plans for defueling the reactor coolant system and associated systems.

In support of GPU Nuclear's characterization efforts, EG\&G Idaho has been providing technical support and hardware to take in situ gamma spectral measurements of primary system components. Personnel are using two types of gamma spectrometer systems to take these measurements: the New York University-designed portable sodium iodide system and the EG\&G Idaho mobile gammaray spectrometer.

The university-designed sodium iodide system uses a relatively lightweight, portable, hand-held detector that can be easily assembled and used by one person. The detector is shielded by approximately $3.8 \mathrm{~cm}$ of tungsten, and a variety of collimator lengths and widths are available to optimize the counting geometry. The system can effectively distinguish the $2.186 \mathrm{MeV}$ gamma-ray emission from ${ }^{144} \mathrm{Ce} /{ }^{144} \mathrm{Pr}$, which is associated with fuel debris. Taking gamma spectral measurements of the A steam generator, the sodium iodide detector found no measurable amount of fuel debris on the generator's upper tube sheet. GPU Nuclear reported a minimum detection limit of 0.6 to $2.5 \mathrm{~kg}$ of total $\mathrm{UO}_{2}$ material, assuming uniform deposition on the upper tube sheet. Steam generator A will be further characterized in 1985 in a project that will include internal sampling of the upper tube sheet and acquisition of the handhole cover backing plate. The handhole cover backing plate will be sent to the INEL for surface deposition studies.

The EG\&G Idaho mobile gamma-ray spectrometer uses a high-resolution, hyper-pure germanium detector encased in $12.7 \mathrm{~cm}$ of cylindrical lead shielding. The system has been designed to operate remotely from a distance of up to $45.72 \mathrm{~m}$ after initial manual positioning. The system is on a rolling cart, and the shielded assembly can be remotely rotated and aimed from 0 to 180 degrees at a level perpendicular to the floor. A digital readout is provided at the control console to indicate the angle. The system has been outfitted with a remotely operated $1-\mathrm{mW}$ helium neon laser to aim the detector. The unit is also equipped with a portable video camera to monitor system alignment in remote situations. A sonar rangefinder is used on the unit to determine distances between the detector and the source.

The mobile gamma spectrometer was used at the INEL to perform in situ gamma scan measurements at the Power Burst Facility in support of the Severe Fuel Damage experiments. The purpose of these measurements was to determine fission product deposition on the main and overvessel steam discharge lines. The mobile gamma spectrometer will be used at TMI-2 in the Auxiliary and Fuel Handling buildings to assess fuel and fission product deposits in selected tanks and pipes. GPU Nuclear also will use the spectrometer to perform gamma spectral measurements of the steam generator upper tube sheets if preliminary scans using the sodium iodide detector indicate the presence of significant amounts of fuel debris.

Reactor Building Surfaces. Analysis of concrete core samples from selected Reactor Building surfaces was completed in 1984 . The examination consisted of longitudinal gamma scans using a highly collimated germanium detector and an acid leach test on 8-mm wafers sectioned from specified concrete cores to determine penetration of radionuclide contamination. Indications are that the protective coatings on the concrete core surfaces provided significant protection against radionuclide penetration. Radiocesium generally was confined to within a few millimeters of the top surface of the coating on core samples from the 305 - and 347 -ft-elevation 
floors. Concrete corings whose coatings appeared to be damaged exhibited a radiocesium penetration of up to several centimeters into the concrete. Analysts attributed this penetration to the fact not only that the coating was damaged enough to expose the concrete surface, but that the surface was exposed to contaminated water for a relatively long time. Figures 21 and 22 are typical profiles of radiocesium activity along the lengths of two concrete cores.

Reactor Building Source Term. Results of the radiochemical and elemental analyses performed on the reactor coolant drain tank, the building sump, and the air coolers were reported in 1984, along with the quantities of fission products and core materials that were measured on Reactor Building surfaces and in basement water and sediment.

Among the major results, $59 \%$ of the ${ }^{3} \mathrm{H}, 2.7 \%$ of the ${ }^{90} \mathrm{Sr}, 15 \%$ of the $129 \mathrm{I}, 20 \%$ of the $131 \mathrm{I}$, and $42 \%$ of the ${ }^{137} \mathrm{Cs}$ originally in the core could be accounted for outside the core and in the Reactor Building. Quantities of all accounted nuclides processed through the SDS and EPICOR II and in stored, processed water were compared to mass balance analytical quantities to prevent double nuclide accounting. The majority of the radionuclides released, with the exception of $90 \mathrm{Sr}$ and ${ }^{144} \mathrm{Ce}$, was found dispersed in the basement water and sediment. Copper and silver were among the major elements in the basement floor sediment, and there appears to be a correlation between the concentrations of copper and silver and insoluble ${ }^{129} \mathrm{I}$. Most of this insoluble iodine is probably present as copper iodide and silver iodide; iodide was the predominant species of iodine in solution.

Accounting for most of the activity in the basement sediment were ${ }^{137} \mathrm{Cs}$ and ${ }^{90} \mathrm{Sr}$, with respective average concentrations of 1.4 and $0.9 \mathrm{nCi}$ per dry gram. The total mass of the basement sediment was estimated to be $380 \mathrm{~kg}$, based on basement video surveys and calculations. Table 1 illustrates the total quantities of fission products, fuel, and core materials in the Reactor Building. The table illustrates the relatively small quantities of fission products measured on the air cooling assembly and structural surfaces. The relative quantities of silver, indium, and cadmium found in the reactor coolant drain tank are significant because these values are substantially different from their original ratios in the control rod material. This finding indicates that the silver, indium, and cadmium materials were not dispersed to the drain tank as broken bulk material, but rather transported as condensed vapor.

\section{Resistance Temperature Detector Acquisition.} A fast-response RTD and its thermowell were removed in April 1984 from the inlet to steam generator A and sent to the INEL for electrical evaluation and thermal response tests. Because the thermowell's outside surface protruded into the primary system piping and was in contact with the primary coolant during the accident, analysts saw the need to examine it for fission product deposition. Preliminary results of thermal response tests indicated no significant degradation. The RTD was capable of providing good temperature measurements, meaning no degradation of temperature response. Insulation resistance measurements were not as high as desired but were not as low as those from in situ tests, the difference being the conduit was no longer moist by the time the RTD was tested at the INEL. In 1985, the ORNL will further examine the RTD and evaluate its response time characteristics.

In radiochemical analyses, the RTD thermowell was immersed in a series of decontamination solutions, with gamma scanning between each immersion. Preliminary results indicated a tightly adherent, insoluble chemical species for most radionuclides detected. Aggressive acid leaching was necessary for removing most of the surface activity from the thermowell. Predominantly, ${ }^{137} \mathrm{Cs}$ and ${ }^{90} \mathrm{Sr}$ were removed from the thermowell, while lesser amounts of ${ }^{54} \mathrm{Mn}, 60 \mathrm{Co},{ }^{125} \mathrm{Sb},{ }^{134} \mathrm{Cs}$, and $144 \mathrm{Ce}$ were removed. Technicians did not attempt to remove all of the surface activity from the thermowell body because they did not want to risk breaking through the thermowell and damaging the RTD element. In 1985, an RTD thermowell likely will be acquired from the primary system inlet to steam generator B for additional surface deposition analyses.

Reactor Vessel Internals Documentation. The INEL developed a video enhancing system and delivered it to TMI in October 1984. The enhancement system, composed of an audiovisual recorder, digital video processor, video printer, and video monitors, produces refined still images from quality video input. The system is capable of enhancing the video images on-line while producing hard copies in the form of photographs. The unit is outfitted with a Polaroid-type video printer, but it does have 35-mm film capabilities. 


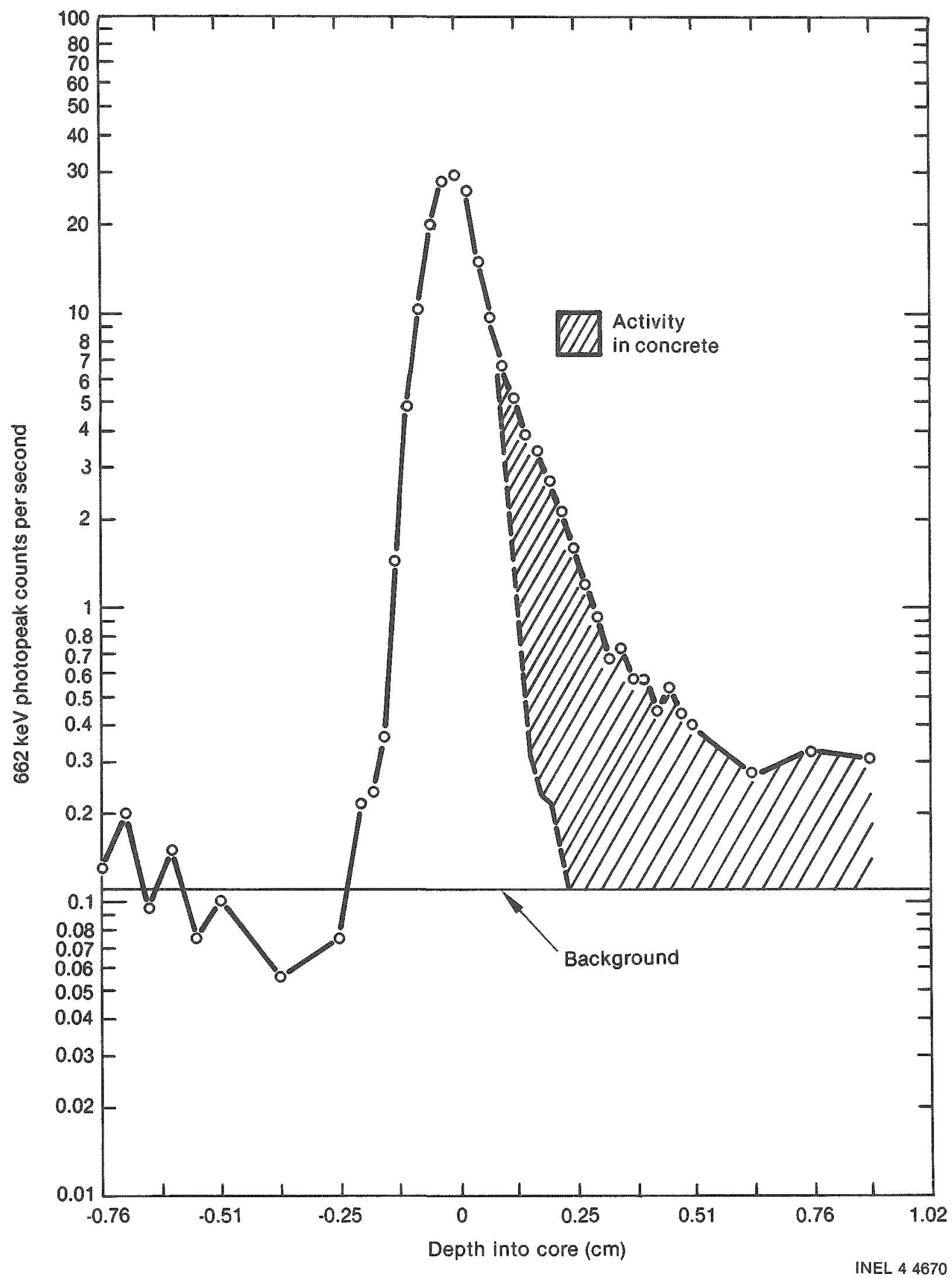

Figure 21. This profile conveys radiocesium activity along the length of a concrete core sample taken from the $305-\mathrm{ft}$ elevation. 


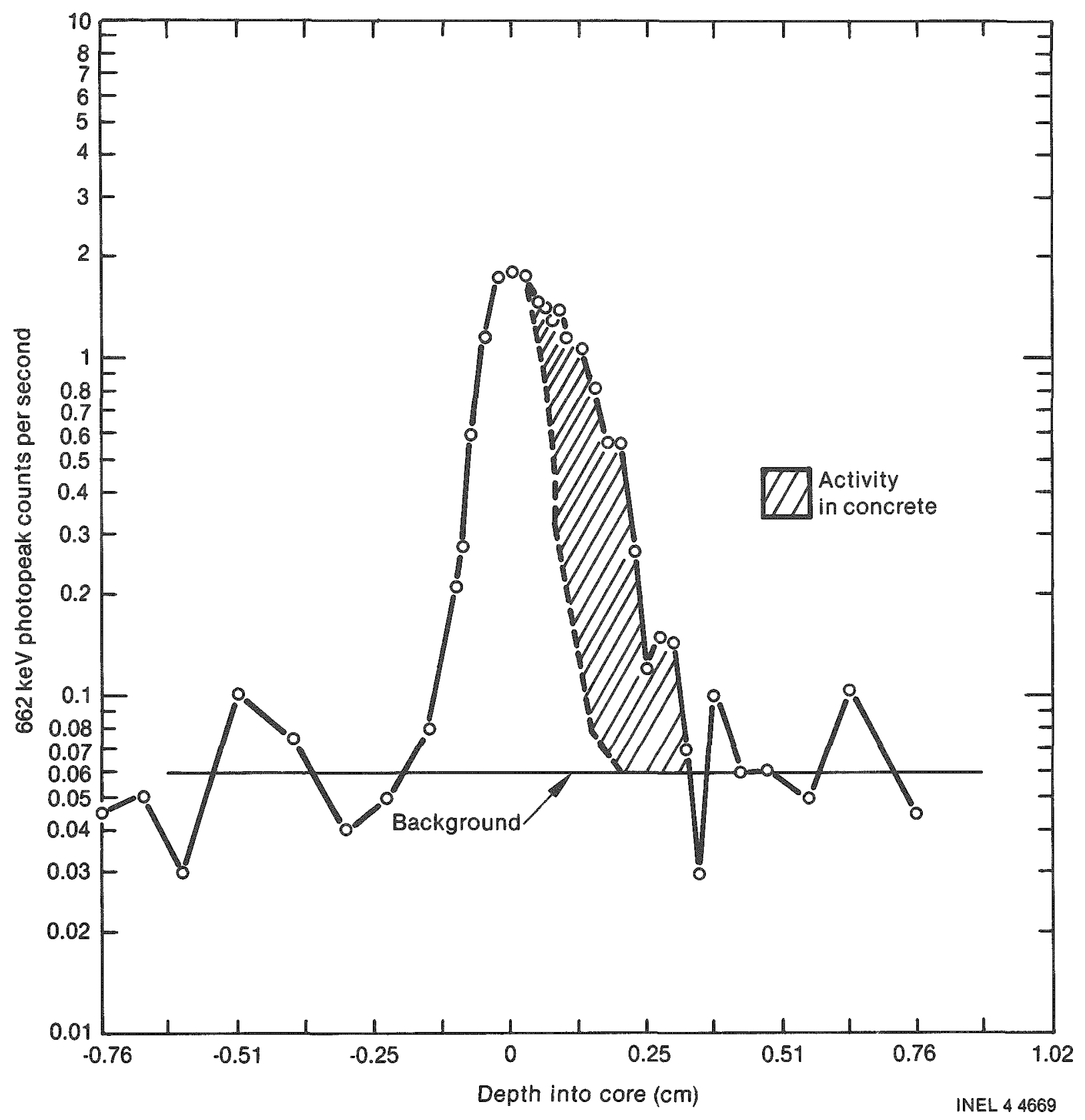

Figure 22. This profile conveys radiocesium activity along the length of a concrete core sample taken from the 347 -ft elevation. 
Table 1. Total quantities of fission products, fuel, and core materials in the TMI-2 Reactor Building

\begin{tabular}{|c|c|c|c|c|c|c|}
\hline \multirow[b]{2}{*}{$\begin{array}{l}\text { Isotope/ } \\
\text { Element }\end{array}$} & \multicolumn{6}{|c|}{ Percent of Core Inventory } \\
\hline & Basement & $\begin{array}{c}\text { Coolant } \\
\text { Drain } \\
\text { Tank } \\
\end{array}$ & $\begin{array}{l}\text { Reactor } \\
\text { Coolant } \\
\text { Systen } \\
\end{array}$ & $\begin{array}{l}\text { Air Cooling } \\
\text { Assembly }\end{array}$ & $\begin{array}{l}\text { Structural } \\
\text { Surfaces }^{\mathrm{a}}\end{array}$ & Total \\
\hline${ }^{3} \mathrm{H}$ & $5.7 E+1$ & $3.3 \mathrm{E}-2$ & $2.2 \mathbb{E}+0$ & $-b$ & $-b$ & $5.9 E+1$ \\
\hline $90_{\mathrm{Sr}}^{\mathrm{ni}}$ & $1.7 E+0$ & $6.3 \mathrm{E}-2$ & $9.6 \mathbb{E}-1$ & $2.0 \mathrm{E}-4$ & $2.3 \mathrm{E}-3$ & $2.7 E+0$ \\
\hline $106 \mathrm{Ru}$ & $4 E-3$ & $1.6 \mathrm{E}-3$ & -b & $-^{b}$ & -b & $5.6 \mathrm{E}-3$ \\
\hline $125 \mathrm{Sb}$ & $3 \mathrm{E}-1$ & $3.6 \mathrm{E}-3$ & $-b$ & -b & $1.1 \mathrm{E}-2$ & $3.1 E-1$ \\
\hline 129 & $1.4 E+1$ & $5.5 \mathrm{E}-3$ & $1.2 E+0 c$ & 2.2 E-1 & $6.4 \bar{E}-2$ & $1.5 \mathrm{E}+1$ \\
\hline $131_{1}^{1}$ & $2.0 \mathbb{E}+1$ & $-b$ & -b & $-b$ & $-b$ & $2.0 \mathrm{E}+1$ \\
\hline $134 \mathrm{Cs}$ & $4.2 E+1$ & $5.2 \mathrm{E}-3$ & $7.7 \mathrm{E}-1$ & $8.1 \mathrm{E}-3$ & $3.5 \mathrm{E}-2$ & $4.3 E+1$ \\
\hline $137 \mathrm{Cs}$ & $4.1 E+1$ & $4.7 \mathbb{E}-3$ & $8.1 \mathrm{E}-1$ & $7.7 \mathrm{E}-3$ & $3.5 E-2$ & $4.2 E+1$ \\
\hline${ }^{144} \mathrm{Ce}$ & $1.0 \mathrm{E}-3$ & $9.5 E-4$ & -b & $-\mathrm{b}$ & -b $^{\mathrm{b}}$ & $2.0 \mathrm{E}-3$ \\
\hline U & $8 \mathrm{E}-4$ & 1.2 E-4 & $-b$ & $-b$ & -b & $9.2 \mathrm{E}-4$ \\
\hline $\mathrm{Pu}$ & $6 E-4$ & -b & $-b$ & $-b$ & $-b$ & $6 \mathrm{E}-4$ \\
\hline $\mathrm{Cr}$ & $5 \mathrm{E}-1$ & $1.2 \mathrm{E}-2$ & $-b$ & $-b$ & $-b$ & 5.1 E-1 \\
\hline $\mathrm{Fe}$ & $1 E+0$ & $2.1 \mathrm{E}-1$ & $-b$ & $-b$ & $-b$ & $1.2 E+0$ \\
\hline $\mathrm{Ni}$ & $8 \mathrm{E}-1$ & $3.8 \mathrm{E}-1$ & $-b$ & $-b$ & -b & $1.2 E+0$ \\
\hline $\mathbb{Z r}$ & $4 \mathrm{E}-4$ & $2.2 \mathrm{E}-4$ & $-b$ & $-b$ & $-b$ & $6.2 \mathbb{E}-4$ \\
\hline $\mathrm{Ag}$ & $2 \mathrm{E}-1$ & $7.4 \mathrm{E}-3$ & $-b$ & $-b$ & $-b$ & $2.1 \mathrm{E}-1$ \\
\hline $\mathrm{Cd}$ & $3 \mathrm{E}-1$ & $2.3 \mathrm{E}-1$ & -b & $-b$ & $-b$ & $5.3 \mathrm{E}-1$ \\
\hline In & $9 \mathrm{E}-1$ & $4.0 \mathrm{E}-2$ & $-b$ & $-b$ & $-b$ & $9.4 \mathrm{E}-1$ \\
\hline $\mathrm{Sn}$ & $7 \mathrm{E}-2$ & $3.9 \mathrm{E}-2$ & $-b$ & $-b$ & $-b$ & $1.1 \mathrm{E}-1$ \\
\hline Gd & $<1 E-1$ & $1.5 \mathrm{E}-1$ & $-b$ & $-b$ & -b & $1.5 \mathrm{E}-1$ \\
\hline
\end{tabular}

a. Total surface activities were reported in Surface Activity and Radiation Field Measurements of the TM1-2 Reactor Building Gross Decontamination Experiments, GEND-037, October 1983, p. 102.

b. Not measured.

c. August 14, 1980 reactor coolant sample. 
The heart of the system is the digital video processor, which allows the user to adjust the video signal-to-noise ratio for maximum picture quality. This feature is particularly useful when monitoring low-light images. The enhancement system also effectively eliminates the raster line interference generally associated with photographs from video images. This raster line often masks important details in the photographs.

The video enhancing system was installed in the TMI-2 Command Center in November to monitor the video inspections of the plenum assembly before it was jacked. The inspection focused on the overall conditions of the plenum structure and any specific conditions that might have precluded safe jacking. The end fitting removal sequence also was closely monitored so that GPU Nuclear would have a full visual accountability of all end fittings removed. Approximately $28 \mathrm{~h}$ of plenum inspection and end fitting removal work were recorded on videotapes that were then sent to the INEL for review and analysis.

The video system was used again during plenum jacking (enhanced photographs of which are presented in Figure 11), postjacking inspections, the followup end fitting removal sequence that occurred in December, and again when workers probed the core. In this last project, a long-handled, pointed tool was lowered into the debris bed at 18 core grid locations. The probe was manually inserted into the bed until penetration ceased. Workers then hammered the tool with a $9.1-\mathrm{kg}$ slide hammer until the probe would penetrate no farther. The depth of each probe was recorded at the point the tool touched the rubble bed, after each subsequent penetration, and once the tool finally hit an impenetrable surface. Results of this work are given in Table 2.

The data obtained indicate that the depth of the debris bed ranges from approximately 35.6 to $106.7 \mathrm{~cm}$; the base of the debris bed appears to be 228.6 to $254 \mathrm{~cm}$ below the $312-\mathrm{ft}, 1 / 2-\mathrm{in}$. elevation-the base of the plenum before it was jacked. Approximately $24 \mathrm{~h}$ of core probing was recorded on videotape. INEL engineers will use the tapes to identify potential locations for sampling after plenum removal and fuel vacuuming.

Table 2. TMl-2 core debris probe data

\begin{tabular}{|c|c|c|c|c|}
\hline $\begin{array}{c}\text { Core } \\
\text { Location }\end{array}$ & $\begin{array}{l}\text { Void Depth } \\
\text { by Sonara, } \\
(\mathrm{cm})\end{array}$ & $\begin{array}{c}\text { Void Depth } \\
\text { by Probinga } \\
\text { (cm) }\end{array}$ & $\begin{array}{l}\text { Depth to } \\
\text { Bottom } \\
\text { of Bed } \\
\text { (cm) } \\
\end{array}$ & $\begin{array}{c}\text { Thickness } \\
\text { of Bed } \\
\text { (cm) } \\
\end{array}$ \\
\hline E-3 & 127 & 182.9 & 255.9 & 73 \\
\hline$C-5$ & 121.9 & 182.9 & 270.2 & 87.3 \\
\hline $0-11$ & 137.2 & 129.5 & 259.4 & 129.9 \\
\hline M-13 & 124.5 & 129.5 & 231.1 & 101.6 \\
\hline B-10 & 132.1 & 231.1 & 241.9 & 10.8 \\
\hline E-13 & 116.8 & 182.9 & 200 & 17.1 \\
\hline $\mathrm{N}-4$ & 160 & 119.4 & 275 & 155.6 \\
\hline M-3 & 139.7 & 241.3 & 254 & 33 \\
\hline $0-5$ & 180.3 & 189.9 & 231.1 & 41.3 \\
\hline$P-6$ & - & - & - & - \\
\hline P- 8 & 162.6 & 210.5 & 266.7 & 56.2 \\
\hline $\mathrm{K}-7$ & 147.3 & 154.9 & 238.1 & 83.2 \\
\hline L-8 & 157.5 & 158.1 & 233 & 74.9 \\
\hline G-9 & 160 & 161.6 & 235 & 73.4 \\
\hline $\mathrm{H}-8$ & 162.6 & 163.2 & 244.8 & 81.6 \\
\hline G-7 & 167.6 & 203.8 & 254.6 & 50.8 \\
\hline B-8 & 127 & 157.5 & 244.3 & 86.8 \\
\hline C-9 & 127 & 144.1 & 279.4 & 135.3 \\
\hline
\end{tabular}

a. All values reflect distance in centimeters from below the upper grid (312-ft, $1 / 2$-in. elevation).

b. Sonar mapping was conducted in late August 1983. 


\section{INFORMATION AND INDUSTRY COORDINATION}

During the past year, the Information and Industry Coordination (I\&IC) staff continued its investigation of industry issues and its activities in technology transfer and program refinement.

\section{Calculation for Determining Safe Storage Time for Waste}

The thrust of the $1 \& I C$ effort in the last quarter of 1984 was in the development of a calculation that utilities could use to meet the requirements of an NRC inspection and enforcement information notice regarding hydrogen gas generation. The NRC is requiring nuclear plant operators to ship wet radioactive waste containers within 10 days of preparation and sealing or, if they cannot meet the 10-day deadline, to vent the containers before shipment. This requirement is in response to concerns that even low-level radioactive waste may generate hydrogen gas. On January 1, 1986, the Low-Level Radioactive Waste Policy Act goes into effect, and at that time many utilities may not have a low-level waste disposal site available to them. Without a method of determining if and when a particular waste container has a combustible gas condition and being unable to ship the container within 10 days, these utilities will have to assume all of their lowlevel radioactive waste poses a gas generation problem. The utilities will have to store and handle the waste accordingly, which could be expensive in the manhours and manrem exposure required to vent radioactive containers.

Based on experience with gas generation in the EPICOR II and Submerged Demineralizer System containers and the experiments and data collected to determine gas generation rates, the nuclear industry may have another, more reasonable alternative: it may be possible to calculate, based on known parameters concerning the waste and container type, the safe storage time before hydrogen gas concentrations reach a combustible mixture ( 4 to $5 \%$ by volume). $I \& I C$ is preparing the technical basis for such a calculation. With this information, a utility could produce a plant-specific procedure to determine safe storage time. Once accepted by the $\mathrm{NRC}$, the calculation will, in most cases, allow utilities much longer than 10 days for storage before shipment. Because the method does not require special tooling or equipment and the calculation is made with data the utilities already have, the method is cost-effective, especially compared to the expense in the manhours and manrem required to vent radioactive waste containers.

This approach was presented to the Utility Nuclear Waste Management Group of the Edison Electric Institute (EEI). The calculation is being refined to make it more specific to waste generation under normal operating conditions at a typical commercial nuclear plant. The EEI will submit the calculation to the NRC for approval-in-principle as a method of determining the safe storage period of radioactive waste from the standpoint of combustible gas generation.

\section{Summary Reports}

The I\&IC staff prepared a number of summary reports that present the results of various TMI programs, address issues of general interest to the commercial nuclear power industry, and provide a concise overview to help users see how TMI program activities could affect their areas of responsibility.

These summary reports have been available to the commercial nuclear industry through a number of networks, including the Update, an international newsletter published by the TI\&EP; the Nuclear Operations and Maintenance Information Service (NOMIS); and the Nuclear Network of the Institute of Nuclear Power Operations (INPO). Summaries on the following subjects were prepared in 1984:

- Gas generation in organic resin storage containers

- Beta- and gamma-measuring dosimeter

- Area radiation monitors

- Loose parts monitoring system examination

- Multielement beta dosimeters

- Determining transuranic concentrations in radioactive ion-exchange waste. 
EPRI will be publishing as technical briefs the summaries on gas generation in organic resin storage containers, multielement beta dosimeters, and area radiation monitors.

INPO, also interested in the summaries, elected to distribute the report on gas generation in organic resin storage containers as an Operation and Maintenance Reminder.

I\&IC prepared an article for publication in a technical journal that describes the various in situ testing methods developed at TMI to evaluate the condition of electrical circuits. The article will emphasize how these techniques can be used at nuclear plants to detect equipment degradation and pending failure. I\&IC personnel anticipate that a number of technical briefs will be issued as a result of the article. I\&IC plans to make this information available to EPRI and INPO as it develops. The article for the technical journal will serve as a pilot effort to expand the I\&IC's audience. If successful, the I\&IC staff intends to use this method of information transfer in the future. 


\section{EPICOR AND WASTE RESEARCH AND DISPOSITION PROGRAM}

In 1984, the EPICOR and Waste Research and Disposition Program began disposing of 46 of the 50 EPICOR II prefiliers that were used in the TMI-2 cleanup and stored during the interim at the INEL. Thirty-seven high-integrity containers (HICs) containing EPICOR II prefilters in 1984 were processed, transported to, and buried at U.S. Ecology, Inc., a commercial disposal facility in Washington state for low-level radioactive waste. Also during the year, program personnel completed research on the other four prefilter liners and continued investigations of ion-exchange resins. In other program activities, the INEL disposed of research samples that were stored there and prepared for the receipt, storage, and disposal of TMI-2 abnormal wastes.

\section{EPICOR Project}

The EPICOR II prefilters that were part of the TMl-2 cleanup were used in research and disposition projects at the INEL and other DOE facilities.

Disposal of EPICOR II Prefilters. In March 1984, Washington state issued a Certificate of Compliance approving use of the HIC. This approval rollowed lengthy negotiations and reviews among Nuclear Packaging, Inc.-designer of the HIC, U.S. Ecology, DOE, the NRC. EG\&G Idaho, and the state. However, this compliance was "...contingent upon successful use and demonstration of the [EPICOR II/HIC] package," as stated in the Certificate of Compliance. The requirement was subsequently met with the successful, safe demonstration disposal of a prefilter in a HIC. Meanwhile, the NRC reissued the CNS 14-190 shipping cask for transporting prefilters from the INEL to the U.S. Ecology disposal facility.

In early 1984, a full-length resin core from one of the EPICOR II prefilters, PF-46, was analyzed for transuranic elements. Results indicated that the transuranic content of PF-46 was considerably below maximum allowable levels for Class $C$ waste (as defined in 10 CFR 61.55). Therefore, all EPICOR II prefilters stored at the INEL were determined to be disposable as Class $C$ wastes when enclosed in HICs because PF-46 contained more transuranic material than any of the other prefilters.
EPICOR II prefilter PF-18, selected for the disposal demonstration, was dewatered, purged, sealed in a HIC, loaded into the CNS 14-190 shipping cask, and stored on the transportation trailer outside Test Area North Building 607. Upon Washington state's approval of the HIC, the shipping cask was purged with argon for three days to remove any combustible gases and released for transport. At the U.S. Ecology site, the HIC containing PF-18 was unloaded from the shipping cask (see Figure 23) and lowered $14 \mathrm{~m}$ into a burial trench (see Figure 24). The HIC was then covered with soil (see Figure 25).

This successful demonstration permitted workers to begin preparing the remaining prefilters for disposal. By the end of 1984, 37 prefilters had been dewatered, purged with argon, sealed in a HIC, loaded into a shipping cask, and transported to the U.S. Ecology disposal facility. Project personnel expect to have 46 of the 50 EPICOR II prefilters buried by mid-1985. The four remaining prefilters will be retained several years at the INEL for NRCsponsored resin research activities.

Resin and Liner Research. In mid-1984, the NRC assumed funding for the EPICOR resin and liner research task at the INEL. This research will enable the NRC to (a) develop a data base for low-level waste by examining resins from the EPICOR II prefilters and (b) obtain information on survival of waste forms composed of radioactive ion-exchange media solidified in cement and Dow polymer.

Liner Integrity studies. As a followup to photographic and metallurgical tests on the epoxycoated steel liners of PF-3 and PF-16, PF-3 in early 1984 underwent metallurgical examination to further identify corrosion around its conductivity patch (the location of greatest corrosion buildup observed in the two liners). Results from those examinations indicate the minimum lifetime for liner PF-3 is 50 years.

Resin Degradation Studies. Samples of irradiated resins from $\mathrm{PF}-8$ and $\mathrm{PF}-20$ and unirradiated resins supplied by Epicor, Inc., were subjected to physical and chemical examinations, specifically infrared spectroscopy, gas chromatography, scanning electron microscopy (SEM), and tests of the American 


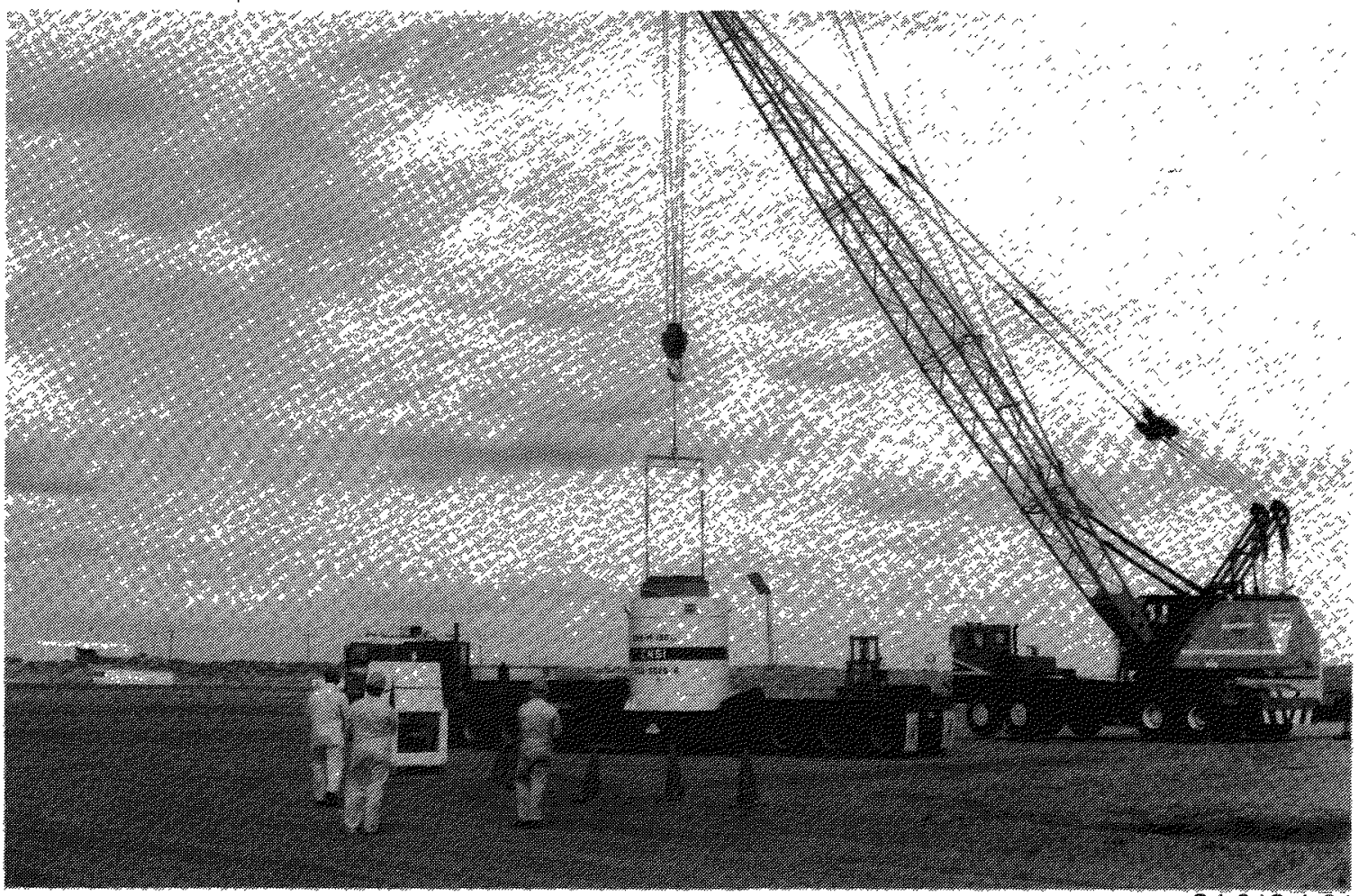

$84-219-1-31$

Figure 23. The demonstration HIC containing EPICOR II prefilter PF-18 is unloaded from the CNS 14-190 shipping cask at the U.S. Ecology disposal facility for low-level radioactive waste.

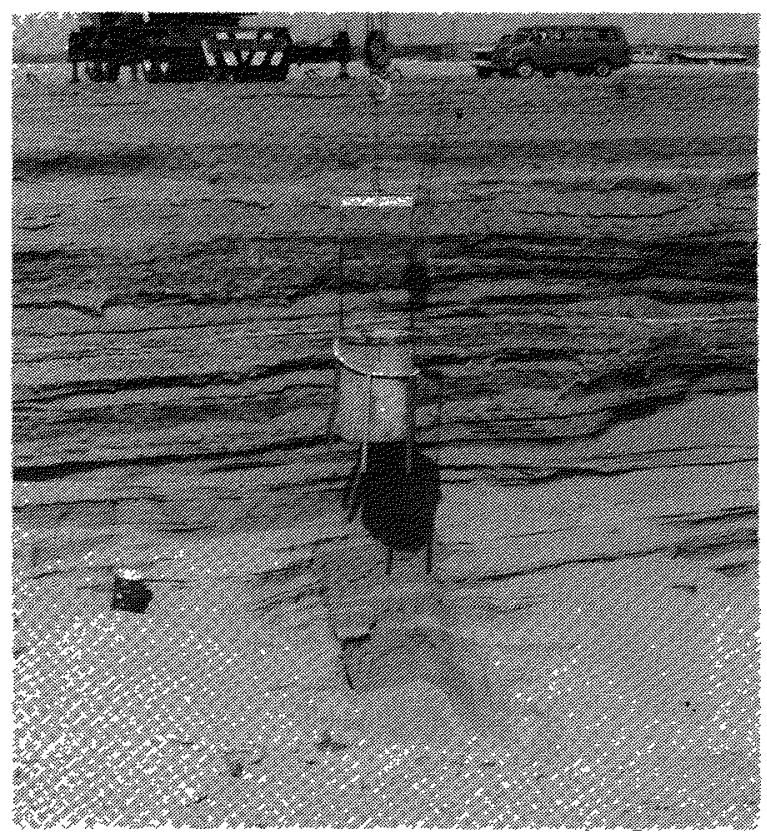

84-219-2-35

Figure 24. The demonstration HIC containing PF-18 is lowered into a burial trench.

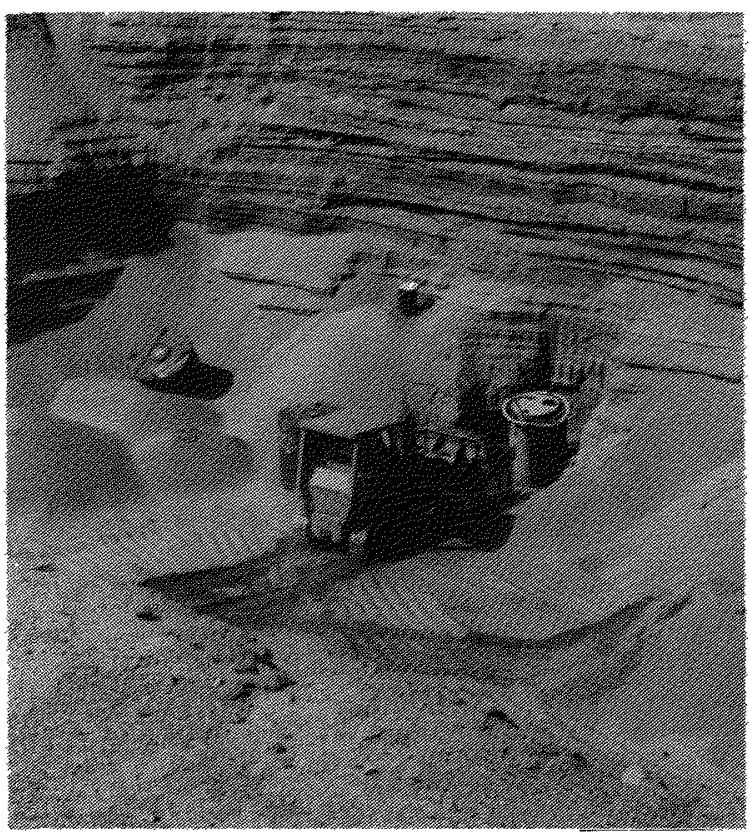

84-219-2-3

Figure 25. The demonstration HIC is buried at the disposal facility. 
Society for Testing and Materials (ASTM). The studies, performed to quantify the extent of degradation caused by radiation, indicated that some degradation of the irradiated resins occurred at radiation doses (approximately $10^{7}$ rad) somewhat lower than predicted. Figures 26 and 27 are SEM photomicrographs of unirradiated and irradiated resin beads, respectively. By comparing the two figures, one can see fracturing of the irradiated bead, presumably from degradation. Results of the examinations are summarized in Table 3. Analysis of resins removed from PF-8 and PF-20 over the next several years should show a further increase in degradation.

Resin Solidification. The EPICOR and Waste Research and Disposition Program has been investigating methods of immobilizing ion-exchange resins by solidification. The work also addresses survival of solidified waste forms during long-ierm storage and disposal. In 1984, INEL personnel documented a project in which 267 waste forms were solidified from resins collected from EPICOR II prefilters PF-7 and PF-24. Under the NRC resin research task, some of the waste forms are being subjected to tests for thermal stability, leachability, biodegradability, or radiation stability to simulate environmental effects experienced during long-term disposal.

To determine resin resistance to bacteria, analysts have been investigating the biodegradability of unirradiated resins solidified in Dow polymer. Much of the work in 1984 focused on the development of experimental procedures and the collection of baseline data. Six strains of microorganisms will be used in tests on both irradiated and unirradiated resins.

Lysimeter Field Testing. Final preparations were made for lysimeter field tests to determine radionuclide leaching from solidified waste forms buried in a natural environment. These solidified wastes will be studied for up to 20 years. Argonne National Laboratory-East (ANL-East) and Oak Ridge National Laboratory (ORNL) were chosen as sites for these experiments. The INEL received two weather station and data acquisition systems, manufactured by Campbell Scientific of Logan, UT, and designed to automatically collect temperature, pressure, precipitation, and humidity data from the lysimeters. The ten lysimeters and related equipment were fabricated at the INEL under DOE capital equipment funding. In December, the lysimeter vessels, the weather station and data acquisition systems, installation tools and procedures, and 70 waste forms were transported to ANL-East and ORNL for the field tests.

Waste Disposition at the INEL. In late 1984, EG\&G Idaho disposed of TMI-2 research samples, including electrical components and instruments, that were kept at the INEL. Samples stored at the Test Reactor Area (TRA) and Auxiliary Reactor Area were identified. Three drums containing two makeup filter housings and a vacuum filter were transported from TRA to the Radioactive Waste Management Complex of the INEL for disposal. Only those samples subject to future examination will be retained.

\section{Abnormal Waste Project}

In October 1984, DOE approved the TMI Abnormal Waste Acceptance Criteria. These criteria provided a framework for contract negotiations with GPU Nuclear regarding disposal of TMI-2 abnormal waste. In December, DOE submitted the draft contract to receive TMI- 2 abnormal waste at the INEL, and designs began for the storage pad on which the abnormal waste will be placed at the INEL.

Following are some of the major points addressed by the criteria:

- Unacceptable materials

- The exclusion of free-standing liquids

- Proper handling, loading, and treatment of waste

- Necessary documents to accompany the shipments 


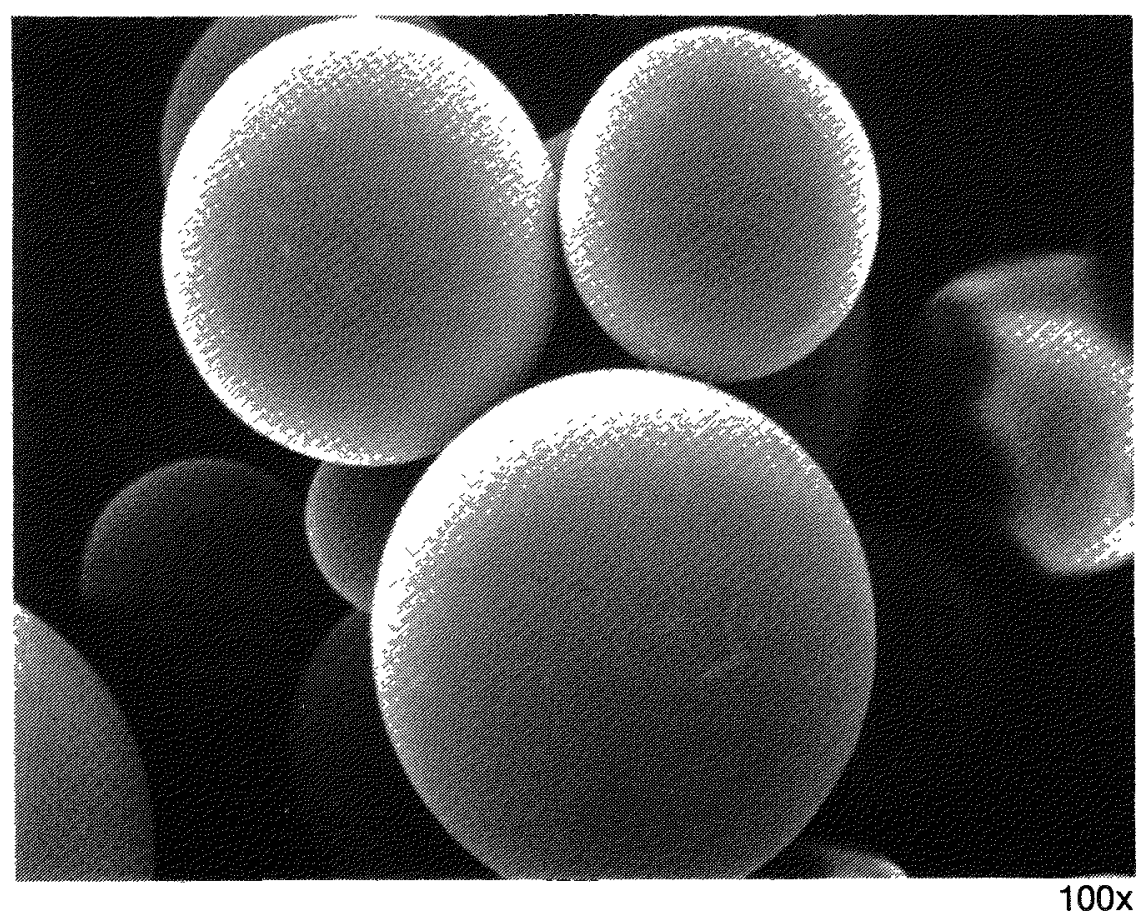

Figure 26. This SEM photomicrograph magnifies unirradiated EPICOR II resin 100 times.

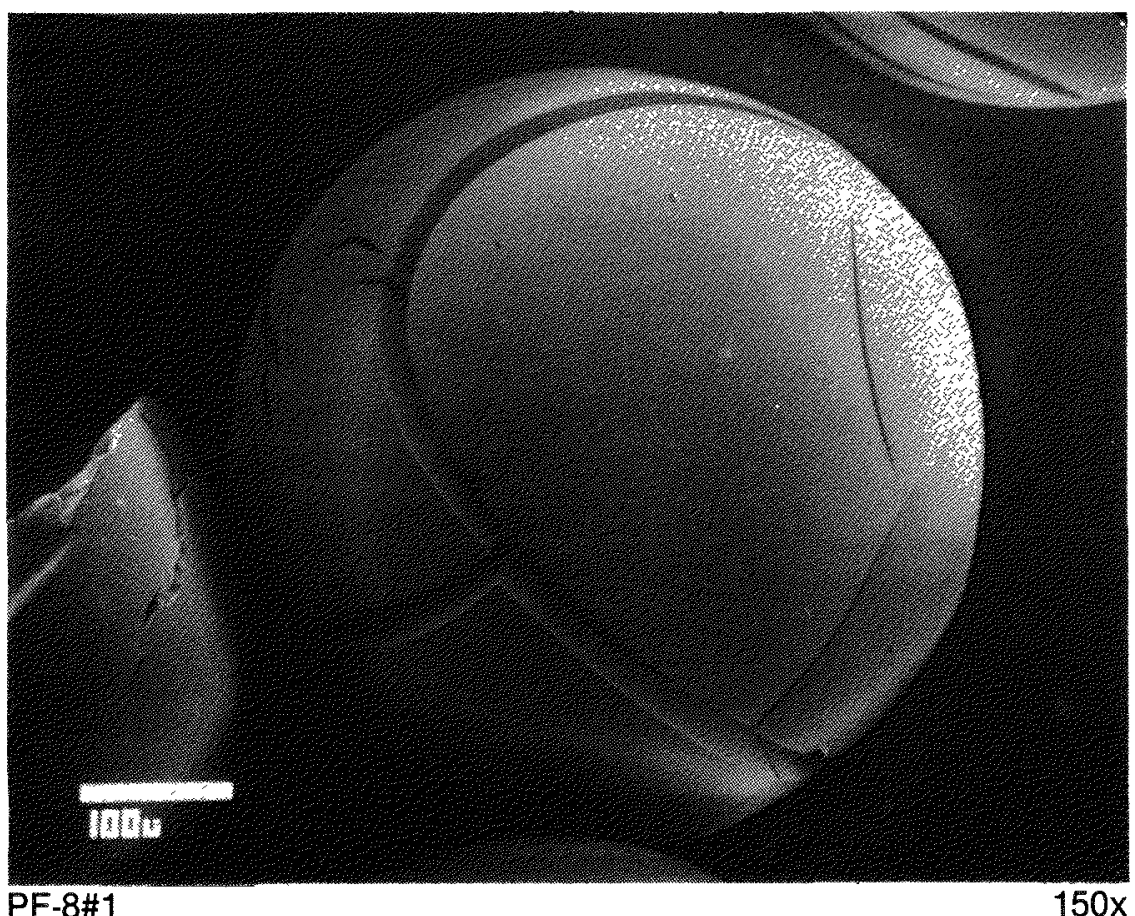

Figure 27. This SEM photomicrograph of EPICOR II resin sample PF-8\#1 shows a closeup of one resin bead magnified 150 times. 
Table 3. Summary of results from analysis of EPICOR II irradiated resin samplesa

\begin{tabular}{|c|c|c|c|}
\hline \multirow[b]{2}{*}{ Analytical Technique } & \multicolumn{3}{|c|}{ Resin Sample } \\
\hline & $\begin{array}{c}\text { PF-20 } \\
\text { Strong Acid Cation } \\
\end{array}$ & $\begin{array}{c}\text { PF-8\#1 } \\
\text { Strong Acid Cation }\end{array}$ & $\begin{array}{c}\text { PF }-8 H 2 \\
\text { Phenolic Cation }\end{array}$ \\
\hline \multicolumn{4}{|l|}{ ASTM tests } \\
\hline Water retention capacity & Increase & Increase & Increase \\
\hline Backwashed and settled density & Decrease & Decrease & Decrease \\
\hline Salt splitting capacity & Decrease & Decrease & Increase \\
\hline Total exchange capacity & Increase & Decrease & No change \\
\hline Infrared spectroscopy & $\begin{array}{l}\text { No apparent changes } \\
\text { in structure }\end{array}$ & $\begin{array}{l}\text { No apparent changes } \\
\text { in structure }\end{array}$ & $\begin{array}{l}\text { No apparent changes } \\
\text { in structure }\end{array}$ \\
\hline Gas chromatography & $\begin{array}{l}\text { No soluble products } \\
\text { determined }\end{array}$ & $\begin{array}{l}\text { No soluble products } \\
\text { determined }\end{array}$ & $\begin{array}{l}\text { Soluble products } \\
\text { observed because of } \\
\text { contamination }\end{array}$ \\
\hline $\begin{array}{l}\mathrm{BaCl}_{2} \text { precipitation for deter- } \\
\text { mination of sulfonic acid groups }\end{array}$ & $\begin{array}{l}\text { Sulfonic acid groups } \\
\text { are being lost }\end{array}$ & $\begin{array}{l}\text { Sulfonic acid groups } \\
\text { are being lost }\end{array}$ & $\begin{array}{l}\text { This resin contains } \\
\text { no sulfonic acid } \\
\text { groups }\end{array}$ \\
\hline Scanning electron microscopy & No damage noted & $\begin{array}{l}\text { Resin bead cracking } \\
\text { observed }\end{array}$ & $\begin{array}{l}\text { Damage observed on } \\
\text { a few particles }\end{array}$ \\
\hline Visual observations & $\begin{array}{l}\text { Nothing unusual } \\
\text { observed }\end{array}$ & $\begin{array}{l}\text { Nothing unusual } \\
\text { observed }\end{array}$ & $\begin{array}{l}\text { Contamination with } \\
\text { PF-8 } 1 \text { resin } \\
\text { observed }\end{array}$ \\
\hline Physical observations & $\begin{array}{l}\text { Nothing unusual } \\
\text { observed }\end{array}$ & $\begin{array}{l}\text { Lack of flow during } \\
\text { elution observed }\end{array}$ & $\begin{array}{l}\text { Nothing unusual } \\
\text { observed }\end{array}$ \\
\hline
\end{tabular}

a. Results are expressed as differences in values observed for irradiated EPICOR II resins versus unirradiated resins supplied by Epicor, Inc.

- Acceptable radiation levels

- Packaging to minimize gas buildup (pressure control)

- Proper identification of packages being shipped

- Thermal power
- Fissionable material

- Provisions for permanently attached, readily accessible lifting fixtures

- Specifications for packages containing materials that present hazards in addition to radioactivity

- Comprehensive reviews. 


\section{CORE ACTIVITIES PROGRAM}

The Core Activities Program encompasses receipr, storage, and examination of core debris, components, and samples from TMI-2. The program is funded by DOE and managed by the Technical Support Branch of EG\&G Idaho. In 1984 , major reorganization and changes in program direction resulted in the merging of the Mass Balance/Source Term Programs into the Core Activities Program that now comprises the TMI-2 Core Receipt and Storage Project and the Core Sample Acquisition and Examination Project. Major activities in 1984 included preparations for receipt and storage of core debris at the $\mathbb{I N E L}$ and examination of core debris and component samples.

\section{Program Planning}

In March 1984, DOE and GPU Nuclear signed a contract, in which DOE accepted responsibility for receipt, transportation, storage, and disposal of the TMI- 2 core.

The new Core Damage Assessment and Fission Product Behavior Technical Evaluation Group (TEG) was formed to combine the Core Damage Assessment and Fission Product Behavior TEGs. The new TEG recommended forming a combined sample acquisition and examination program, satisfying the needs of both the Core Activities and the Source Term programs.

An integrated TMI-2 program plan was prepared based on the current core examination program, augmented TMI-2 program, and severe accident behavior/source term research needs. That plan will be the basis for the augmented and restructured TMI-2 program. This restructuring will continue in 1985 with added attention devoted to accident analysis and source term issues.

\section{TMl-2 Core Receipt and Storage Project}

In 1984, the Core Activities Program began preparations at the INEL for receiving TMI- 2 core debris. The INEL has unique facilities for safe receipt, interim storage, and sample removal for research and examination. Scenarios were developed for receiving the rail casks at the INEL's
Central Facilities Area, transporting the casks to the Test Area North (TAN) hot shop, opening the casks and removing the canisters, placing the canisters in storage modules, and assembling the modules in water pit storage racks. The INEL developed methods for handling the casks and canisters there and began preparing safety documents to support receipt and storage operations. At TAN, the $90.7-\mathrm{Mg}$ crane and radiation monitoring equipment were upgraded, and the overhead manipulator and utility pedestals were refurbished. Also during the year, workers continued to upgrade the pool crane and modify the pool cart. Design and procurement were initiated for the modular rack that will be used to store fuel canisters in the water pit, and designs were under way for support equipment for cask and canister handling and canister venting.

\section{Core Sample Acquisition and Examination Project}

Core Sample Acquisition and Examination Project personnel in 1984 examined core debris grab samples, the $\mathrm{H} 8$ and $\mathrm{B} 8$ lead screws, the $\mathrm{H} 8$ lead screw support tube, and a resistance temperature detector (RTD) from steam generator A. (Acquisition of samples for this project is discussed under the Core Sample Acquisition and Examination Project of the Data Acquisition Program, an earlier section of this report.) Following are the preliminary results of the examinations and the accomplishments in other project tasks.

Core Debris Grab Samples. Scientists at the INEL and B\&W closely examined grab sample material acquired from the TMI-2 core. Eleven samples of loose debris were collected. Six samples were taken at the center of the core (position H8), from the surface to a depth of $78 \mathrm{~cm}$; and five were taken at the midradius point (position E9), from the surface to a depth of $94 \mathrm{~cm}$. Analysts gathered data on the samples' physical makeup, specifically size, shape, structure, and origin. Observers noted that the 11 samples contained fuel pellet fragments and shards of cladding or guide tubes, as well as other core structural material. Analysts studied the chemical and microstructural makeup of some of the particles through metallographic examination, scanning electron microscopy, x-ray diffraction, and Auger analyses. Researchers also have been 
quantifying fission products of the particles. In pyrophoricity tests of the samples, they found that the particle content was not combustible in the presence of oxygen.

The studies revealed particles of a ceramic material of uranium and zirconium that could have formed only at temperatures above $2922 \mathrm{~K}$-which is $156 \mathrm{~K}$ below the melting point of $\mathrm{UO}_{2}$ fuel. The ceramic likely was formed when $\mathrm{UO}_{2}$ fuel in contact with zircaloy cladding at that high temperature was dissolved by the zirconium, forming a liquid phase of Zr-U-O termed "liquefied fuel." Figure 28 is a photomicrograph of a cross section of one of those particles.

Data obtained from the grab samples are providing information on the fractions of core inventory retained. The preliminary ${ }^{137} \mathrm{Cs}$ concentrations showed a lower retention level than ${ }^{90} \mathrm{Sr}$ and ${ }^{129} \mathrm{I}$. Researchers hypothesized that most of the ${ }^{137} \mathrm{Cs}$ was released into the reactor coolant system due to that isotope's high solubility in water. That ${ }^{129} \mathrm{I}$ and ${ }^{90} \mathrm{Sr}$ had a higher degree of retention in the core is important because these radionuclides have more biological significance if released into the environment.

Other gamma-emitting radionuclides present in the core debris in lesser quantities were ${ }^{60} \mathrm{Co}$, ${ }^{106} \mathrm{Ru}, 110 \mathrm{~m}_{\mathrm{Ag}},{ }^{125} \mathrm{Sb},{ }^{154} \mathrm{Eu},{ }^{155} \mathrm{Eu}$, and 241 Am. Comparing computer code estimates to data, analysts saw that some fission products, such as ${ }^{144} \mathrm{Ce},{ }^{154} \mathrm{Eu}$, and ${ }^{155} \mathrm{Eu}$, remained primarily with the fuel and were not transported out of the reactor core. Examination of one sample, for instance, indicated that while $13 \%$ of the ${ }^{137} \mathrm{Cs}$ was retained, 27 to $40 \%$ of ${ }^{106} \mathrm{Ru}$ and 70 to $100 \%$ of ${ }^{144} \mathrm{Ce}$ and ${ }^{154} \mathrm{Eu}$ were retained.

Through the examination effort and the ongoing mass balance work, researchers will be able to establish the behavior of radionuclides in situations like the one at TMI. As those examinations continue, the INEL plans to identify the core materials to which the radionuclides attach themselves. That information will help engineers to gain a better understanding of the accident and, particularly, fission product transport.

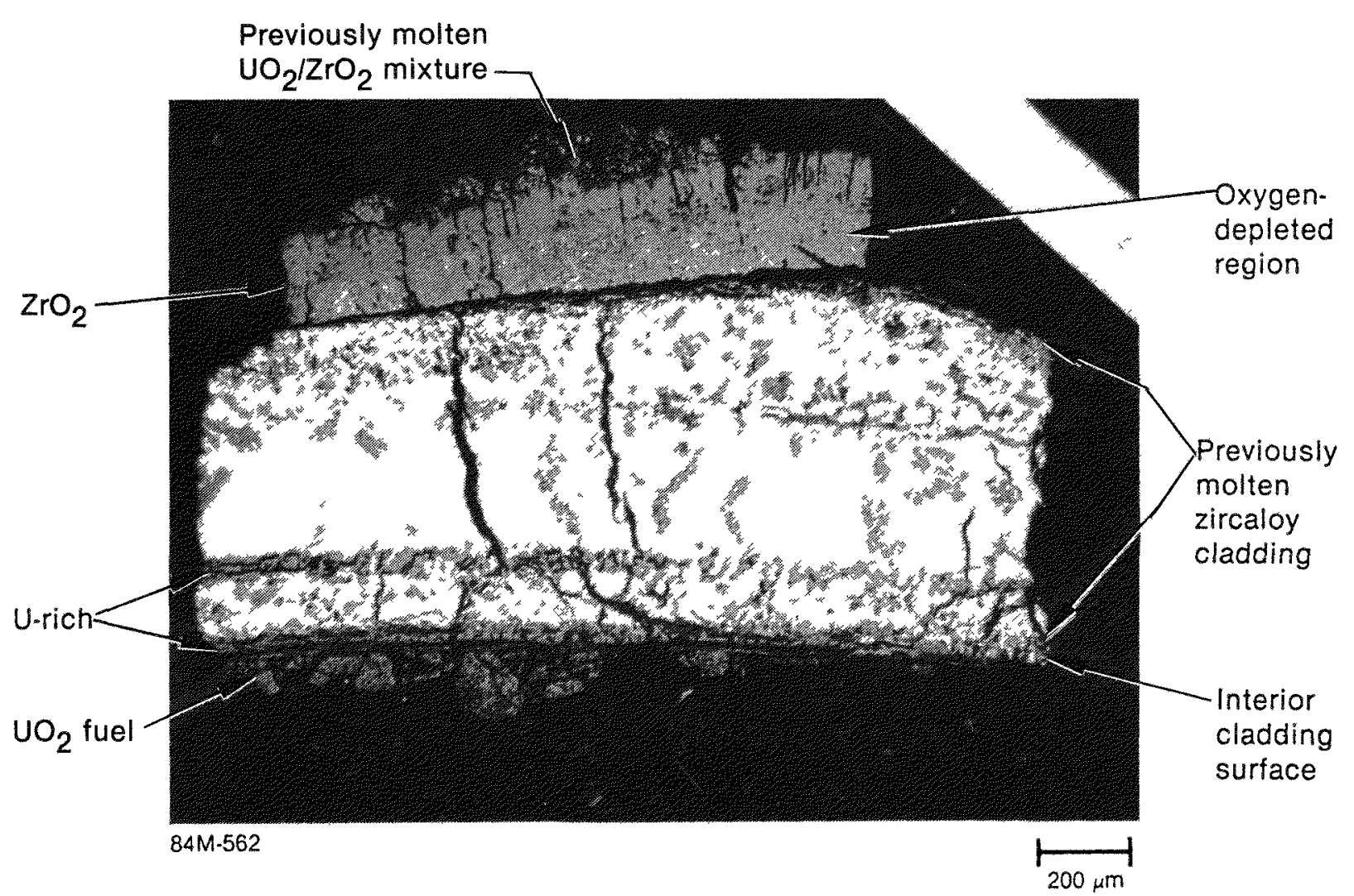

Figure 28. This cross section of particle $1 \mathrm{E}$ from sample 1 (collected from the surface of the debris bed at the $\mathrm{H} 8$ core location), contains previously molten $\mathrm{UO}_{2} / \mathrm{ZrO}_{2}$ material that is ceramic in appearance. 
A series of turbidity, cesium release, and airborne activity potential tests were performed in two stages: undisturbed, without fracturing the debris particles, and disturbed, after crushing the debris particles to expose fresh surfaces. Researchers found that crushing the debris had a minimal impact on turbidity. This work influences plans for defueling the damaged reactor because maximum water clarity is essential. Disturbing the debris by crushing did increase the soluble ${ }^{137} \mathrm{Cs}$ concentrations by a factor of 4 or 5 . The soluble ${ }^{137} \mathrm{Cs}$ went into solution in $5 \mathrm{~min}$, with little subsequent leaching. In evaporation tests, airborne activities of both the undisturbed and disturbed particles were similar. They increased 2 to 3 orders of magnitude near the end of the process, just before the liquid dried out. Also, as soon as the liquid evaporated, airborne activity decreased almost to zero, indicating the activity possibly was transported with the water vapor. The studies of cesium release and airborne activity potential are essential to establishing radiation exposure controls for personnel who will participate in the defueling operations.

The physical form of the core debris is significant because small particles may be suspended in the reactor coolant system water during defueling and cause cloudiness. Knowledge of the distribution of particle sizes is necessary to determine the type, number, and effectiveness of filters to be used to clean the water. The content of retained fission products also is important because it represents a radiological source that must be controlled. Researchers must define core source term and levels of leachable radionuclides, such as ${ }^{137} \mathrm{Cs}$, that have the potential for dissolving in the water during defueling operations. Meanwhile, the type of material in the rubble bed will influence tool design and the defueling method.

H8 and $B 8$ Lead Screws. EG\&G Idaho examined the $\mathrm{H} 8$ and $\mathrm{B} 8$ lead screws from the Unit 2 reactor. Portions of the lead screws were visually examined and chemically and radiologically analyzed, and temperature estimates were taken. Objectives of these examinations were to estimate maximum temperatures experienced along the length of the lead screws in the plenum assembly region and to determine the extent and nature of the core component material and radionuclide deposition on plenum assembly surfaces. Hardness measurements and microstructural analyses suggested a significant temperature gradient between the portions of the lead screws closest to the bottom and top of the plenum. The temperatures ranged from 700 to $1255 \mathrm{~K}$ for $\mathrm{H} 8$ and 755 to $1117 \mathrm{~K}$ for B8. Chemical analyses indicated that $\mathrm{UO}_{2}$ and zirconium were deposited to a greater extent on surfaces closer to the core. An axial gradient in surface radionuclide concentrations was observed, with the highest concentration near the top of the plenum assembly. The data indicate changes in chemical composition and gradients in the surface radionuclide concentrations in the plenum assembly. Based on preliminary calculations extrapolating the lead screw data to the plenum assembly as a whole, the fractions of total core inventory of radionuclides retained on plenum assembly surfaces are small-less than $2 \%$. Also, very little silver $(1 \%)$ is deposited on the plenum's surfaces from the control rod material.

Lead Screw Support Tube. The center lead screw support tube was removed from the reactor vessel dome, and the lower $10-\mathrm{cm}$ section was removed and transported to Battelle Columbus Laboratories in August 1984 for examination. The purpose of the examination was to characterize surface deposits, determine the removability of surface deposits, and determine the prior peak temperature of the support tube. Examination of the section was completed in December, and principal observations are as follows:

- Surface deposits on the lead screw support tube are similar to those on the control rod lead screws

- One solution proposed for use in decontaminating the reactor coolant system appeared effective in removing deposits

- The prior peak temperature of the support tube during the TMI-2 accident was 783 to $1005 \mathrm{~K}$.

Resistance Temperature Detector. After its removal from the inlet to steam generator $\mathrm{A}$ and shipment to the INEL, a dual-element RTD was subjected to gamma spectroscopy and decontamination tests, and the surface deposits on the thermowell underwent chemical and radiochemical analyses. A principal observation is that a very small fraction of the core inventory is plated out on the reactor coolant system surfaces.

Reactor Coolant System Gamma Scans. EG\&G Idaho has been technically supporting the development of measurement devices and the evaluation of 
data in a project to map fuel debris in the reactor coolant system. GPU Nuclear estimated that a fraction of the core debris was swept out of the reactor vessel into the reactor coolant system piping. One of the measurement devices, fabricated at the INEL in fiscal year 1983, is a shielded, portable sodium iodide gamma-ray spectrometer system. This system will be used at TMI-2 to determine the presence of fuel in the primary system piping by measuring quantities of gamma-emitting radionuclides expected to stay chemically associated with fuel material. In 1984, the INEL electronically and mechanically modified another measurement device, the hyper-pure germanium spectrometer system, to improve its performance. Also in 1984 , a computer-based, multichannel analyzer system was purchased; this system is compatible with both measurement devices.

The detector and shield of the hyper-pure germanium mobile spectrometer were modeled using a modified Monte Carlo gamma-ray transport code. This model will be used to develop a computer code that will empirically calculate detection efficiencies and ultimately provide quantitative information of radionuclide concentrations on surfaces and in pipes and tanks. To verify the accuracy of the code work developed, experimental efficiencies were measured from five gamma radiation sources (a point, a planar disk, and three pipe sources with 0.5 - to 1.8-in. outside diameters) and compared to the empirically calculated efficiencies. The sources contained ${ }^{152} \mathrm{Eu}$ and ${ }^{144} \mathrm{Ce}$ gamma-emitting radionuclides with emission energy peaks covering the expected range of energies in TMI-2. The computer code developed has general applications for other spectrometer systems used at TMI and throughout the industry.

The mobile spectrometer was used to quantitatively measure radionuclide deposits on piping at the Power Burst Facility (PBF) after the Severe Fuel Damage Test 1-3. The measurements at PBF were successful, and the spectrometer system was transported to TMI for use in the Auxiliary Building and for calibrating other smaller sodium iodide detector systems at TMI-2.

Core Damage Saquence. Analysts have been reevaluating the TMI-2 core damage scenario, considering additional data obtained since the accident. Future work that has been identified includes probing the in-core instrument guide tubes, analyzing in-core instrument data, obtaining additional debris bed samples, and correlating the data. Two multipoint strip charts used to record 36 self-powered neutron detector (SPND) outputs during the accident were decoded and analyzed for a correlation with known events. In an effort to interpret the data and correlate them with core temperatures, two new tests will be performed on TMI-2-type SPNDs: a separate-effects test to measure SPND response to temperature in an oxidizing atmosphere and a test correlating SPND response with core damage factors such as water level and fuel temperature in the Loss-of-Fluid Test (LOFT) Facility. During the TMI-2 accident, SPNDs either measured or produced data representative of core thermal events. The devices are the only in-core instruments installed at TMI- 2 and, as such, are very important to defining the core damage sequence of events. The laboratory testing of these SPNDs is designed to identify and reproduce phenomena that produced large positive current outputs from the SPNDS during the accident.

SPNDs were manufactured at the INEL for beta radiation and steam environment thermal tests. By December, personnel performed tests to determine ionic, galvanometric, material failure, and temperature effects on SPND response. Tests to determine the consequences of beta radiation will follow in 1985.

The second test of correlating SPND response with core damage factors supports placement of a TMI-2-type instrument assembly containing SPNDs into the center guide tube of the LOFT FP-2 fuel bundle, which will be subjected to a loss-of-coolant transient following a shutdown. SPND response will be measured with changing water level, temperature, pressure, and fission product release to determine in-pile response.

TMI-2 Typicality Analysis. A best-estimate RELAP5 model of TMI-2 was used to predict plant response up to the time of initial core uncovery and subsequent core heatup. Those calculations were performed to provide a better understanding of the thermal-hydraulic behavior of the accident.

Sensitivity calculations using the Severe Core Damage Analysis Package (SCDAP) were completed using Nuclear Safety Analysis Center boundary conditions and then compared to available TMI-2 data. That series of SCDAP analyses was performed to estimate the state of the damaged TMI-2 core. Calculations of core damage progression and resulting damage features (fission product 
release, hydrogen generation, and core thermal response) showed that hydraulic conditions of the core strongly influence core heatup and degradation. The calculations served as an important benchmark for interpreting core degradation and fission product behavior. As additional data from core characterization become available, the validity of these and future calculations will be confirmed.

Temperature estimates of the upper plenum were obtained during the analysis of the control rod lead screws. These estimates are particularly important because they provide the first measurement of temperature of the core region boundary conditions during the accident. Temperature is a necessary parameter for code verification.

Tellurium Behavior. Samples of core debris, upper plenum lead screws, makeup filter debris, and the Reactor Building sump are being analyzed for tellurium using a carbon rod atomic absorption spectrophotometer. Results will be used on all TMI-2 samples to estimate tellurium distribution and release fractions for comparison to current bestestimate behavior models. Because the radioactive tellurium has significantly decayed, the INEL developed methods to quantitatively analyze the samples for stable tellurium. Analysts compared the observed TMI- 2 tellurium behavior to the predicted behavior from present models (TRAP-MELT) and from $P B F, O R N L$, and other laboratory-scale experiments. One conclusion of this comparison is that tellurium released from fuel is absorbed in zircaloy cladding and not released from the core until a significant zircaloy-water reaction occurs, suggesting that tellurium releases from the TMI- 2 core probably were low.

This estimate agrees with the simulation test of the TMI-2 accident at PBF. Fuel temperature histories, system geometry, surface and steam temperature histories, and system flow rates were obtained to enable a calculation of tellurium release, transport, and deposition during the TMI-2 accident. Data are being collected from TMI-2 and through laboratory-scale tests at PBF, ORNL, and the SASCHA test reactor in the Federal Republic of Germany. The NRC released data from PBF on tellurium behavior for comparison with TMI-2 data. Work is continuing on acquisition and analysis of additional data from core and reactor vessel samples. The additional analyses and comparisons will continue to clarify and quantify preliminary results.

An analysis technique was prepared for lowtemperature acid dissolution of samples containing tellurium and iodine. The technique was developed to permit separation of tellurium and iodine from sample matrices, such as ceramic or metallic solids, where fractions of tellurium and iodine usually are lost by volatilization when more aggressive dissolution techniques are used.

Mass Balance Data Base. Mass balance calculations account for the distribution of fission products that resulted from the TMI- 2 accident. The mass balance data base is a collection of radionuclide data, literal comments, and operating data regarding, for example, temperatures, flow rates, and fluid levels obtained from TMI-2. EG\&G Idaho updated and modified the mass balance software supplied by NUS Corporation for INEL use. (NUS Corporation developed the mass balance data base under contract to EG\&G Idaho in fiscal year 1983. The data base was transferred to EG\&G Idaho in fiscal year 1984 and accessed with a data base management system at the INEL.) The software allows interactive access for mass balance calculations using data obtained from the mass balance data base. The data base can provide listings of information by analysis, sample, or event, or chronologically. Fission product retention data are important to the development and verification of computer codes for predicting the consequences of a severe core damage accident. 
